\title{
البحثَ الثنامن:
}

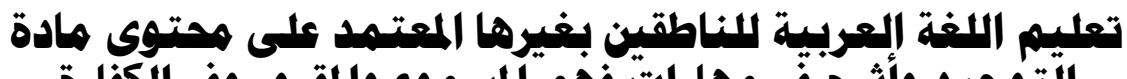

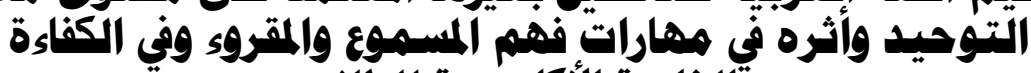

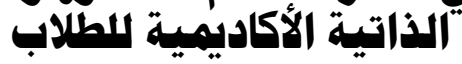

$$
\begin{aligned}
& \text { : إلحاكاك } \\
& \text { دا داب زيناتي عبد الله } \\
& \text { أستاذ مساعد بكليت البنات الإسلاميت بأسيوط }
\end{aligned}
$$





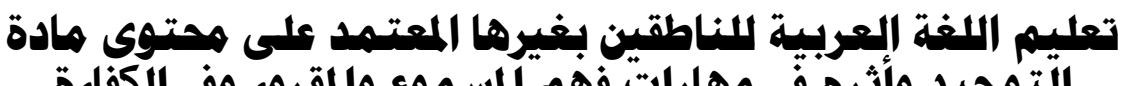

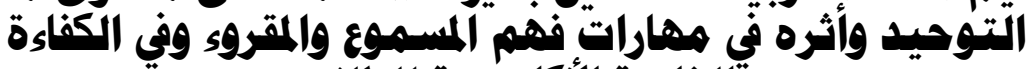

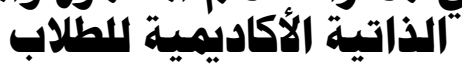

\author{
د/ رحاب زثاتي عبد الله

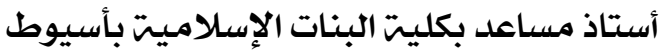

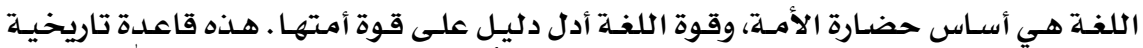

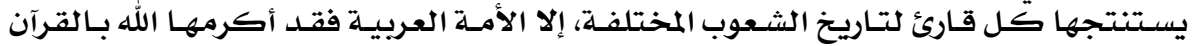

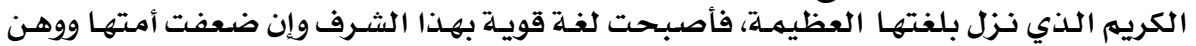

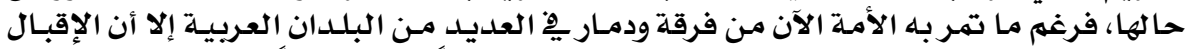

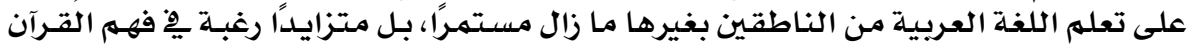

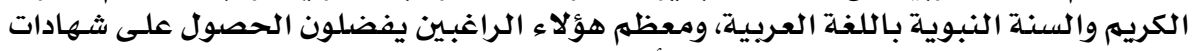

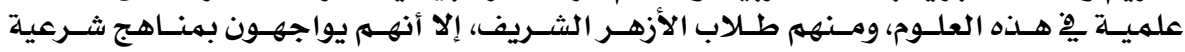

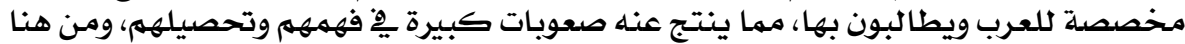

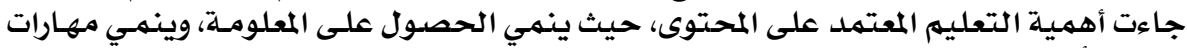

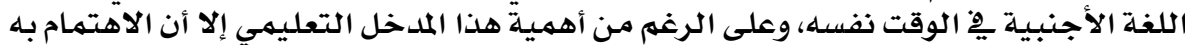

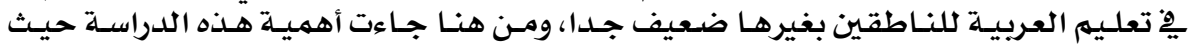

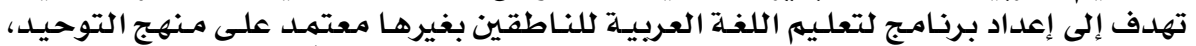

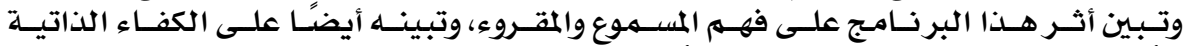

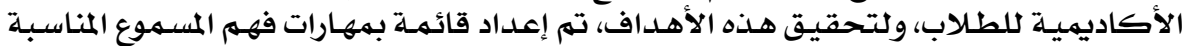

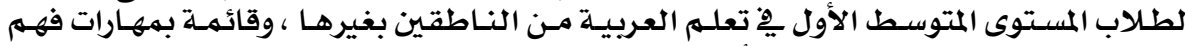

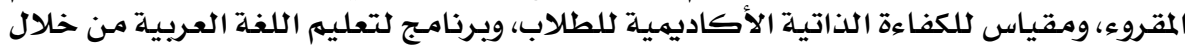

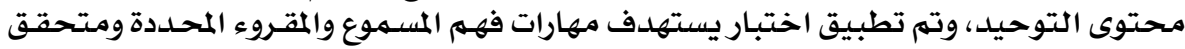

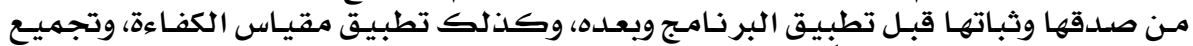

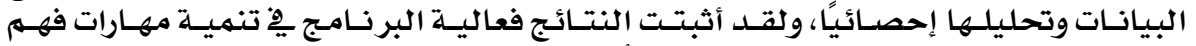

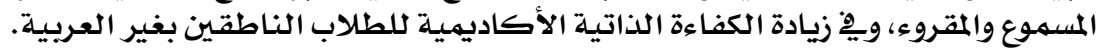

الكلمات المفتاحية : الناطقون بغيرها ، مهارات فهم المسموع والمقروء، مفهوم الكفاءة الذاتية

الأكاديمية.

Teaching Arabic Language to Non-Native Speakers Based on the Content of the Monotheism Subject (Tawheed) and its Effect on the Listening and Reading Texts Comprehension and the Students' Academic Self-efficacy

\section{Dr. Rehab Zanaty Abdul-Allah}

\section{Abstract :}

Language is the backbone of the nation civilization, and the language power is the strongest proof of the nation power. This is a historical postulate that is concluded by every reader of history. The Arab nation was honored by Allah (Glory Be to Him) via the Holy Quran, which was revealed in the greatest language (Arabic), so the Arabic language is a strong language because of such honor regardless of its nation weakness. 
Despite the Arab nation's current division and destruction in many countries, there is a growing desire to learn the Arabic language from nonnative Arabic speakers, and to understand the Holy Quran and the Sunnah in Arabic, so most of those learners hope to obtain degrees in such sciences, including Al-Azhar student. However, those students face legitimate curriculum designed and tailored for the Arab students, so they encounter great difficulties in comprehension and achievement. With this in mind, the importance of content-based education which becomes the prime time player as it allows access to information and develops foreign language skills at the same time. Although such approach is significantly important, it does not receive the due attention. Thus, the current study aimed to develop a program for teaching Arabic to non-native Arabic speakers based on the Monotheism subject (Tawheed) and assessing its effect on comprehending the listening and reading texts and the students' academic self-efficacy. For attaining such objective, a list of listening comprehension skills has been developed for the first intermediate level non-native Arabic speakers, a list of reading comprehension skills, an academic self-efficacy scale for students and a program for teaching Arabic through the content of Monotheism subject (Tawheed). A test assessing the specified reading and listening comprehension skills and a self-efficacy scale were administered before and after the administration of the program after assuring their validity and reliability. The data were collected and statistically analyzed indicating the effectiveness of the proposed program in developing the skills of comprehending the listening and reading texts and developing the academic self-efficacy of the non-native Arabic speaker students.

Key Words: Non-Native Speakers, Listening and Reading Texts Comprehension, Academic Self-efficacy.

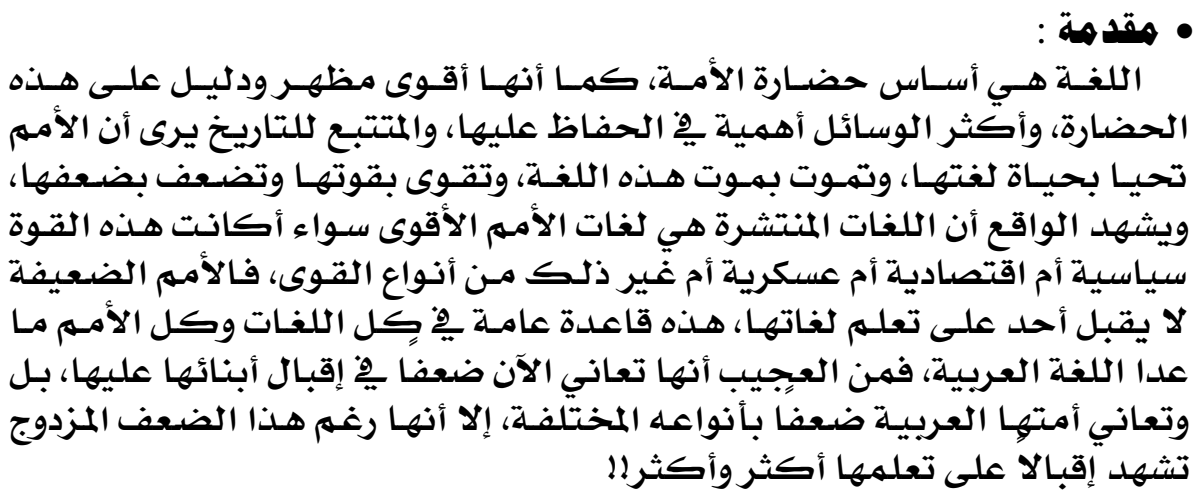

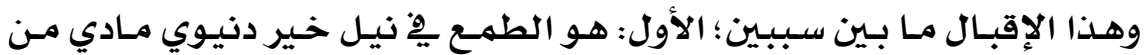

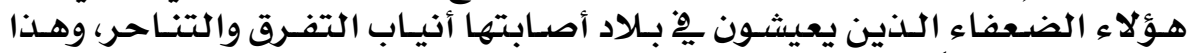

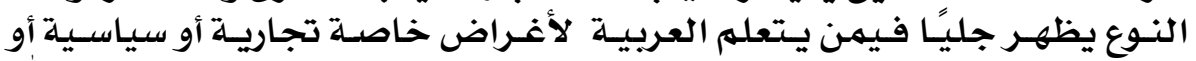

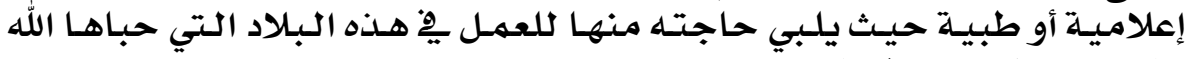
بخيرات كثيرة من فضله حئه

\section{rMY}




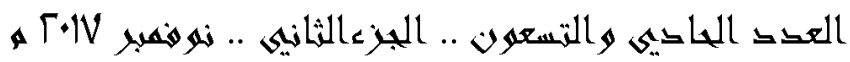

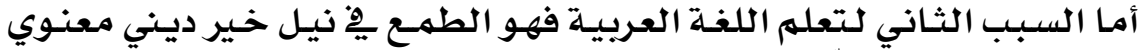

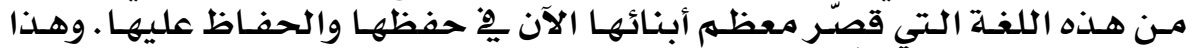

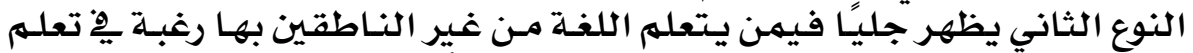

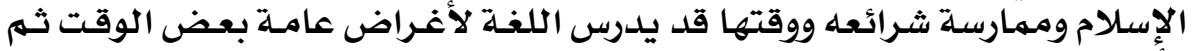

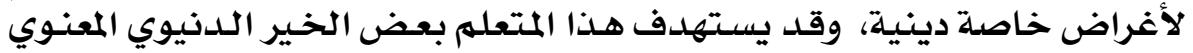

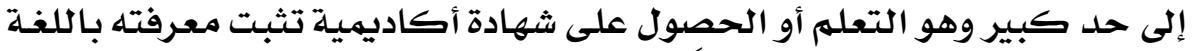

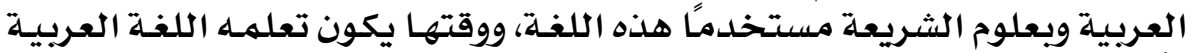
لأغراض أكاديمية.

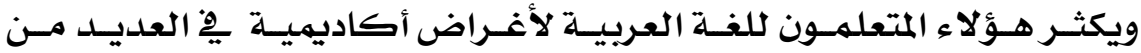

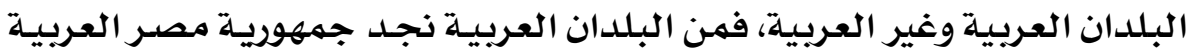

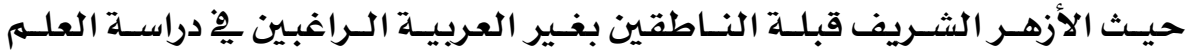

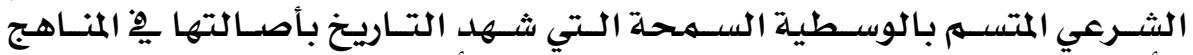

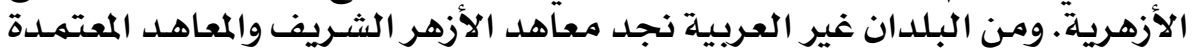

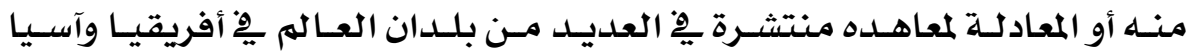

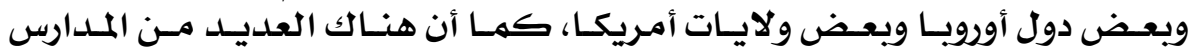

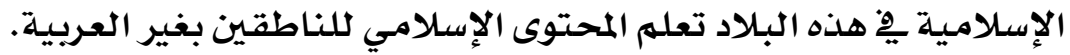

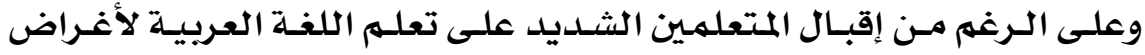

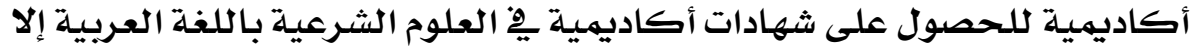

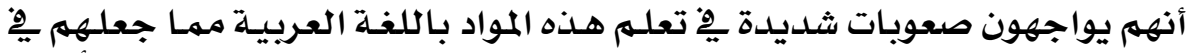

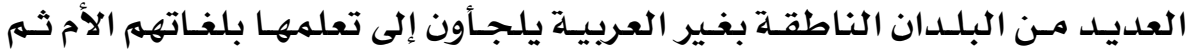

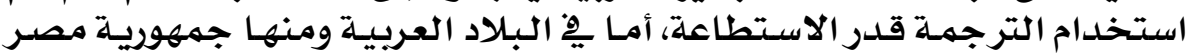

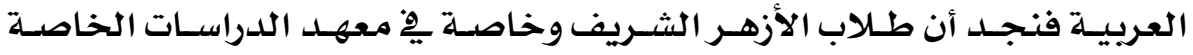

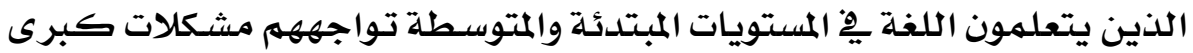

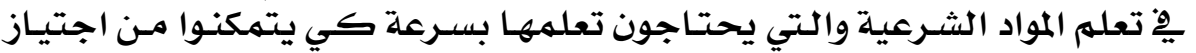

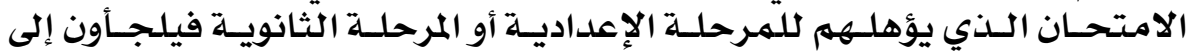

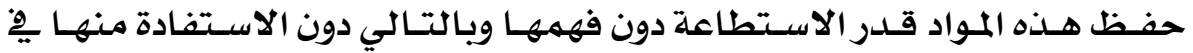
المستوى اللغوي والمهارات اللغوية النهاد.

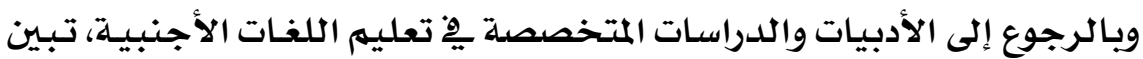

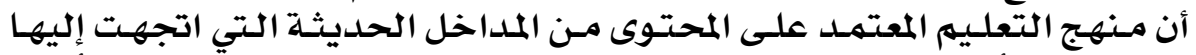

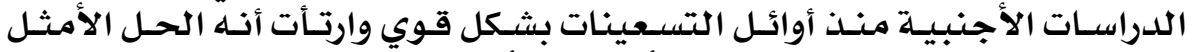

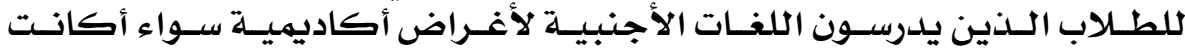

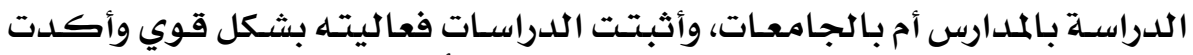

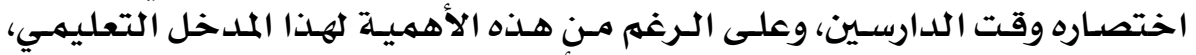

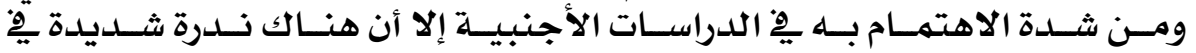

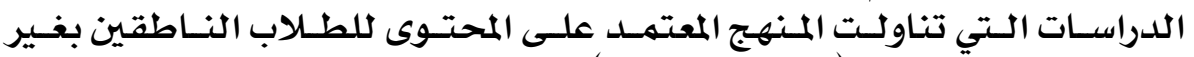

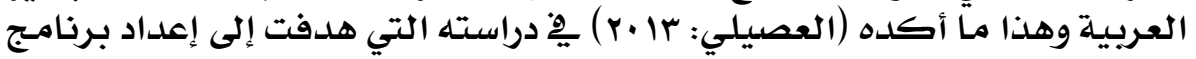

\section{MYV}




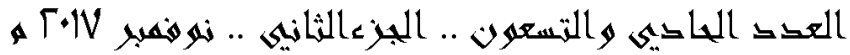

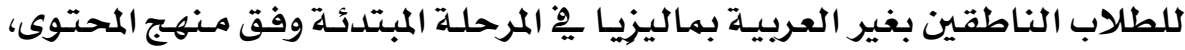

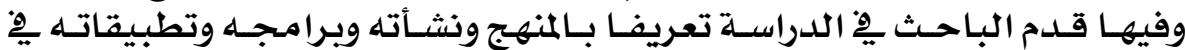

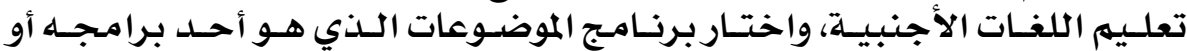

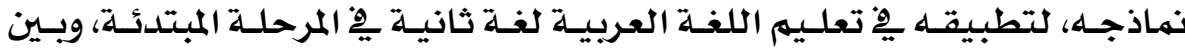

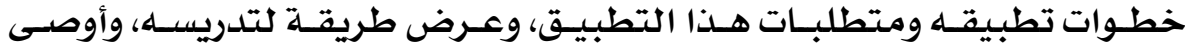

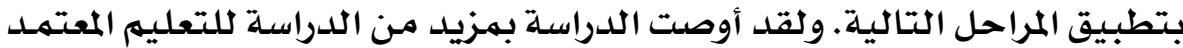

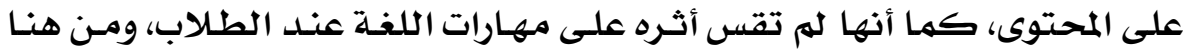

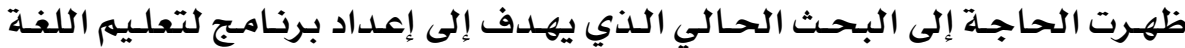

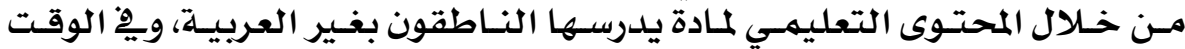

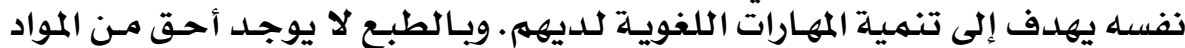

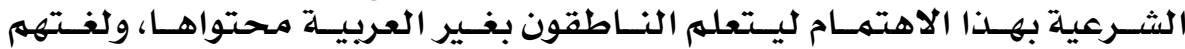
المنشودة.

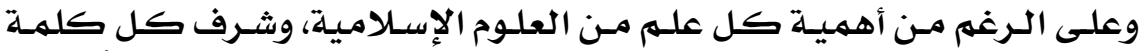

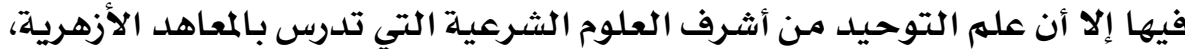

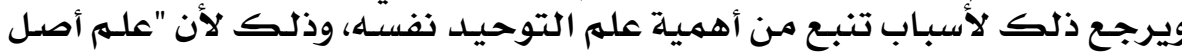

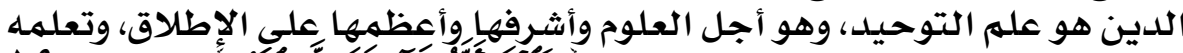

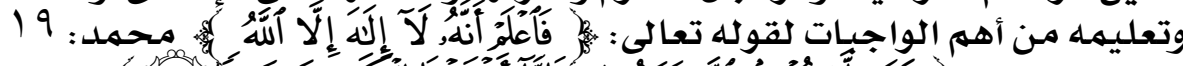

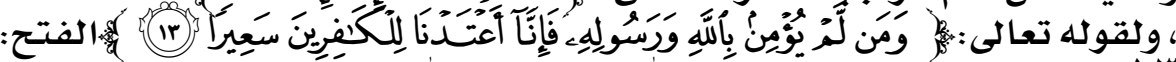

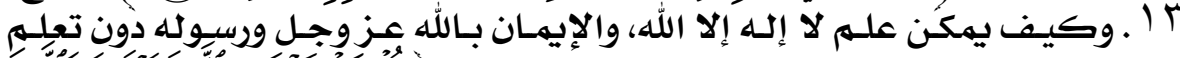

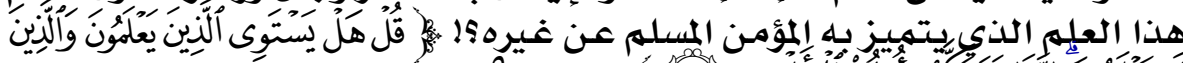

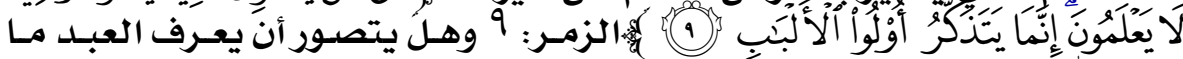

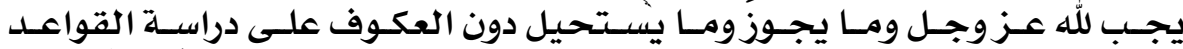

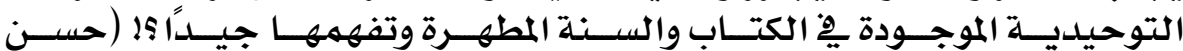

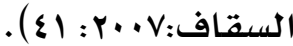

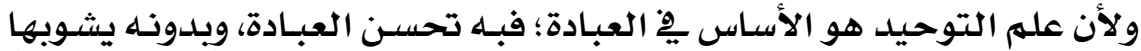

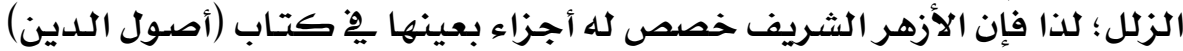

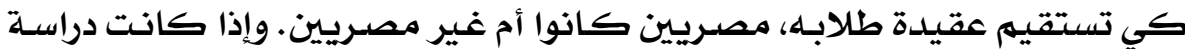

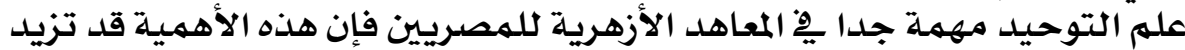

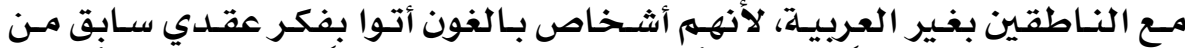

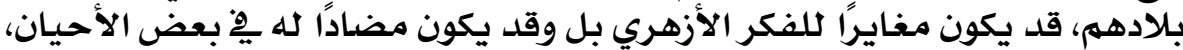

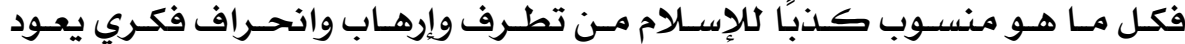

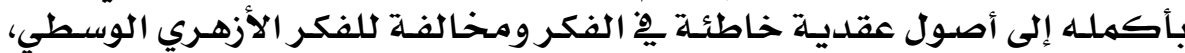

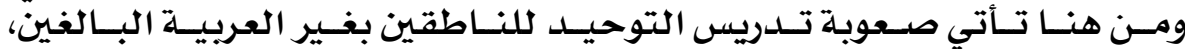

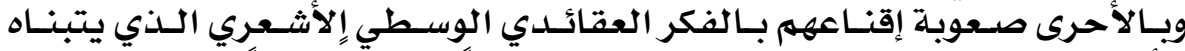

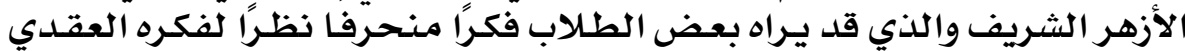

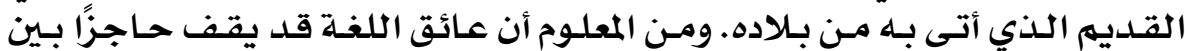

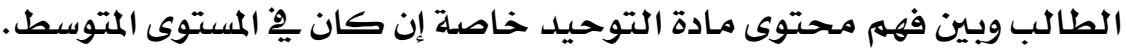

\section{rrA}




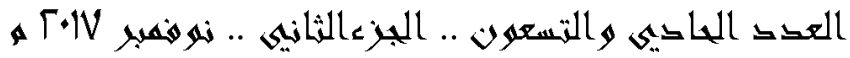

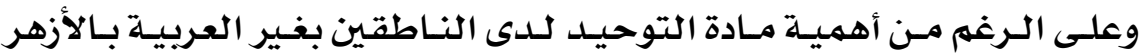

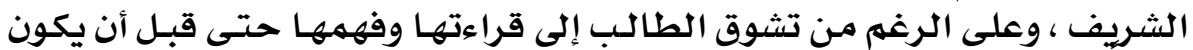

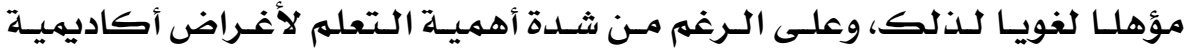

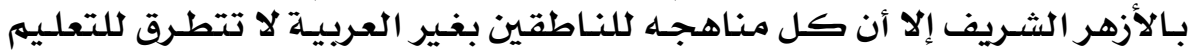

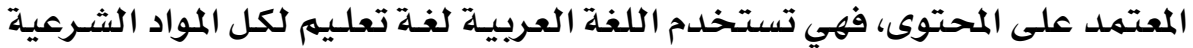

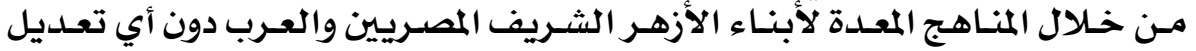

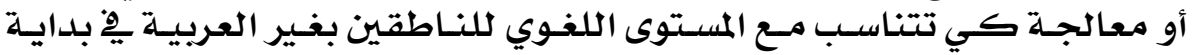

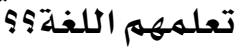

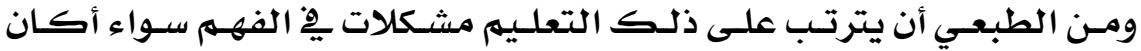

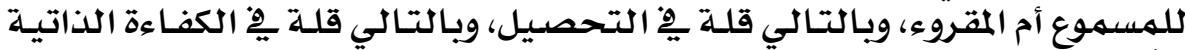

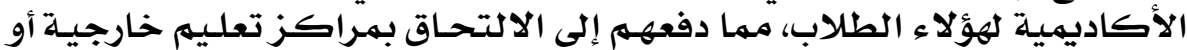

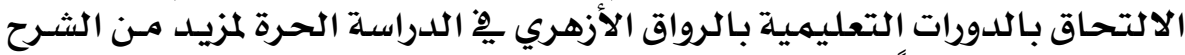

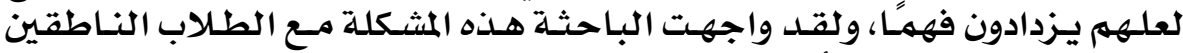

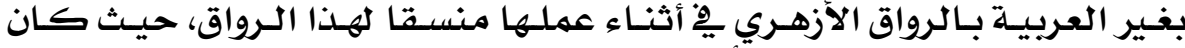

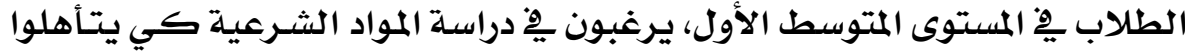

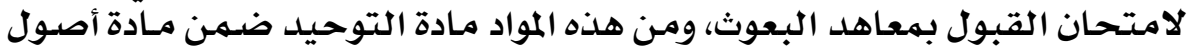

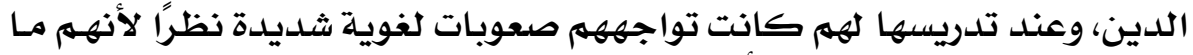

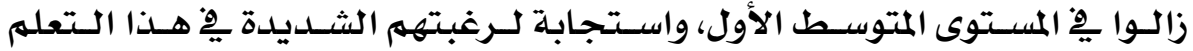

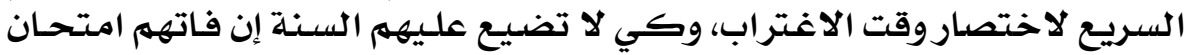

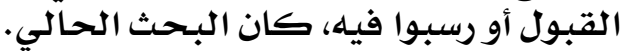

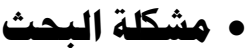

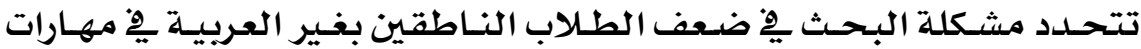

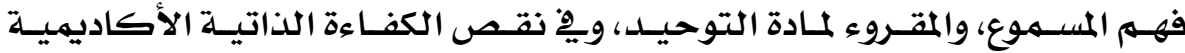

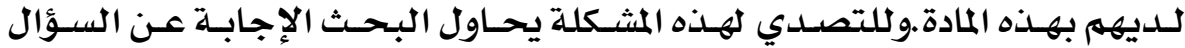

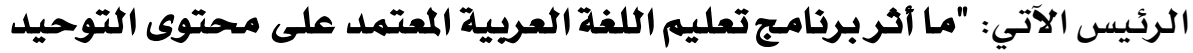

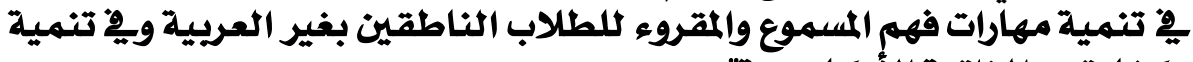

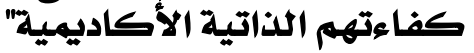

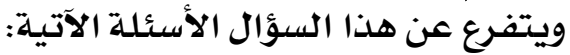

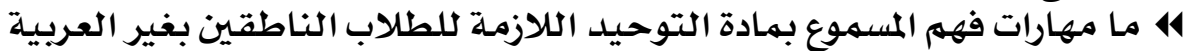

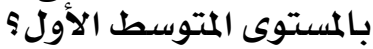

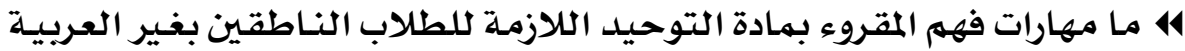

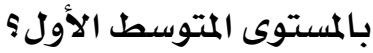

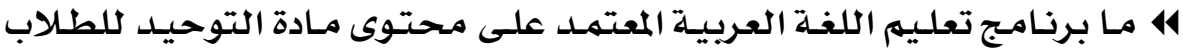

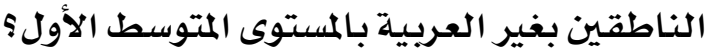

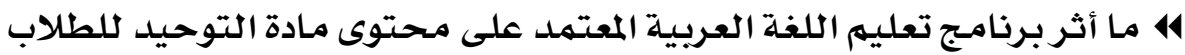

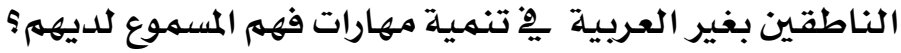

\section{rrq}




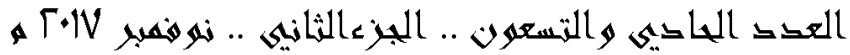

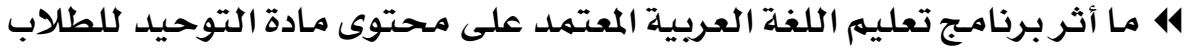

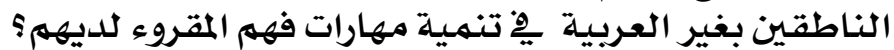

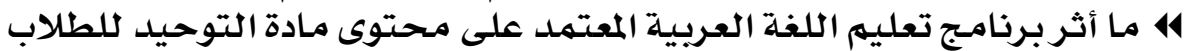

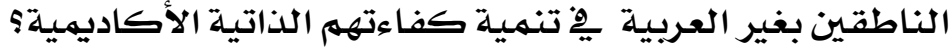

\section{• هصطاحات البحث:}

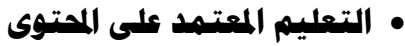

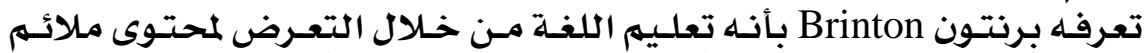

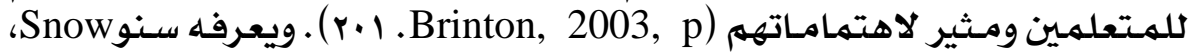

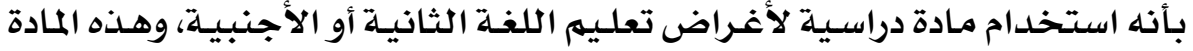

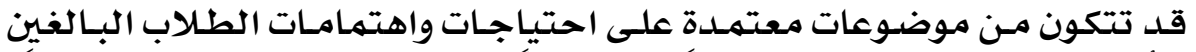

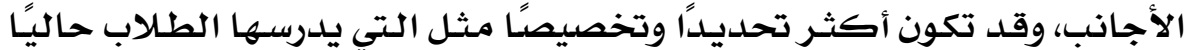

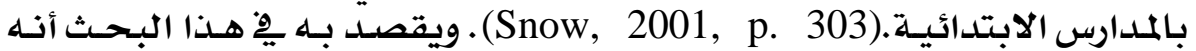

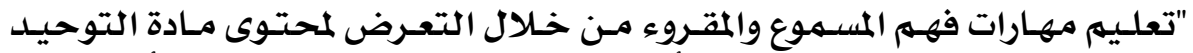

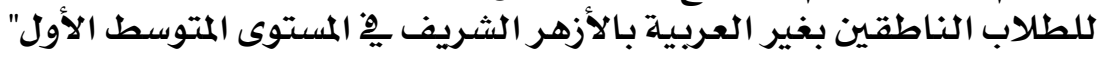

• مادة التوحيد التيدي

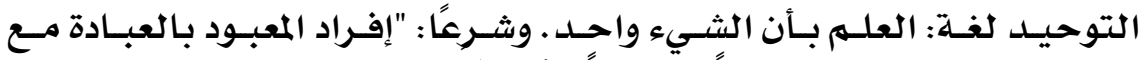

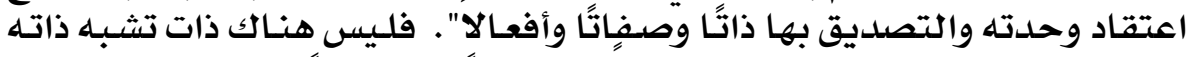

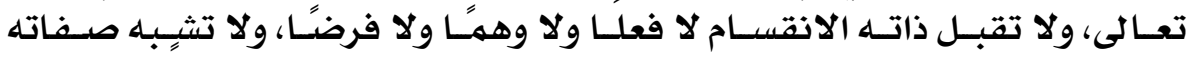

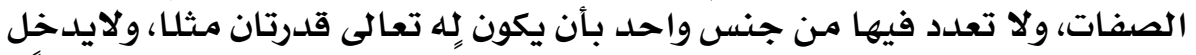

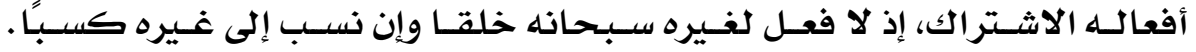

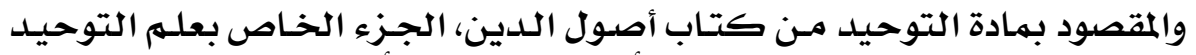

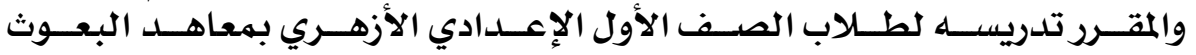

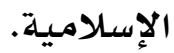

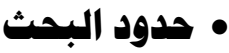

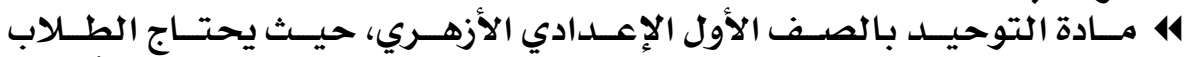

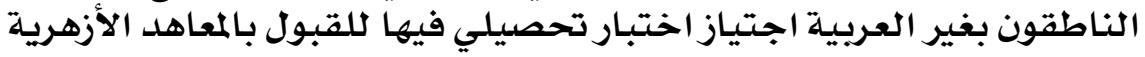

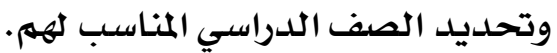

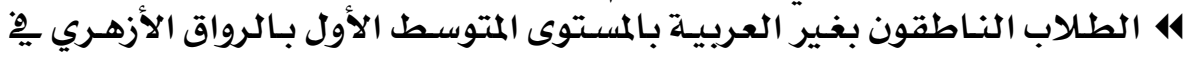

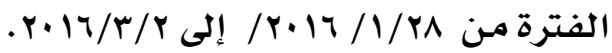

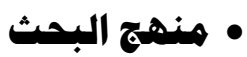

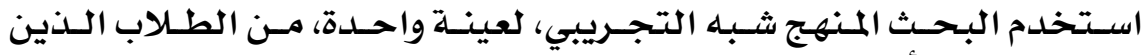

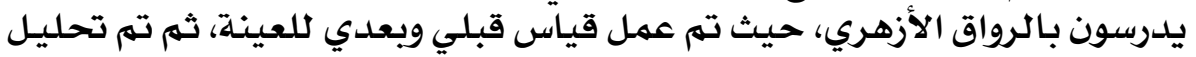

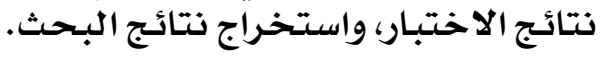

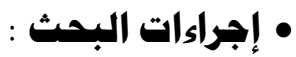

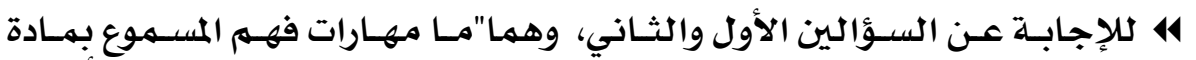

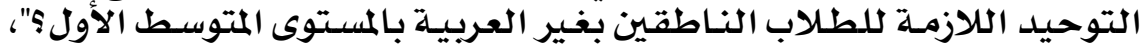

\section{$r \varepsilon$.}




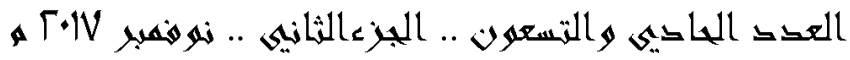

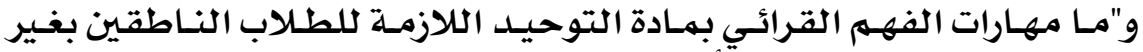

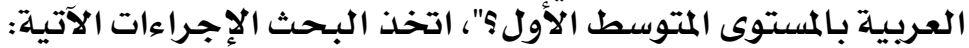

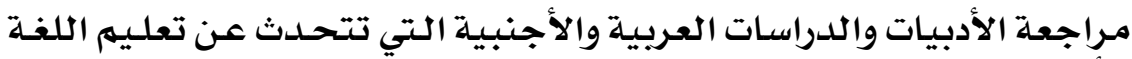

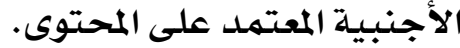

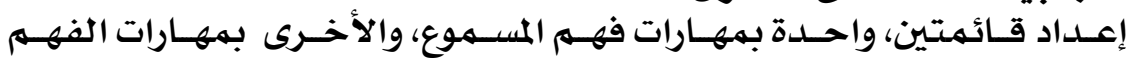

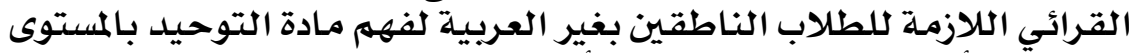

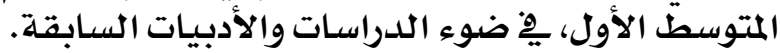

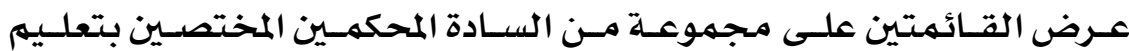

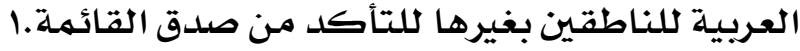

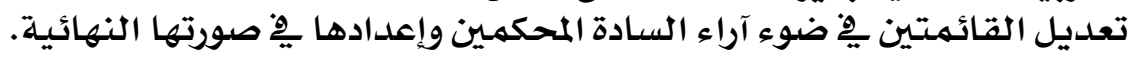

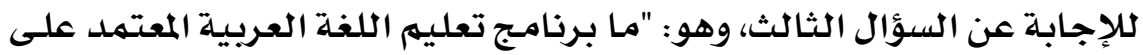

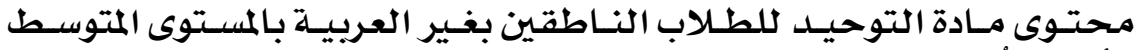

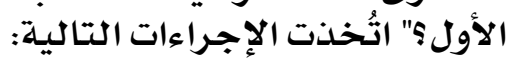

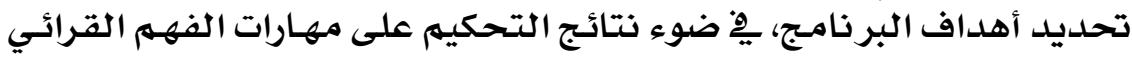

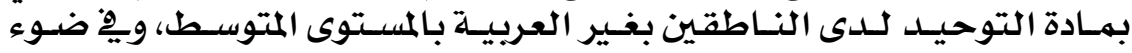

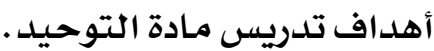

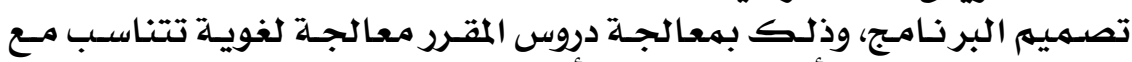

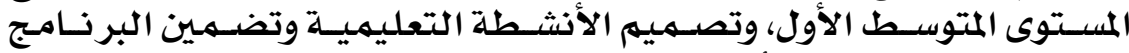

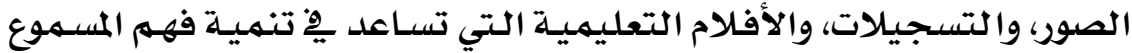

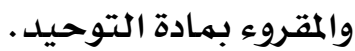

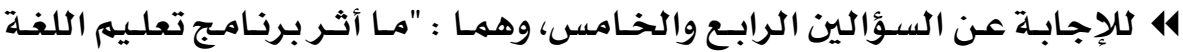

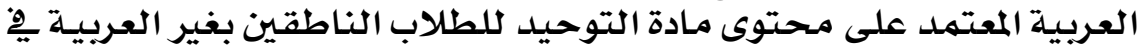

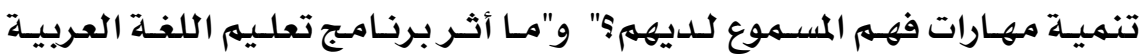

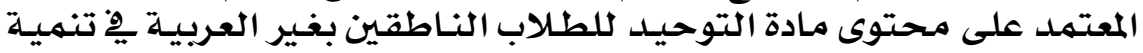

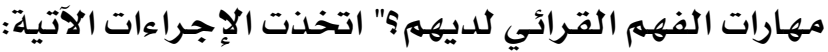

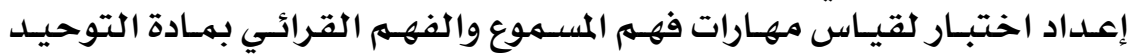

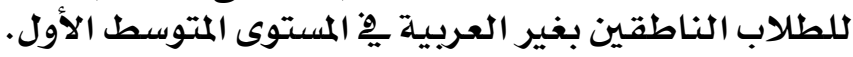

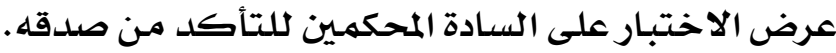

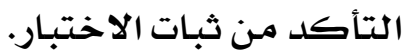

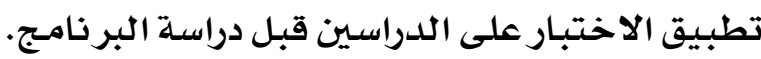
تطبيق البرنامج على الدارسين.

أشرف البحث بتحكيم السادة الآتيت أسماؤهم:

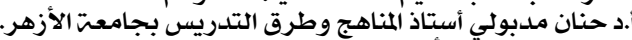

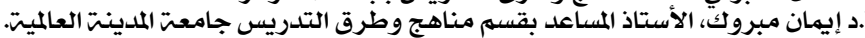

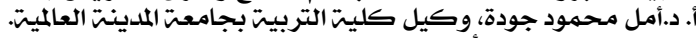

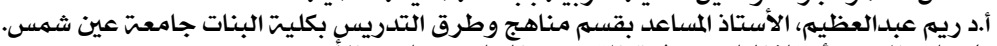

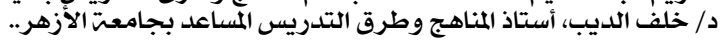

\section{$r \varepsilon 1$}




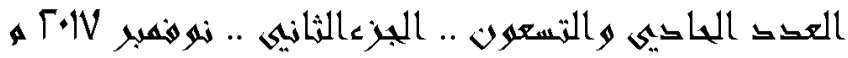

تطبيق الاختبـار على الدارسين بعد دراسـة البر نامـج.

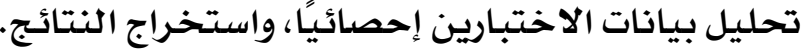

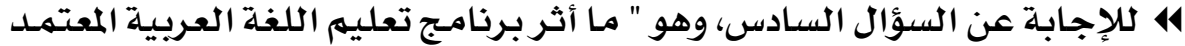

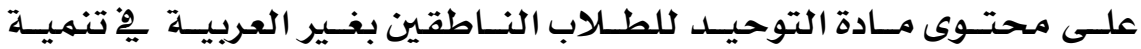

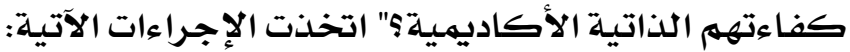

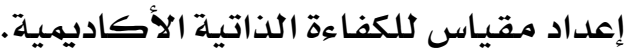

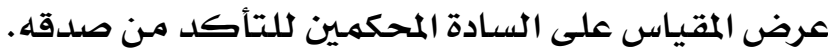
التأكد من ثبات المقياس.

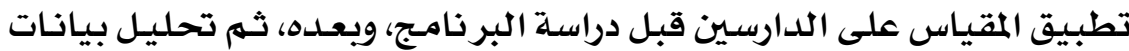
المقياس واستخراج النتائج.

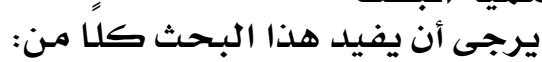

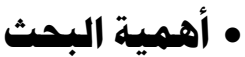

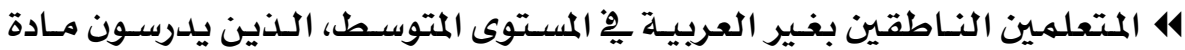

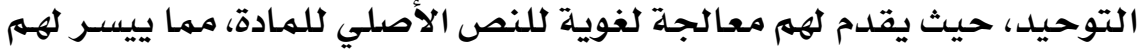

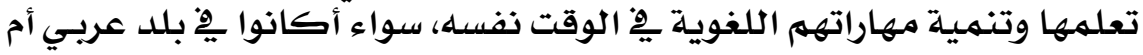

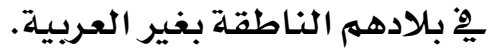

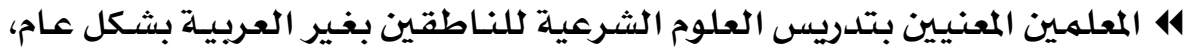

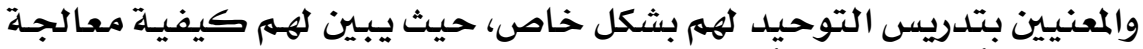

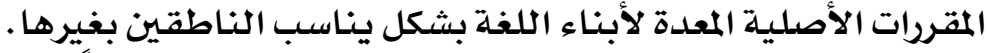
414

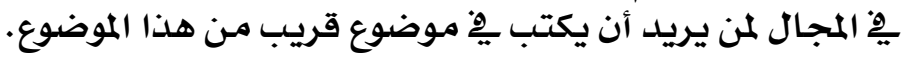

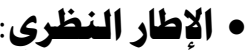

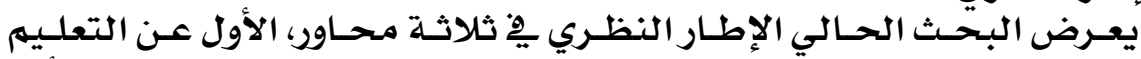

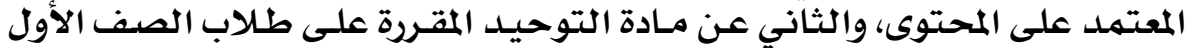

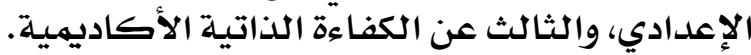

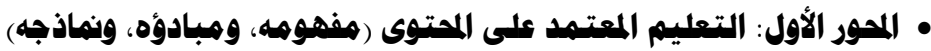

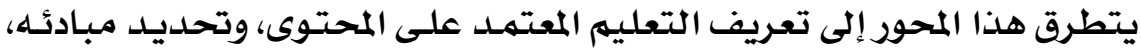

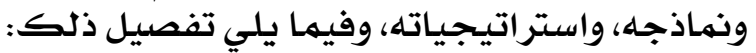

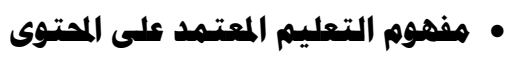

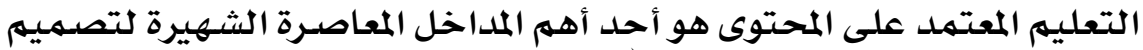

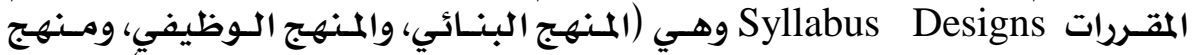

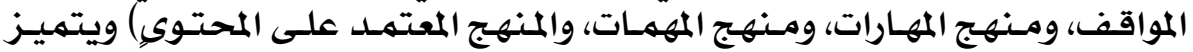

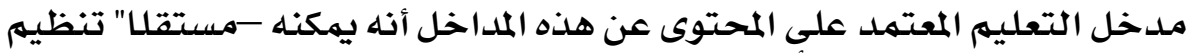

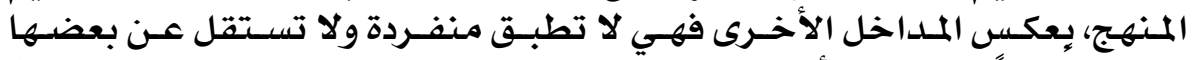

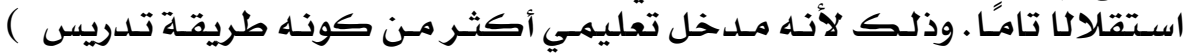

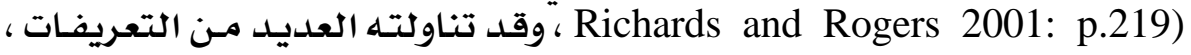

\section{$r \varepsilon Y$}




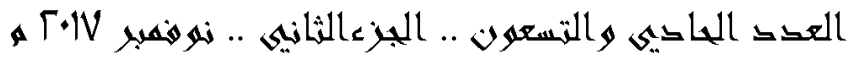

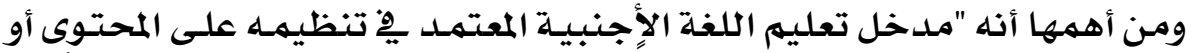

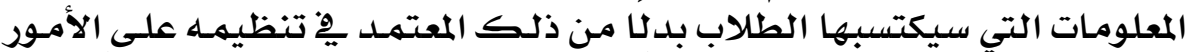

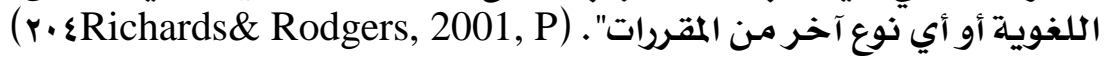

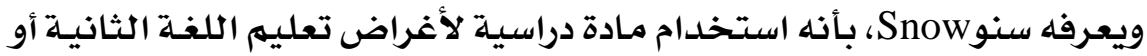

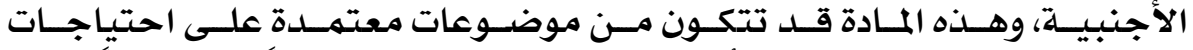

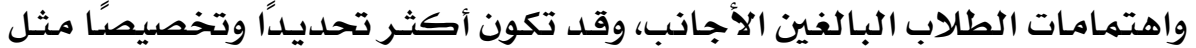

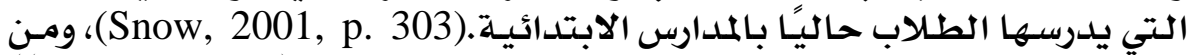

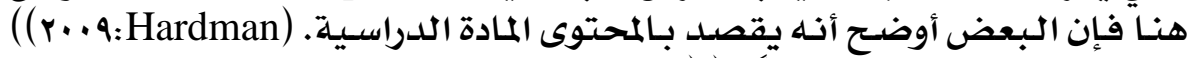

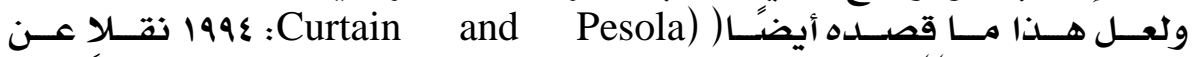

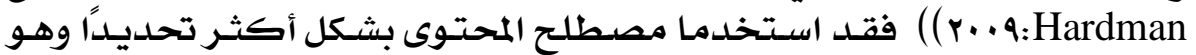

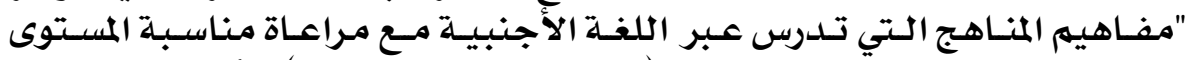

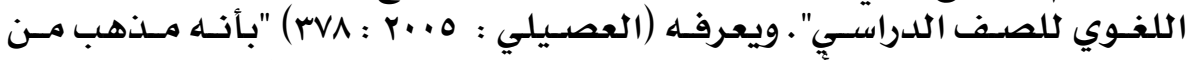

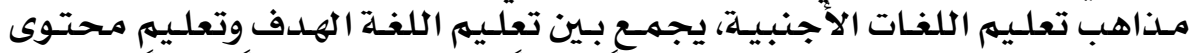

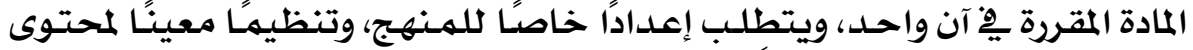

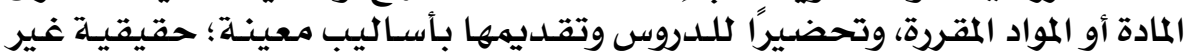

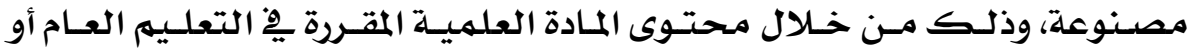

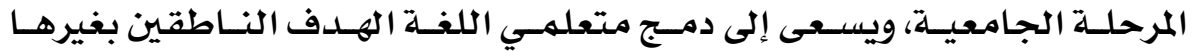

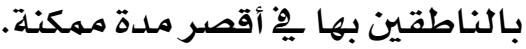

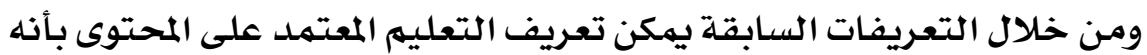

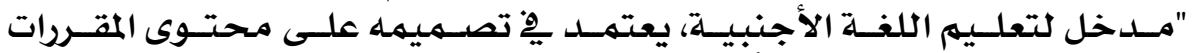

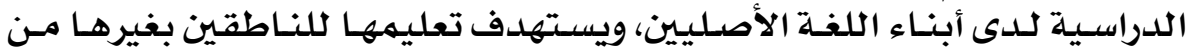

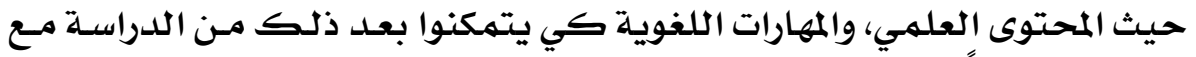

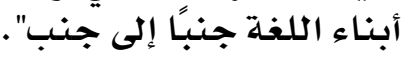

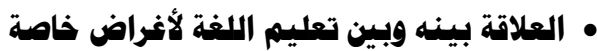

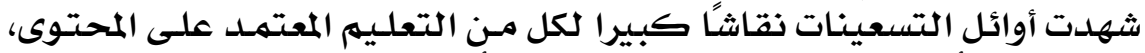

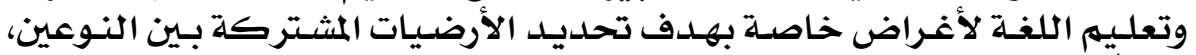

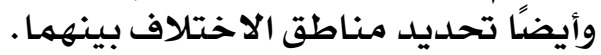

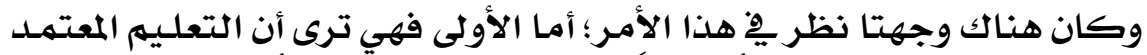

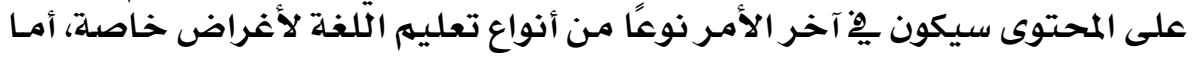

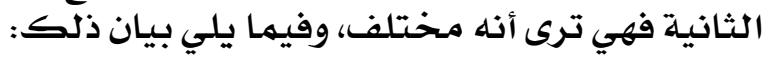

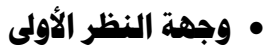

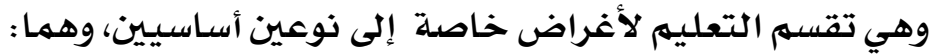

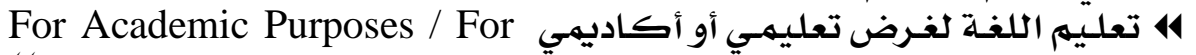

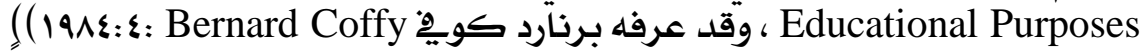

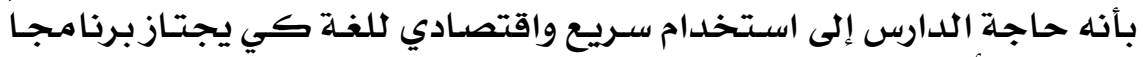

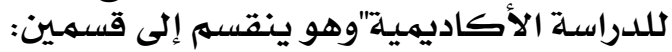

\section{$r \varepsilon r$}




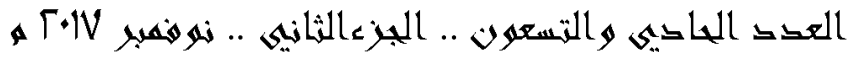

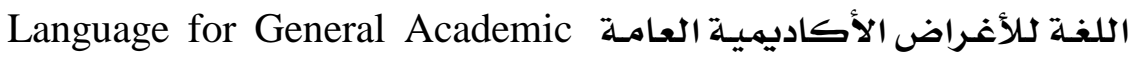

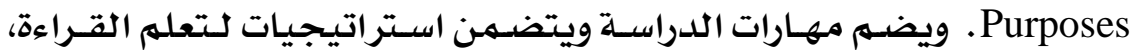

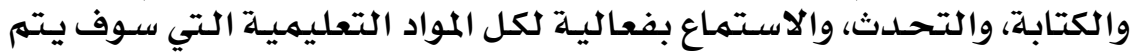
تعلمها.

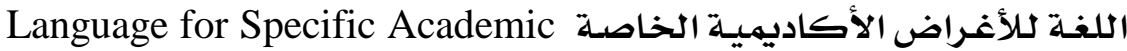

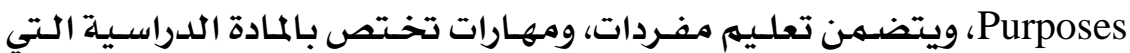

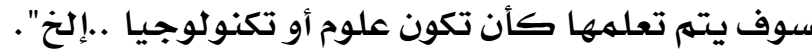
4 تعليه اللغـة لغرض مهني أو وظيفي Occupational Purposes/ Vocational

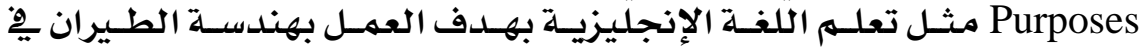

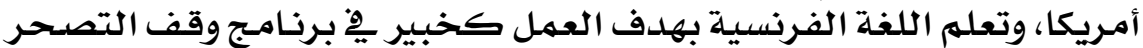

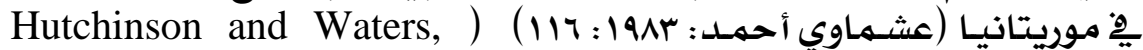
،1987) , (Robinson 1991), (Jordan 1997) (Evans and John 1998)

، (19^乏: (Mackay and Mount Ford (1978) (Coffey

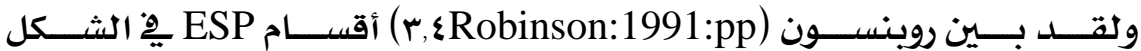

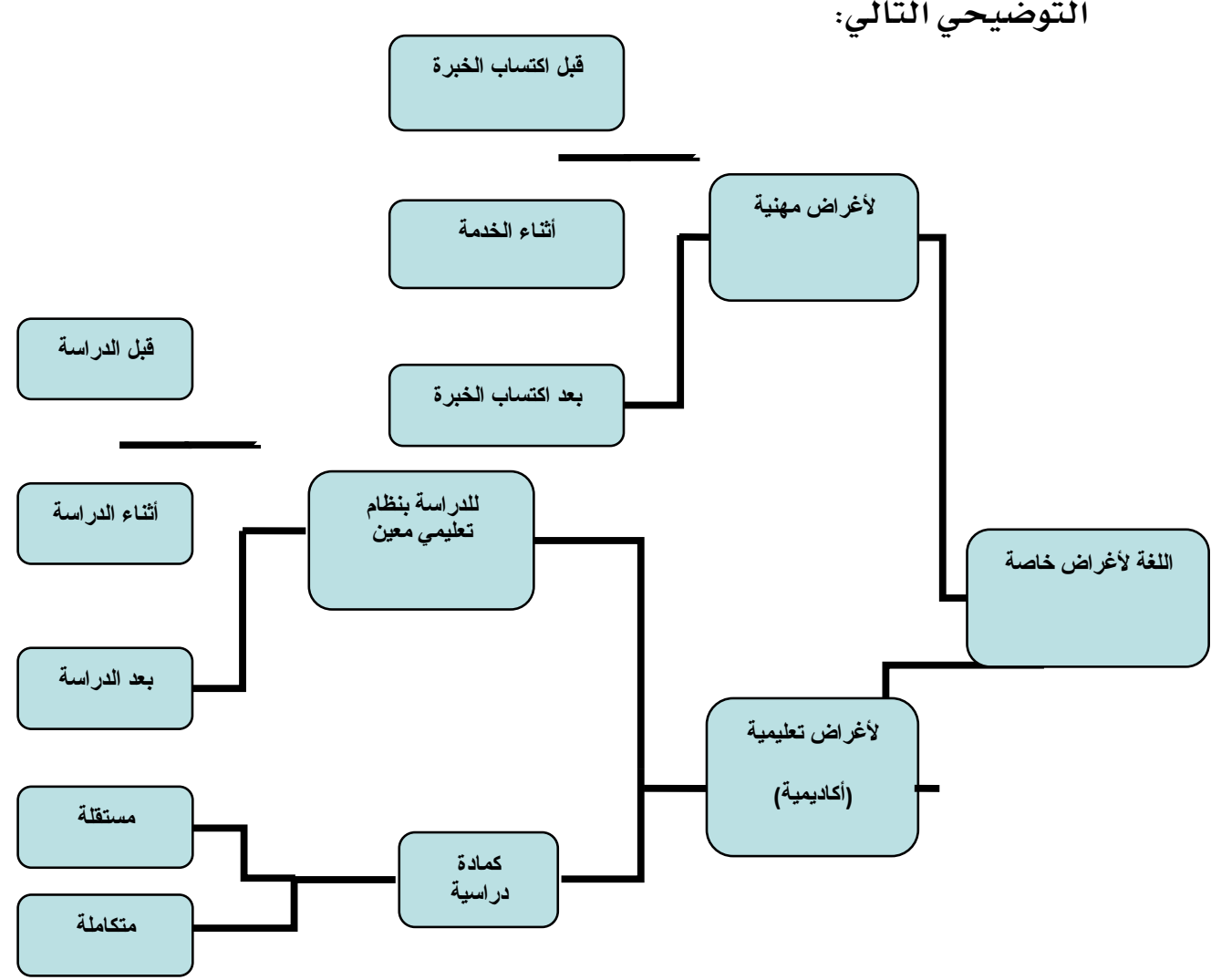

شكل رقم (1) أنواع تعليم اللغت لأثراض خاصت

\section{$r \varepsilon \varepsilon$}




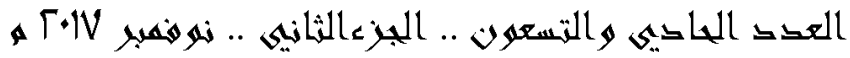

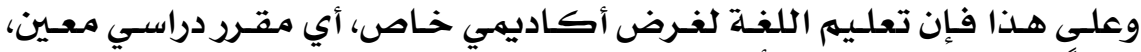

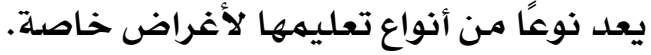

• وجهة النظر الثانية:

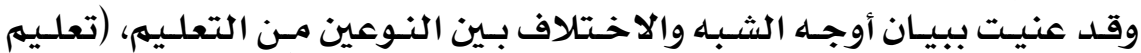

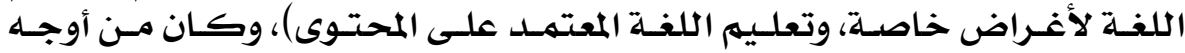

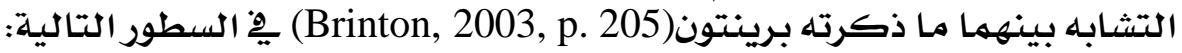

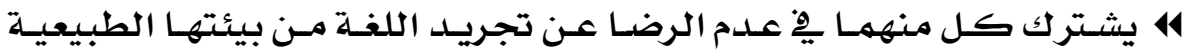

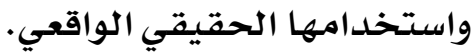

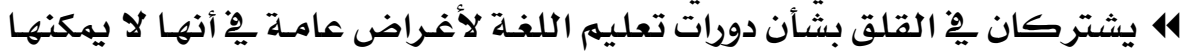

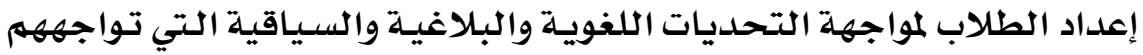

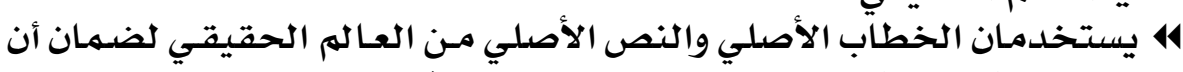

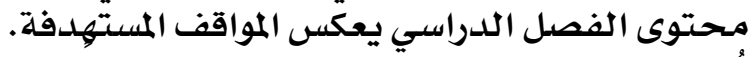

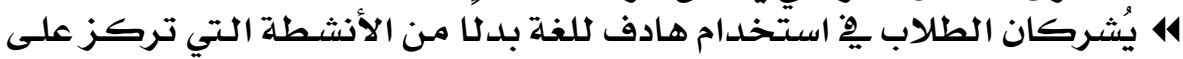
اللغة نفسها.

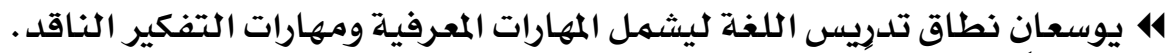

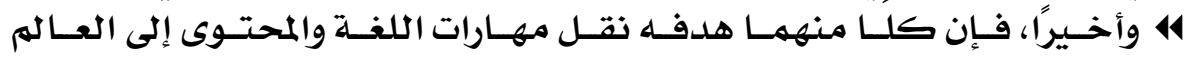
الحقيقي.

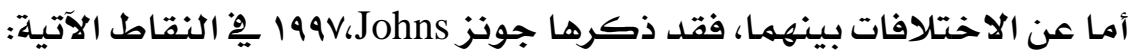

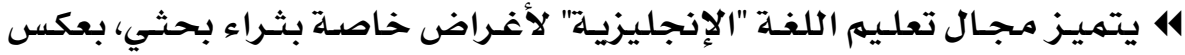

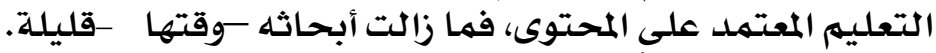

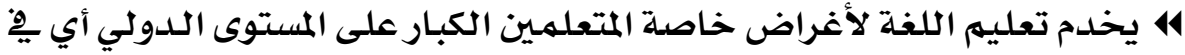

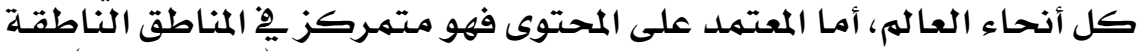

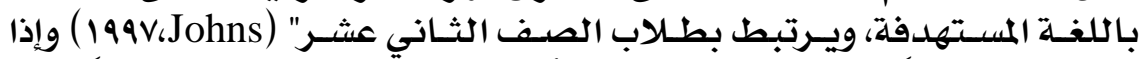

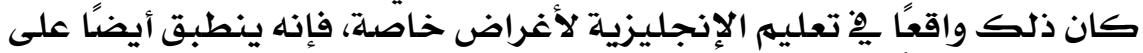

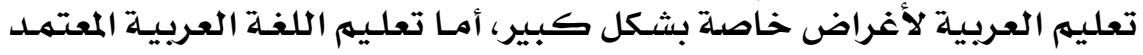

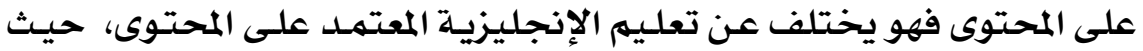

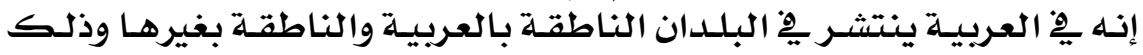

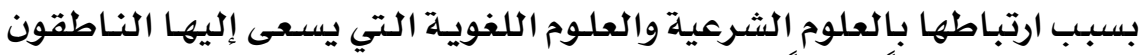

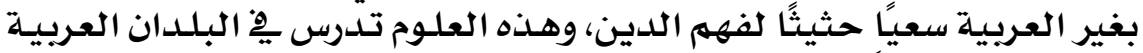

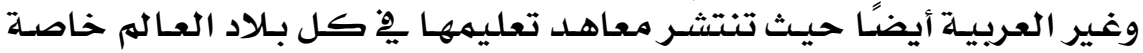

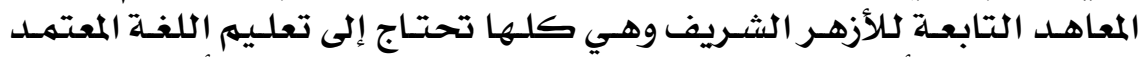

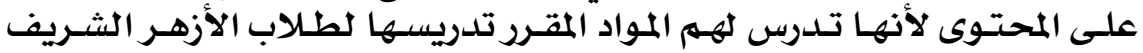
المصريين.

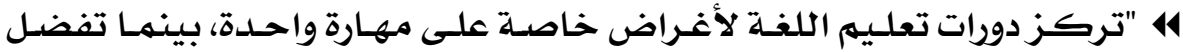

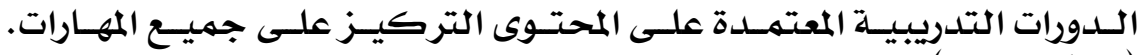
.(199V،Johns)

\section{$r \varepsilon 0$}




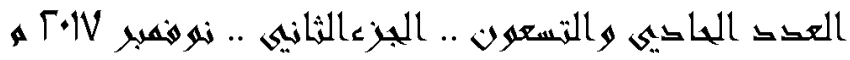

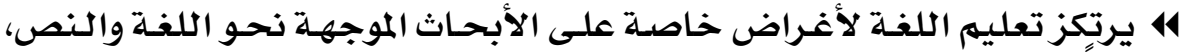

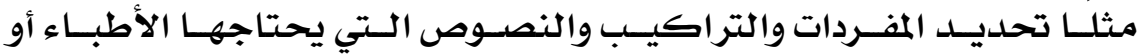

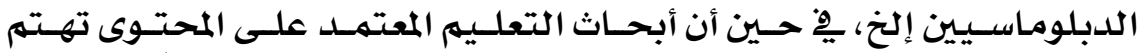

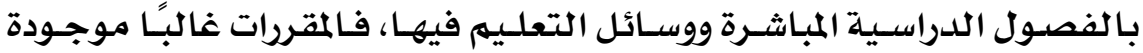

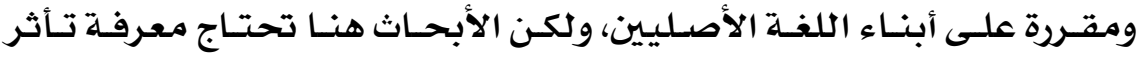

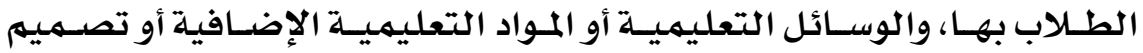

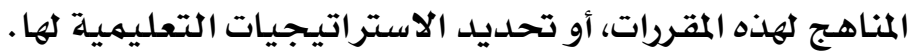

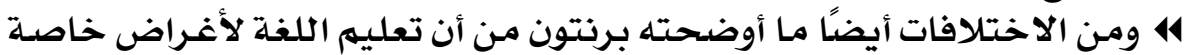

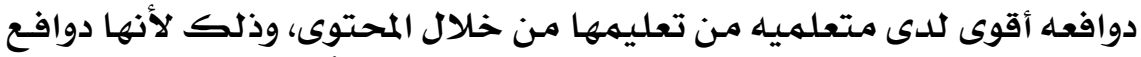

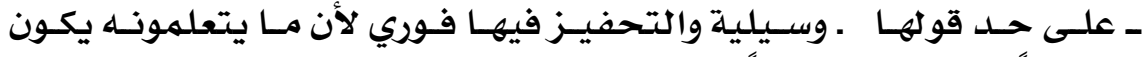

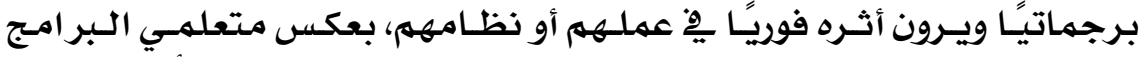

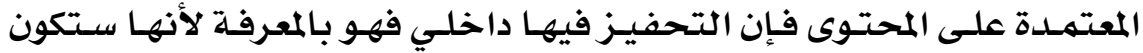

وسيلة للنجاح.

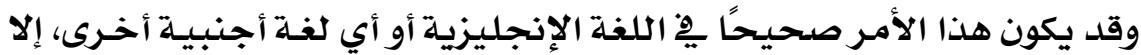

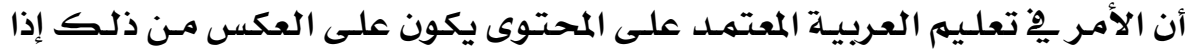

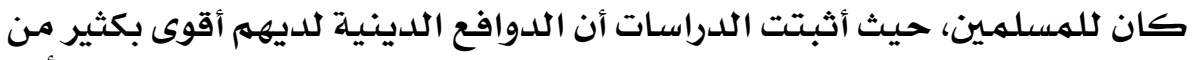

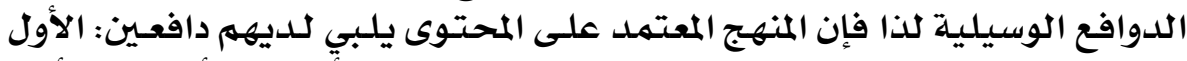

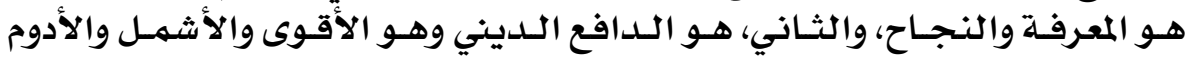

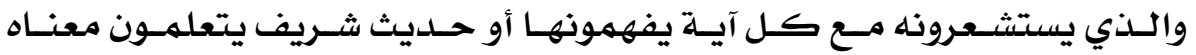

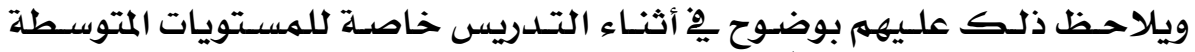

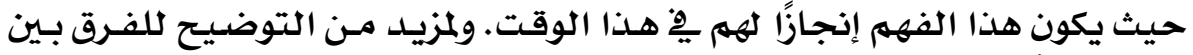

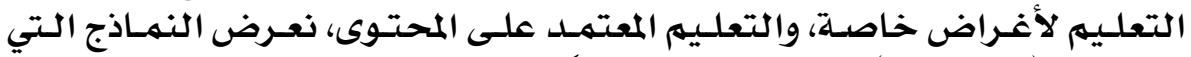

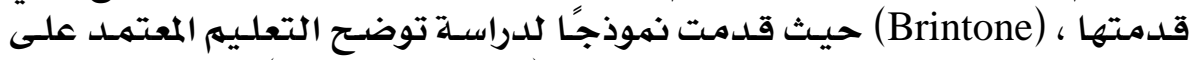

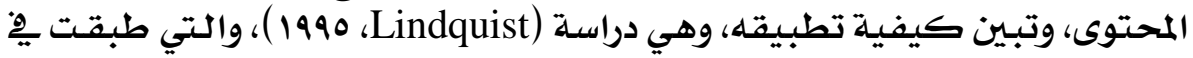

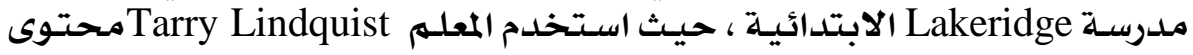

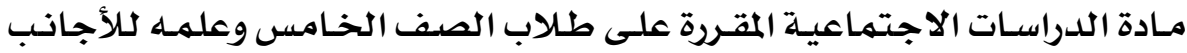

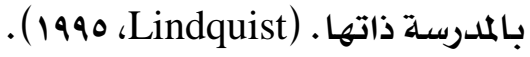

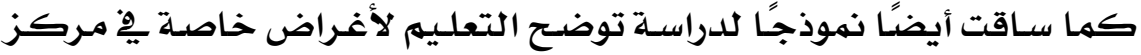

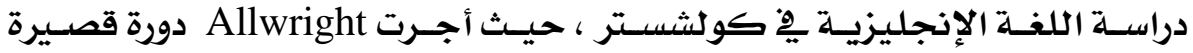

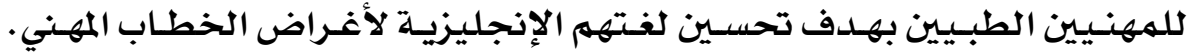

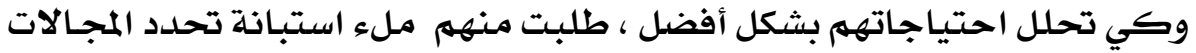

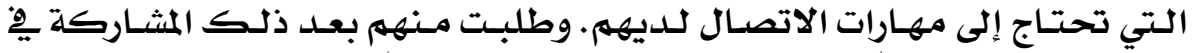

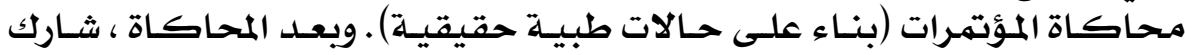

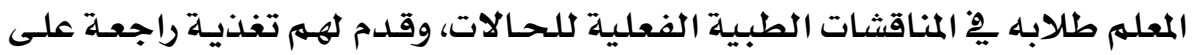

\section{$r \varepsilon 7$}




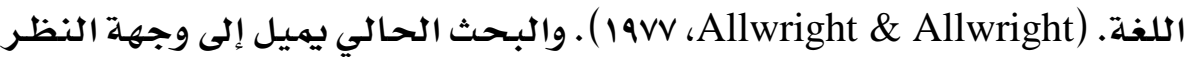

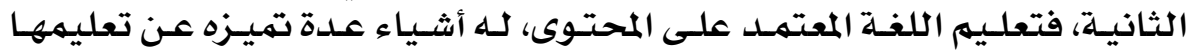

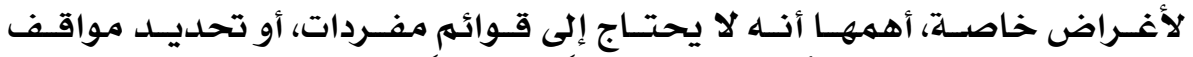

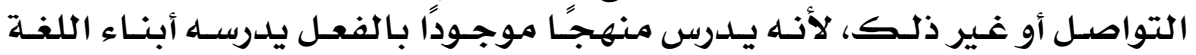
والناطقين بغيرها أيضًا.

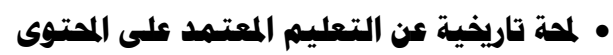

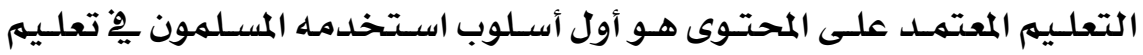

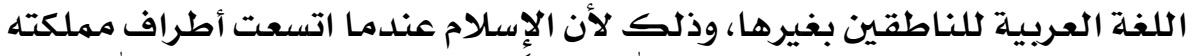

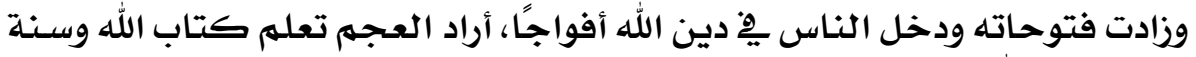

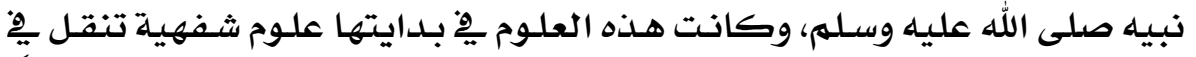

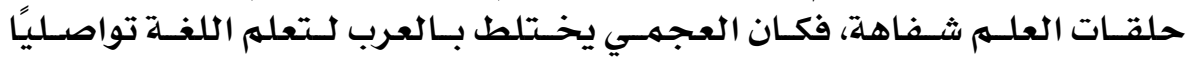

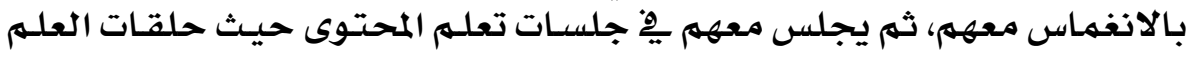

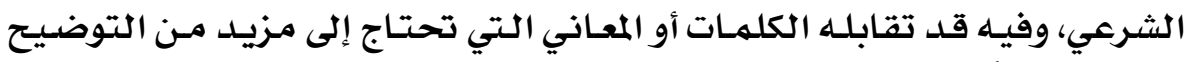

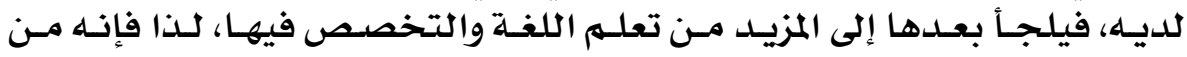

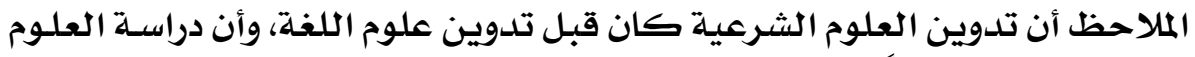

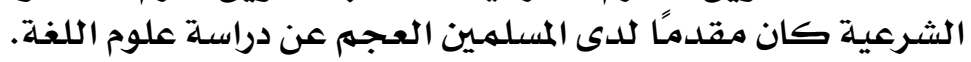

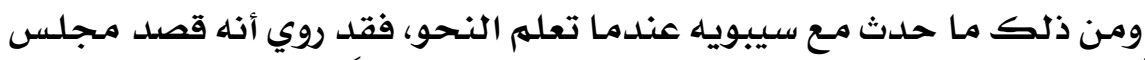

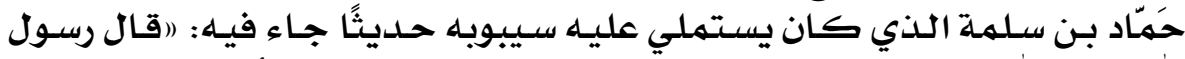

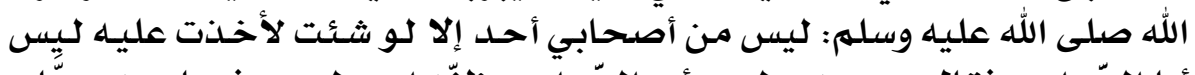

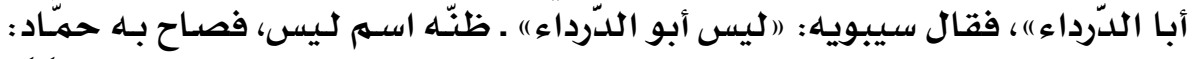

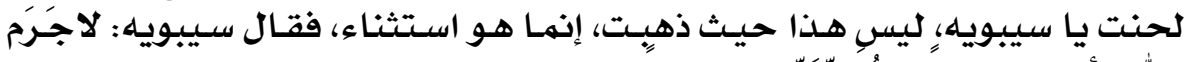

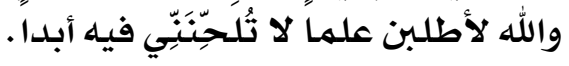

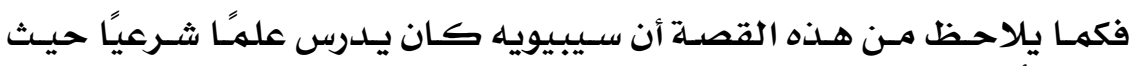

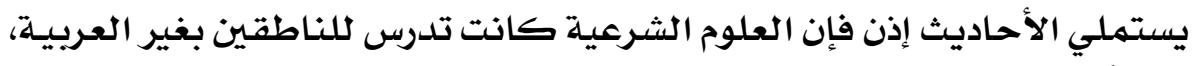

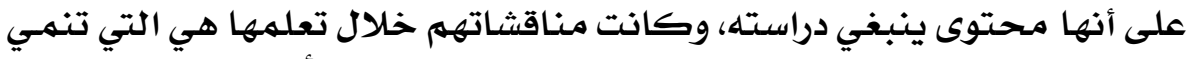

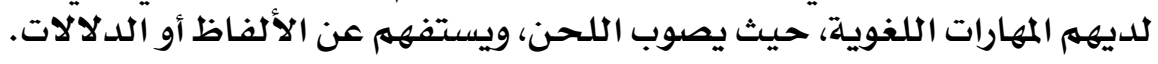

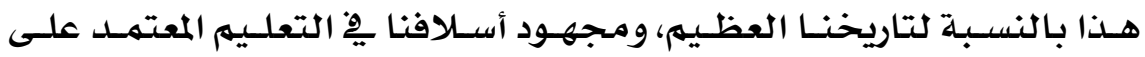

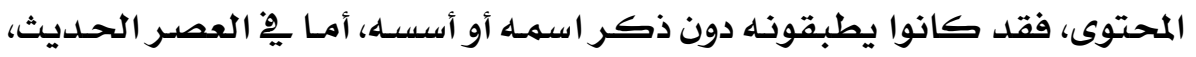

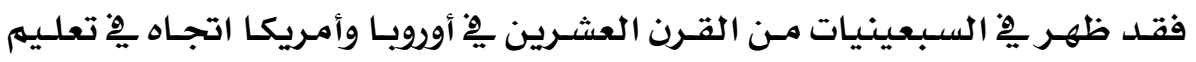

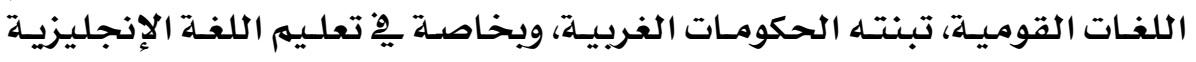

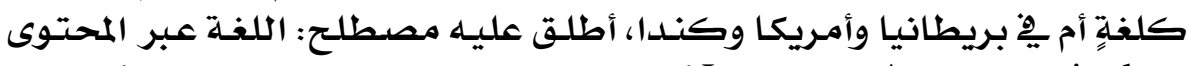
هanguage Across curriculum

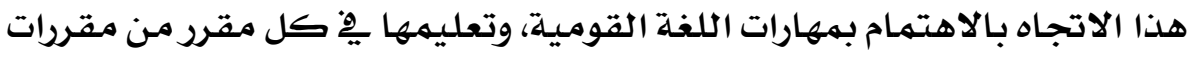

\section{$r \varepsilon V$}




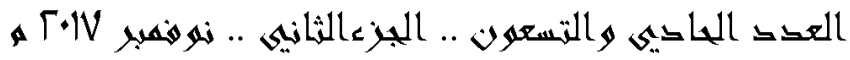

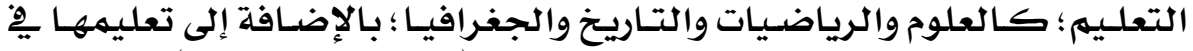

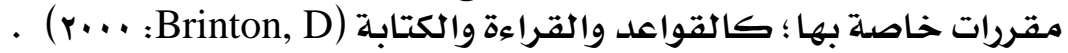

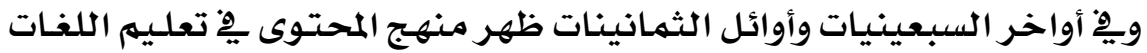

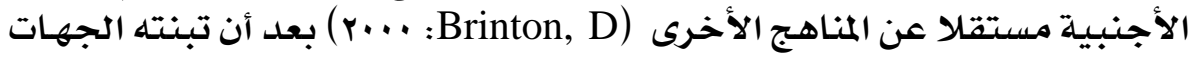

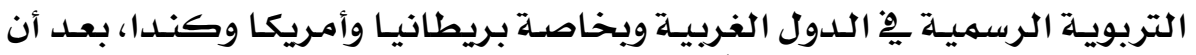

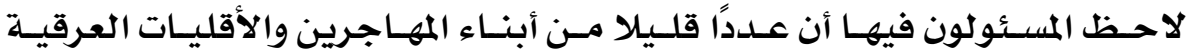

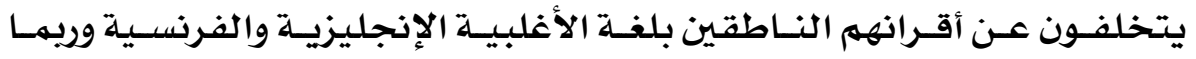

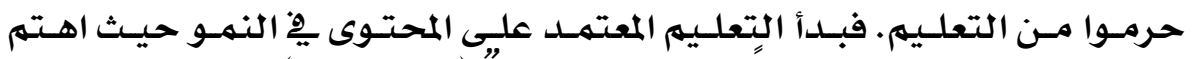

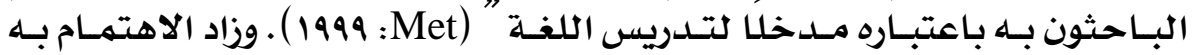

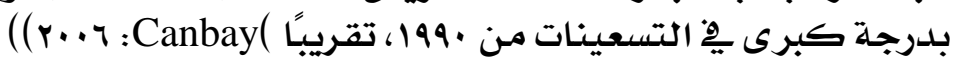

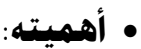

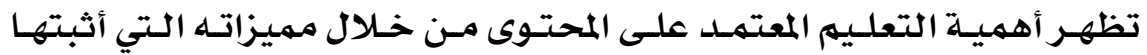

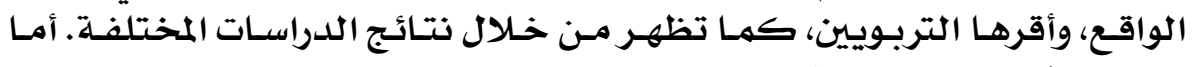

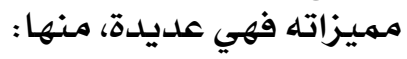

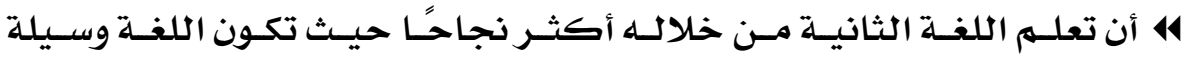

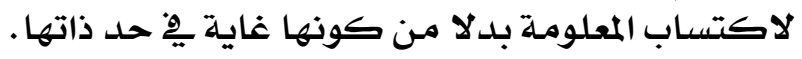

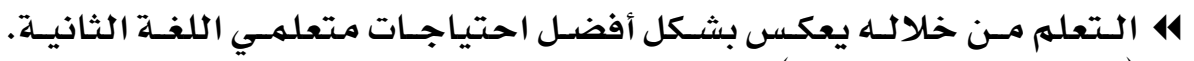

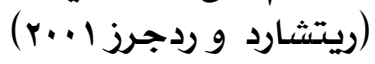

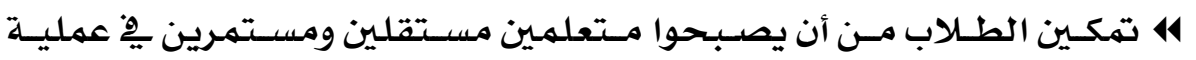

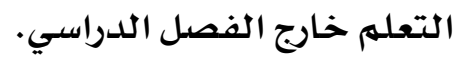

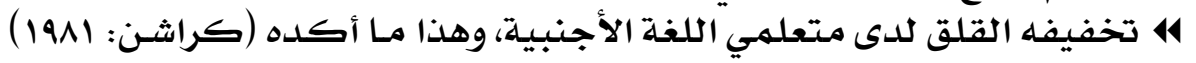

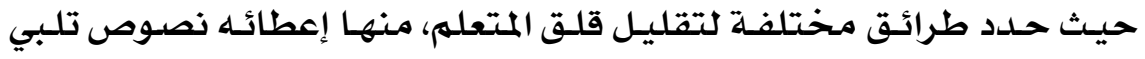

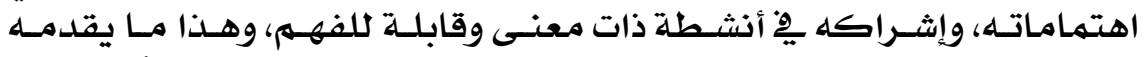

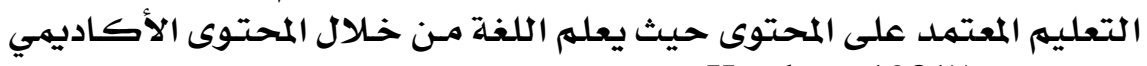
وأنشطته. Krashen :1981)

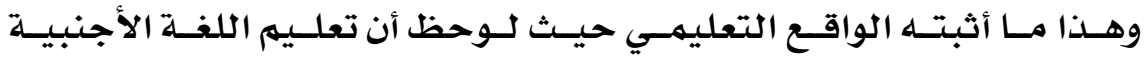

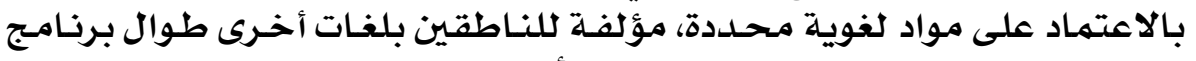

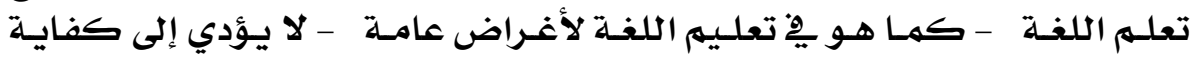

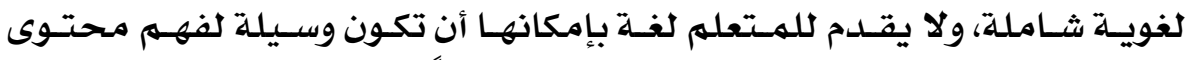

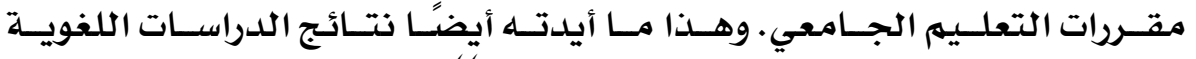

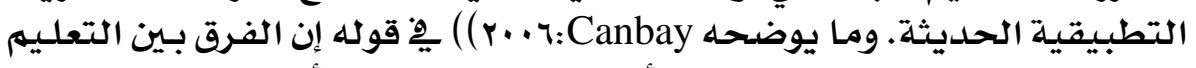

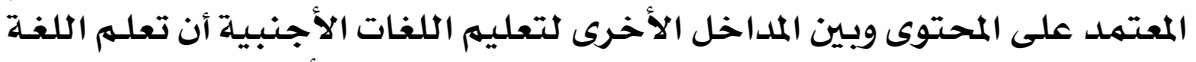

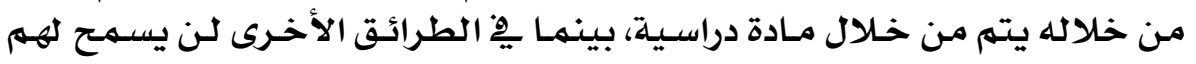

\section{$r \varepsilon \Lambda$}




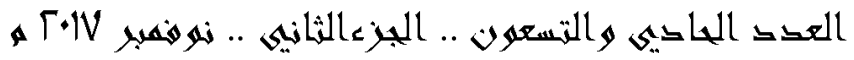

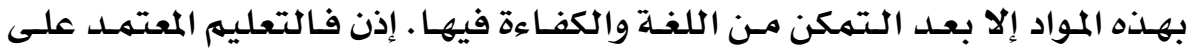

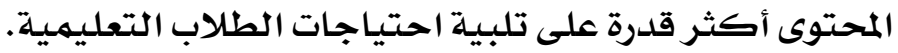

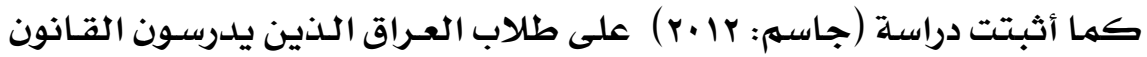

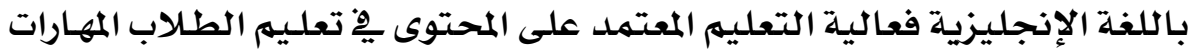

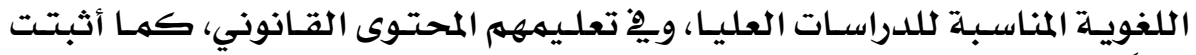

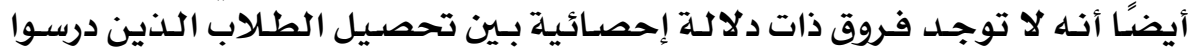

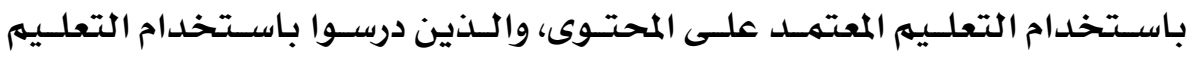

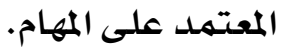

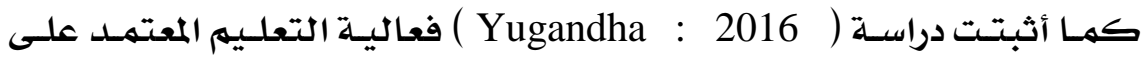

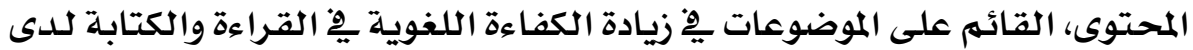

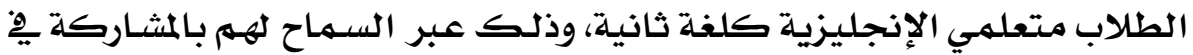

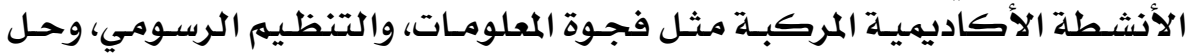

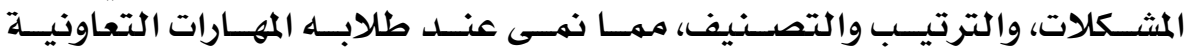
والاجتماعية إضافة إلى الكفاءة اللغوتئية

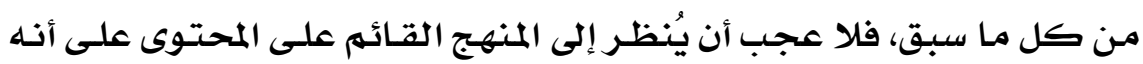

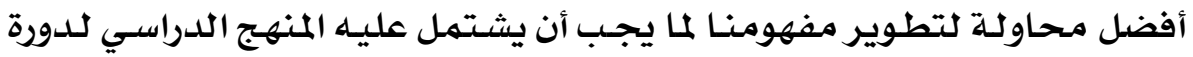

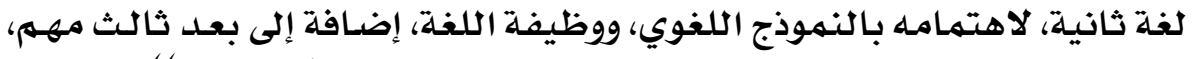

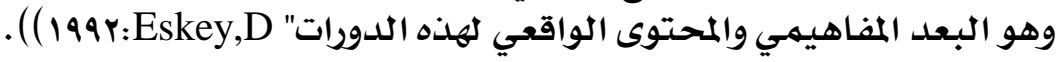

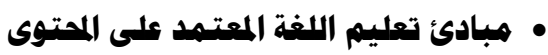

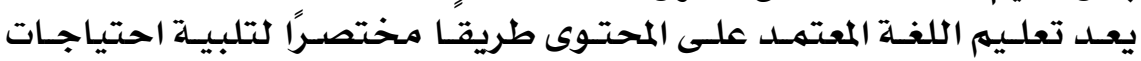

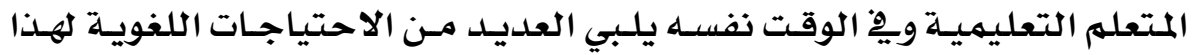

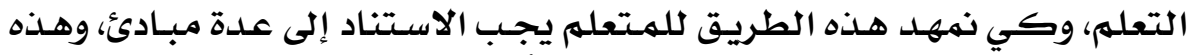

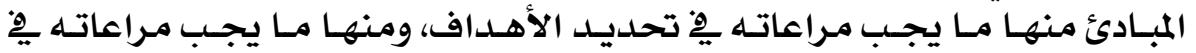

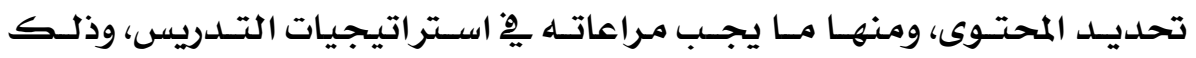

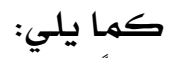
• أولاً: المبادئ التي يبب هراعاتها في أهداف التعليم المعتمد على الحتوى

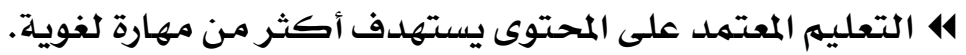

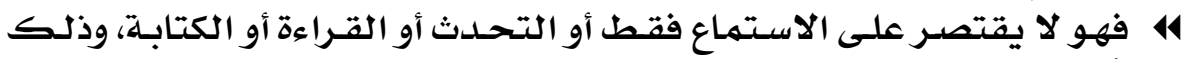

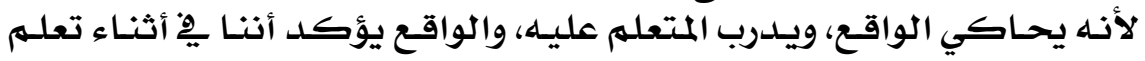

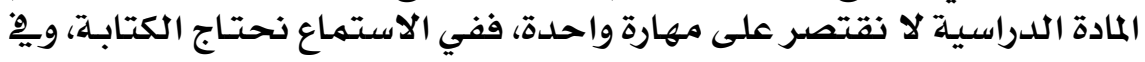

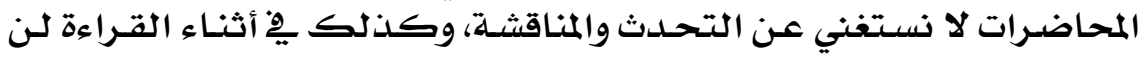
نترك التدوين. 414

\section{r $\& 9$}




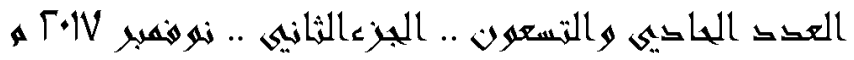

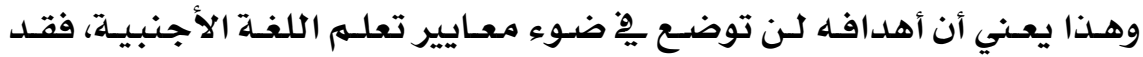

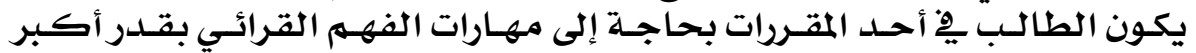

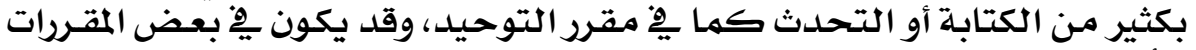

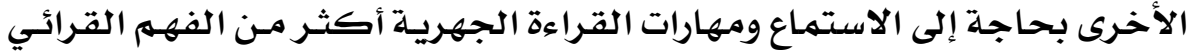

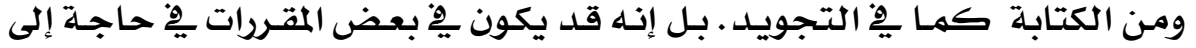

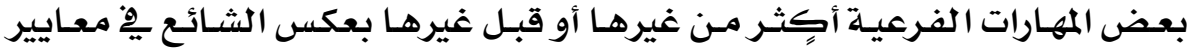

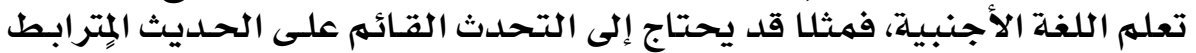

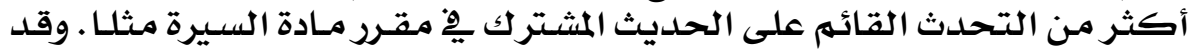

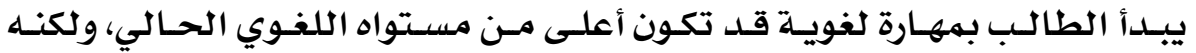

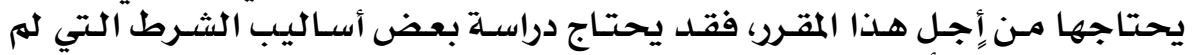

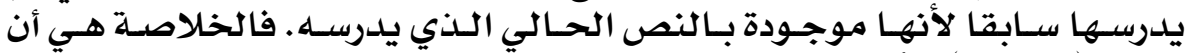

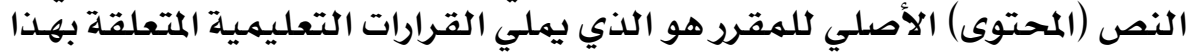

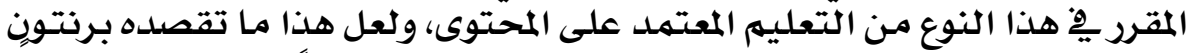

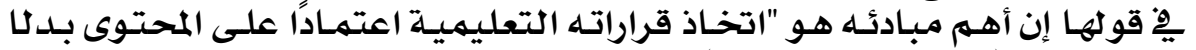

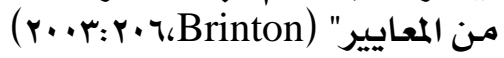

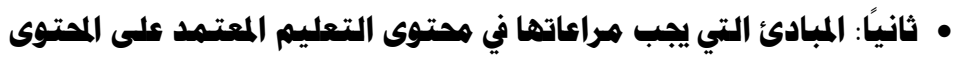

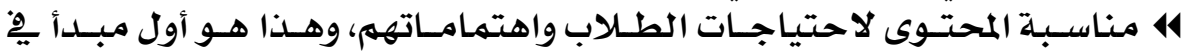

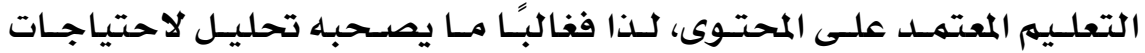

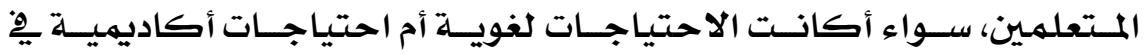

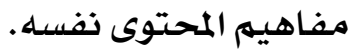

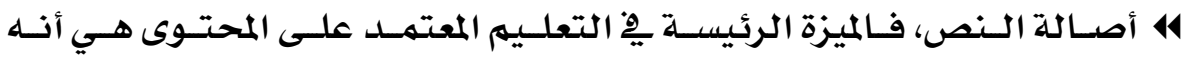

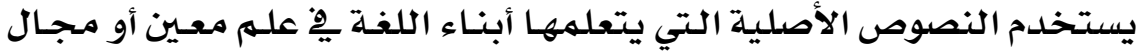

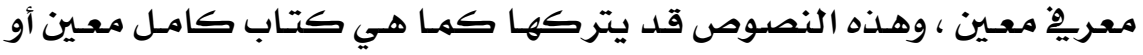

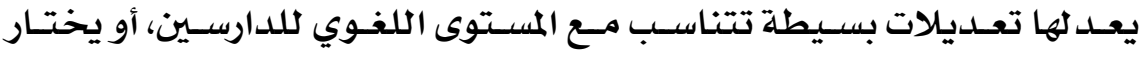

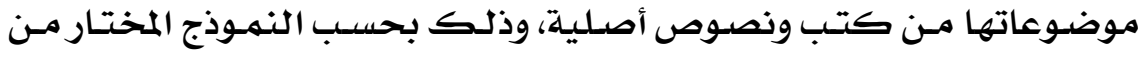

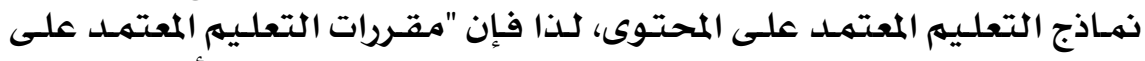

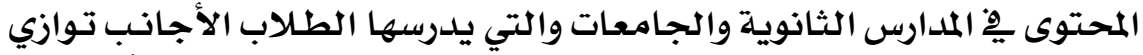

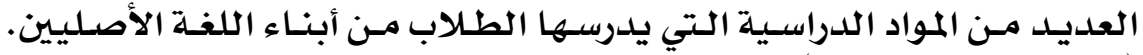

(r- †Brinton,2003:P)

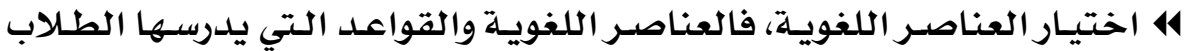

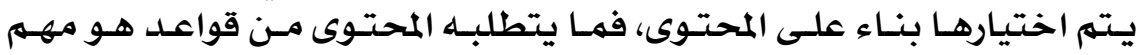

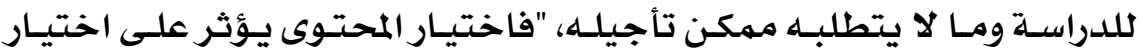

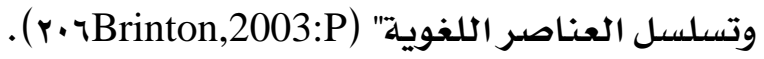

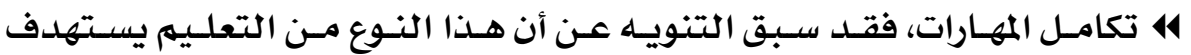

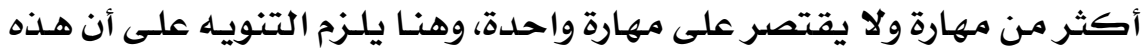

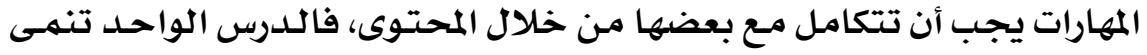

\section{ro.}




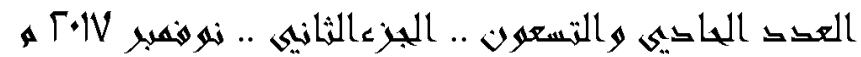

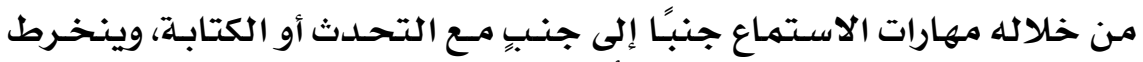

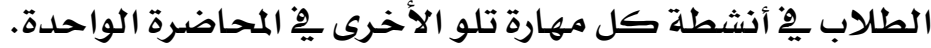

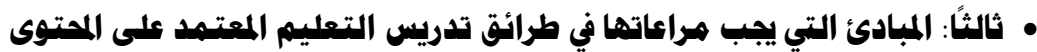

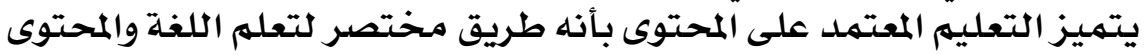

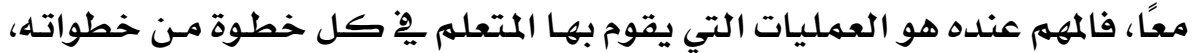

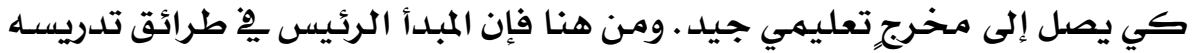

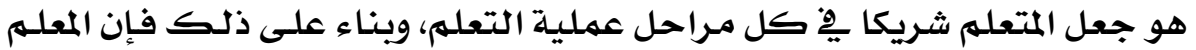

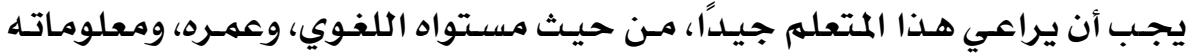

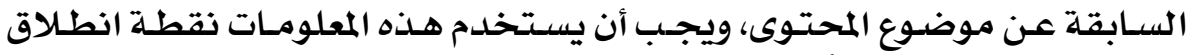

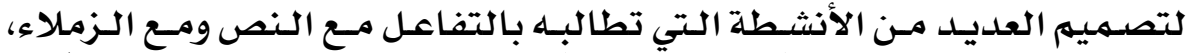

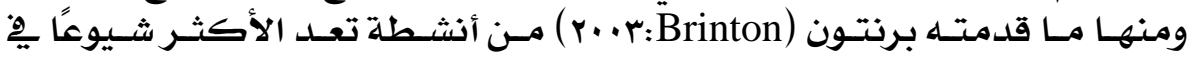

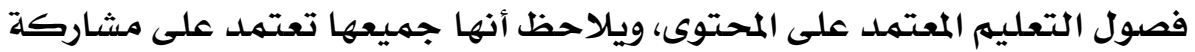

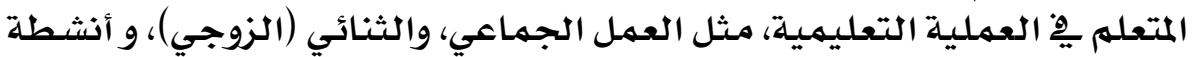

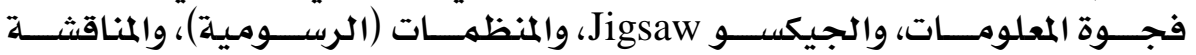

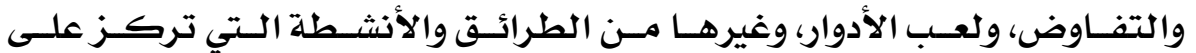

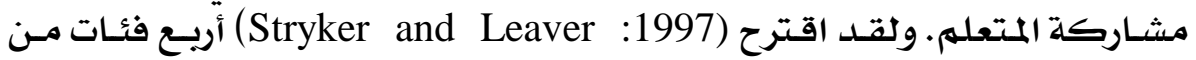

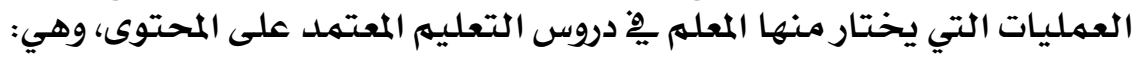

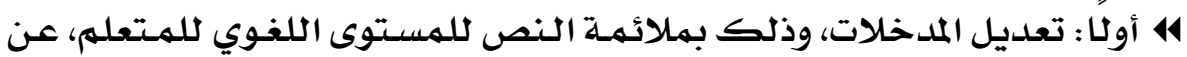

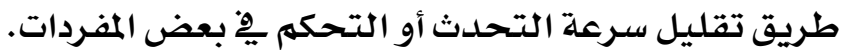

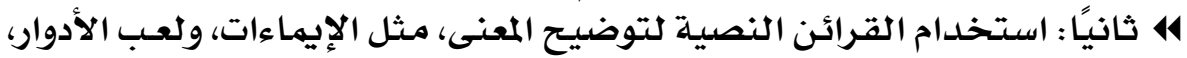

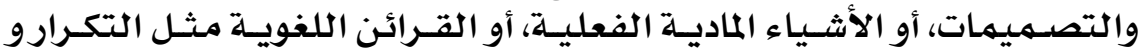

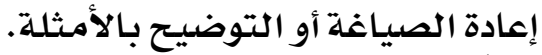

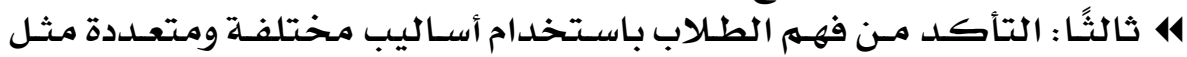

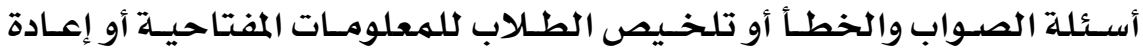

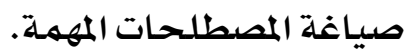

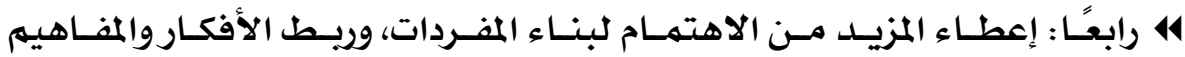

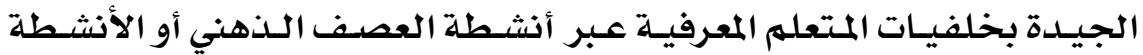

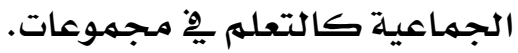

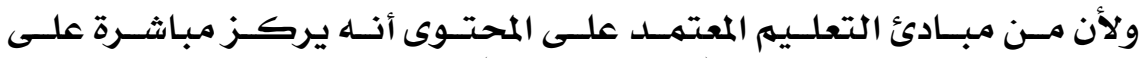

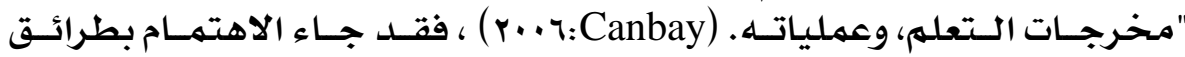

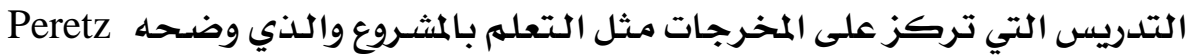

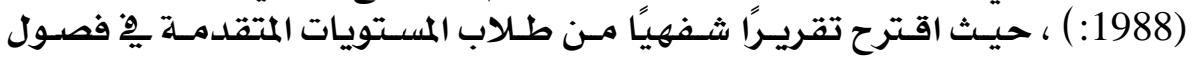

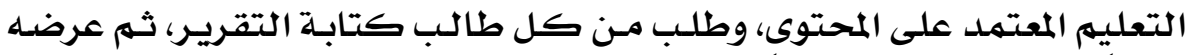

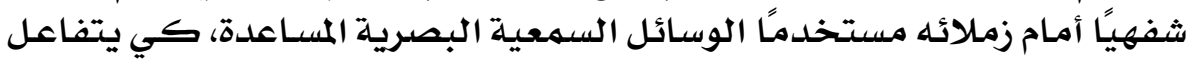

\section{rol}




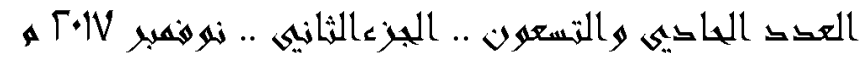

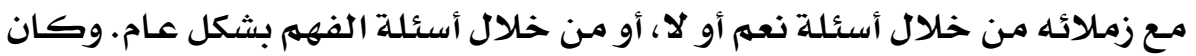

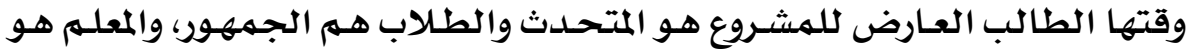

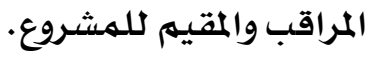

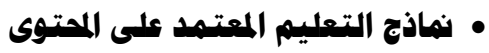

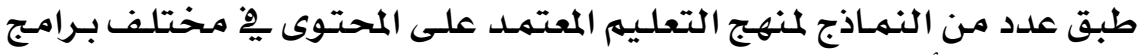

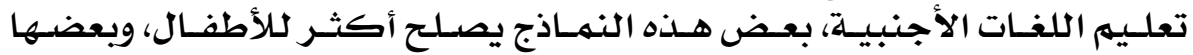

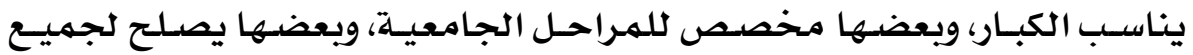

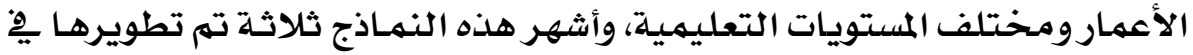

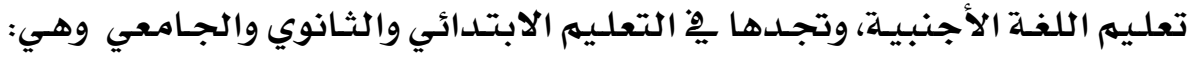

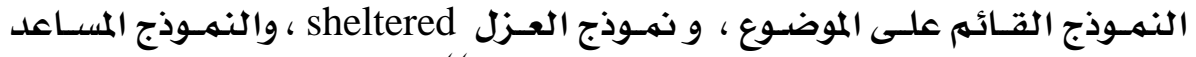

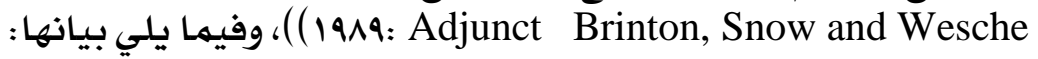
• النموذج الأول: النموذج المعتمد على الموضوعات

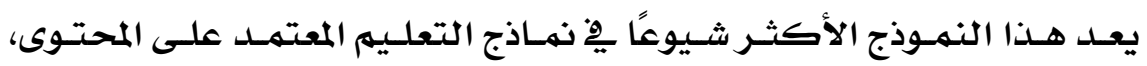

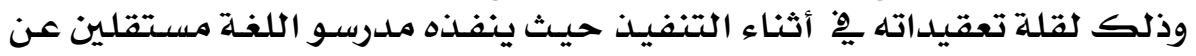
باقي أعضاء هيئة التدريس.

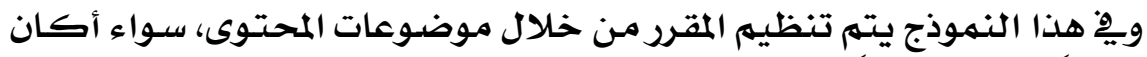

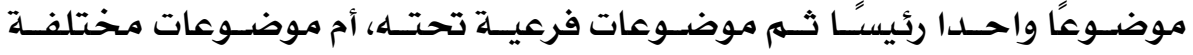

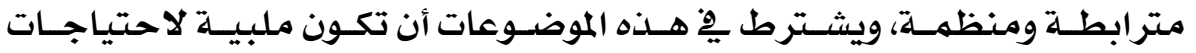

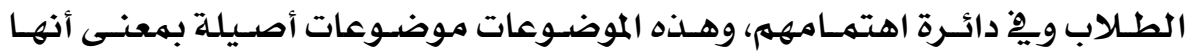

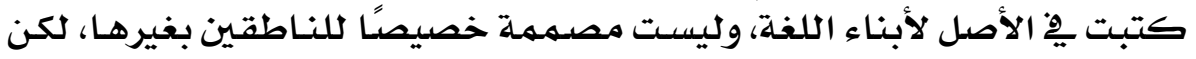

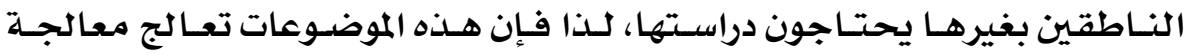

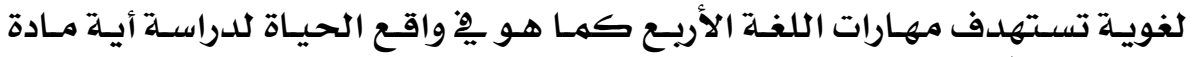

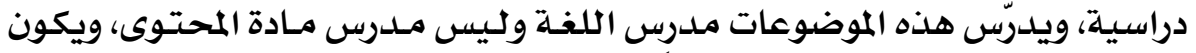

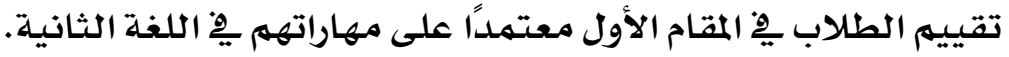

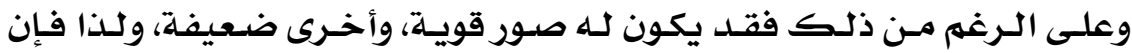

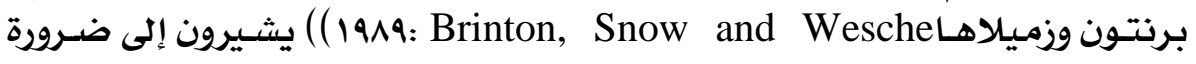

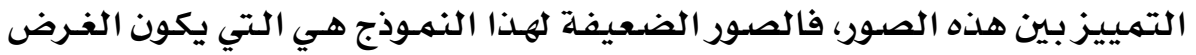

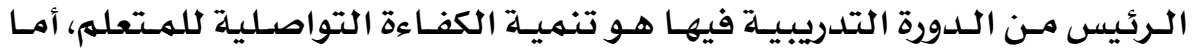

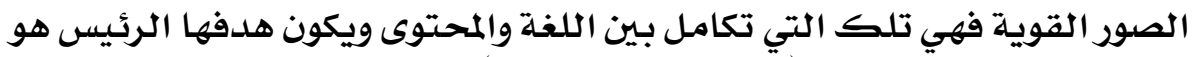

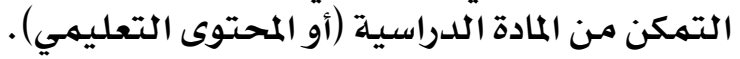

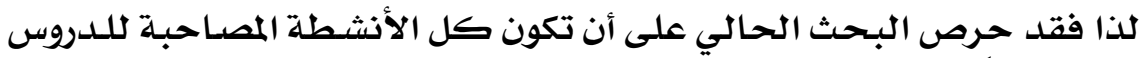

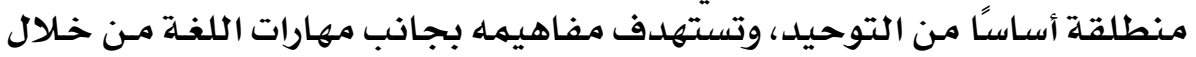
مفرداته وتراكيبه.

\section{YOY}




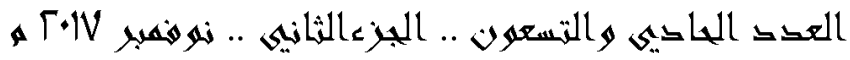

• النهموذج الثاني: تعليم اللغة المساعد Adjunct-model

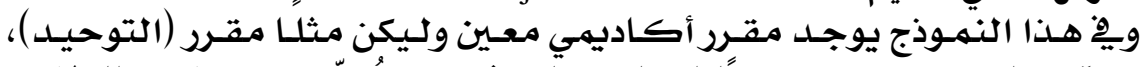

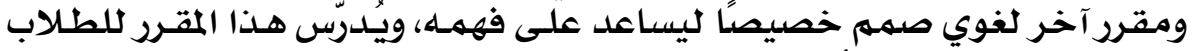

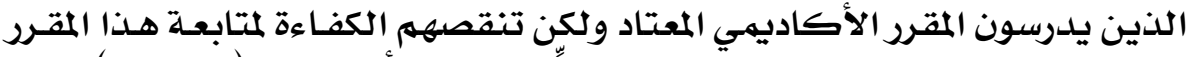

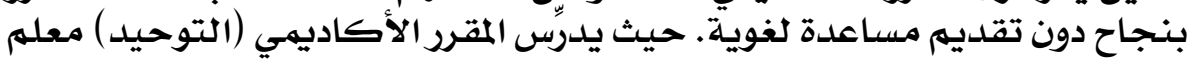

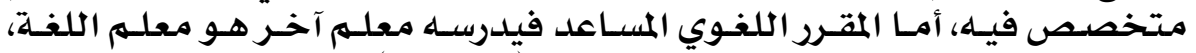

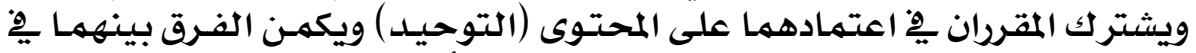

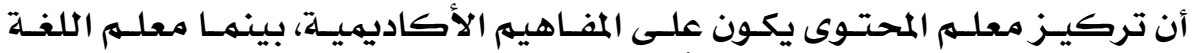

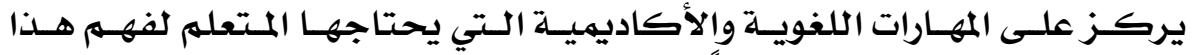

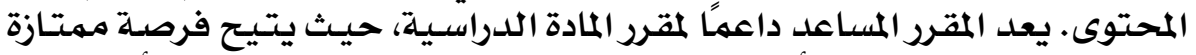

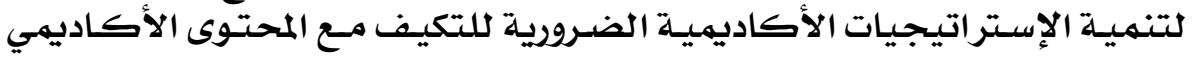

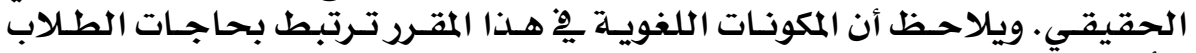

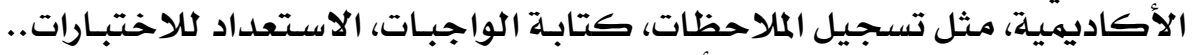

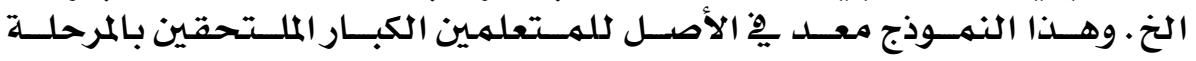

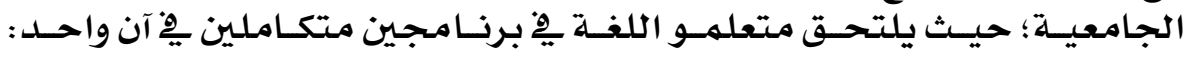

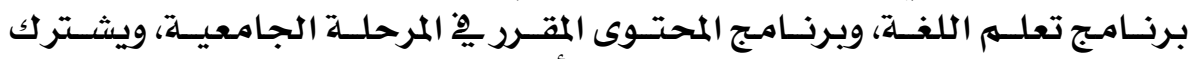

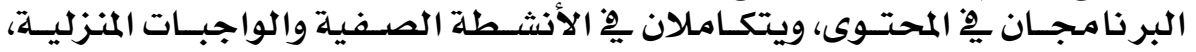
والبحوث الفيرنية.

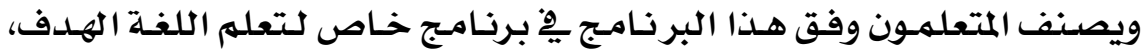

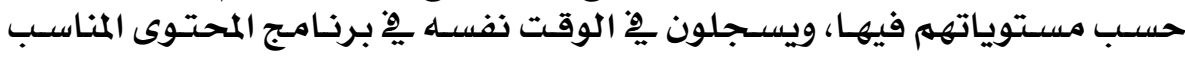

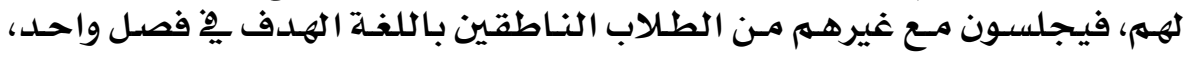

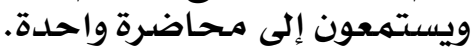

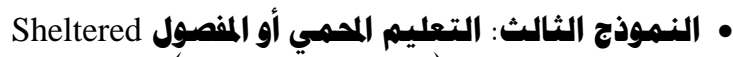

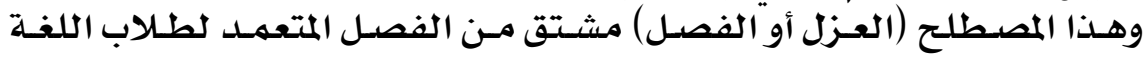

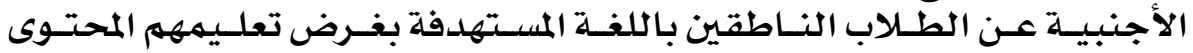
(Brinton, Snow and Wesche: 1989)

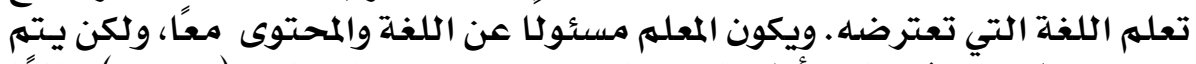

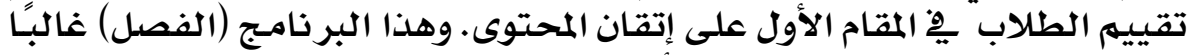

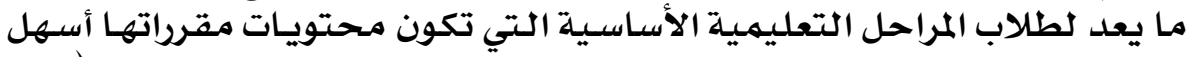

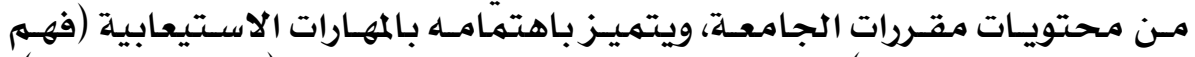

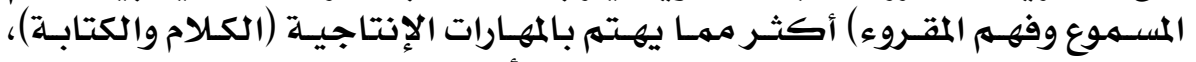

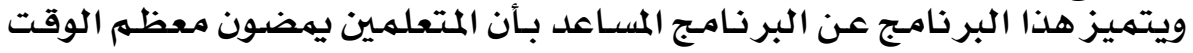

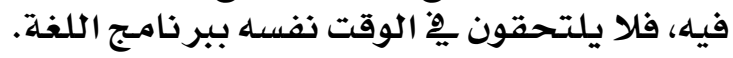

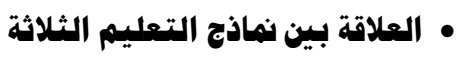

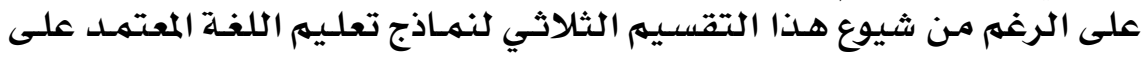

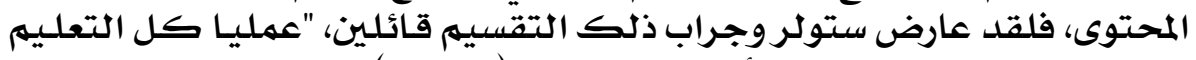

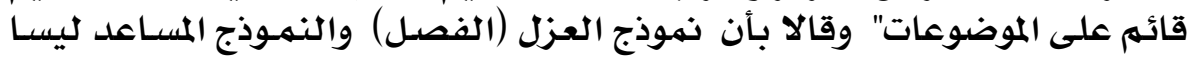

\section{ror}




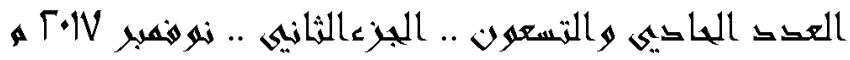

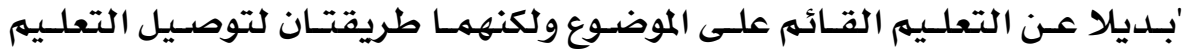

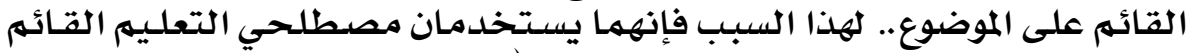

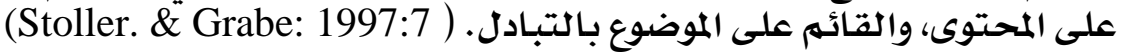

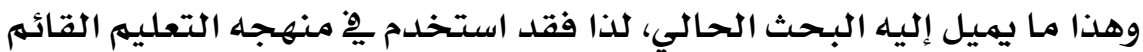

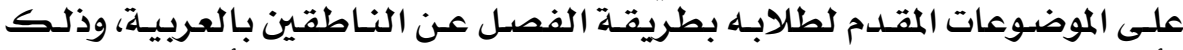

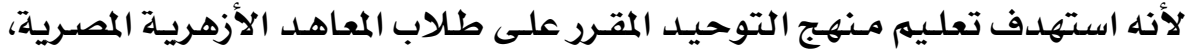

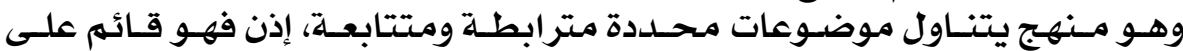

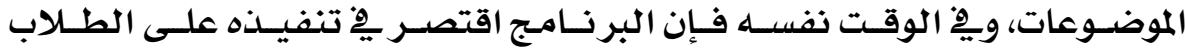

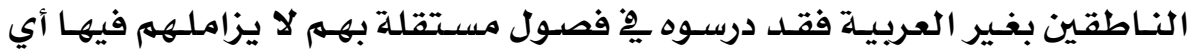

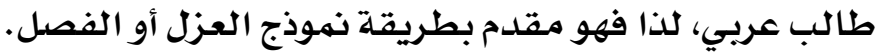

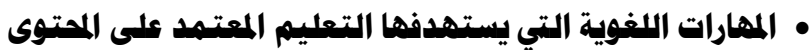

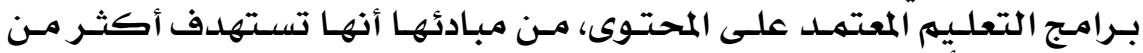

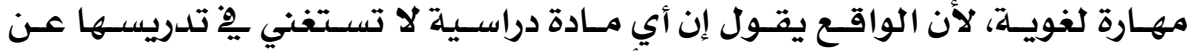

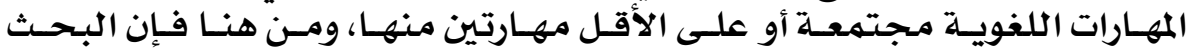

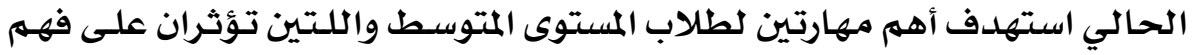

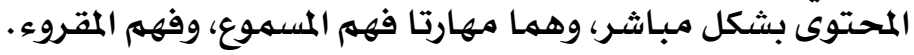

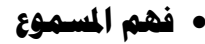

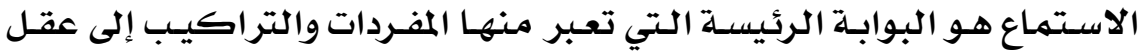

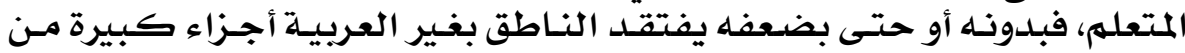

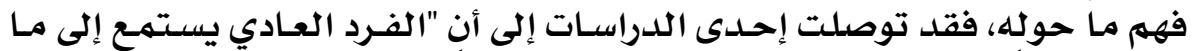

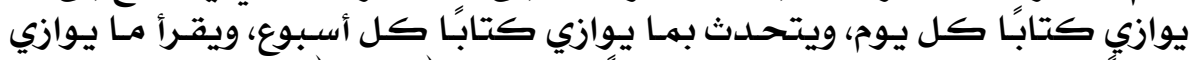

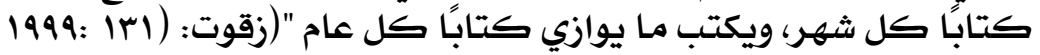

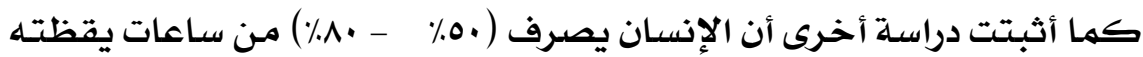

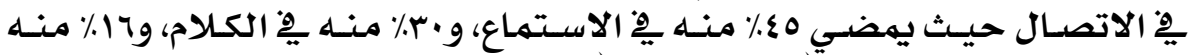

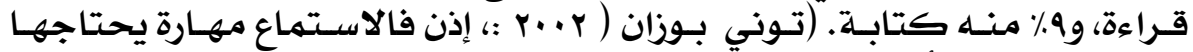

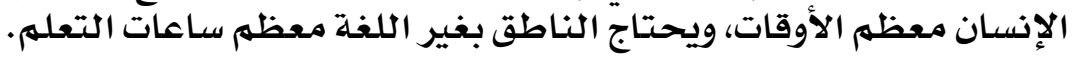

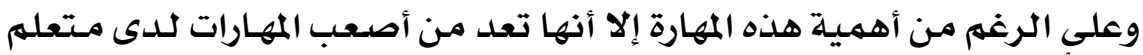

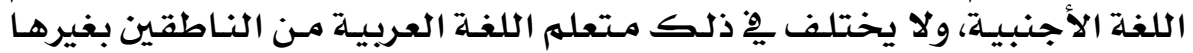
عن باقي المتعلهمين.

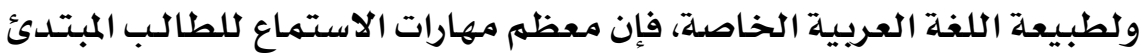

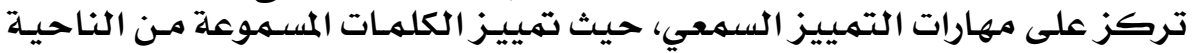

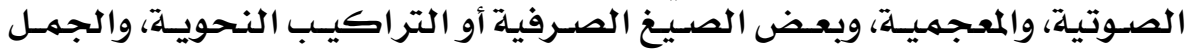

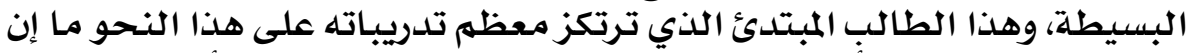

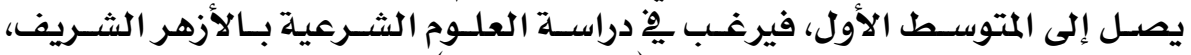

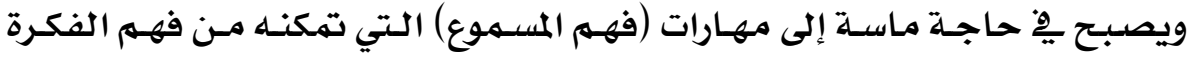

\section{ro\&}




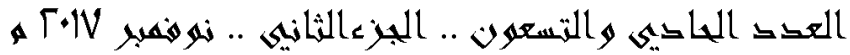

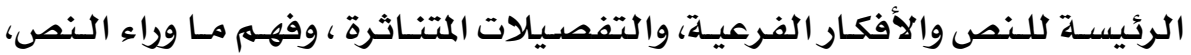

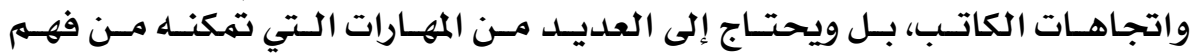

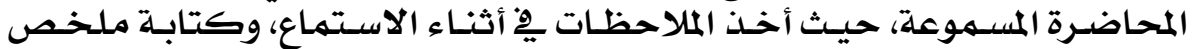

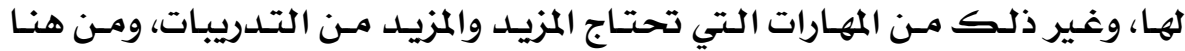

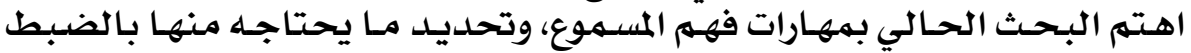

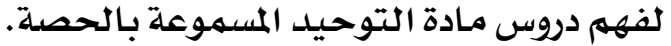

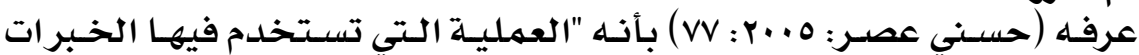

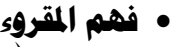

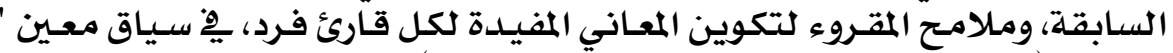

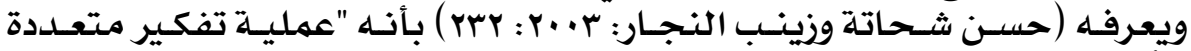

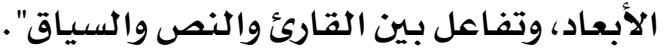

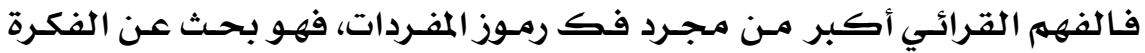

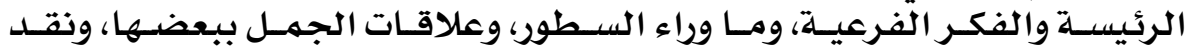

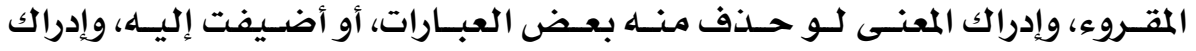

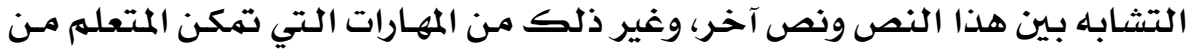

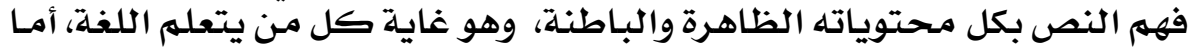

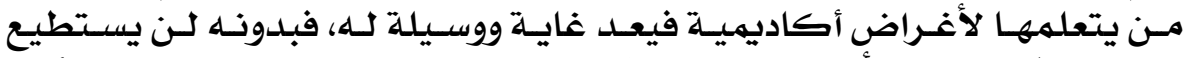

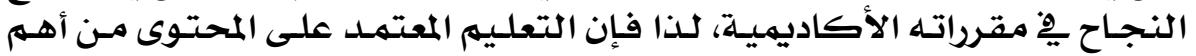

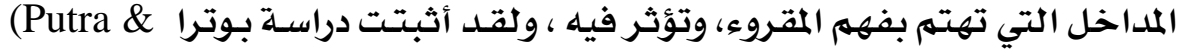

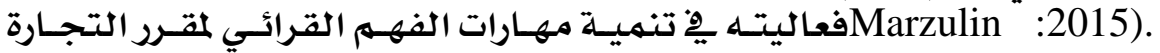

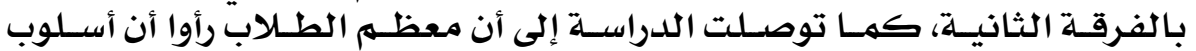

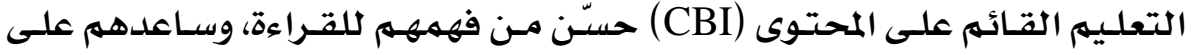

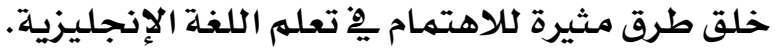

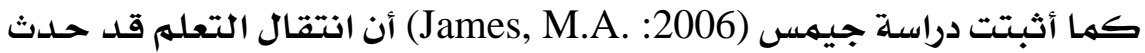

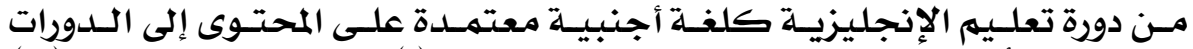

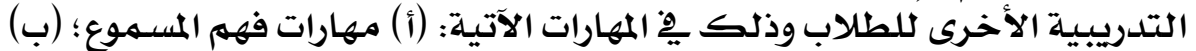

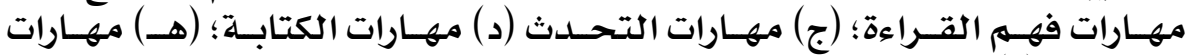

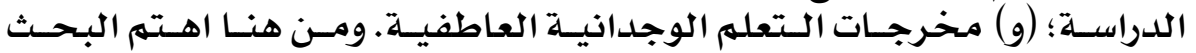

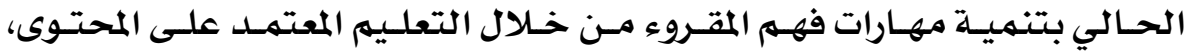

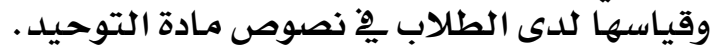

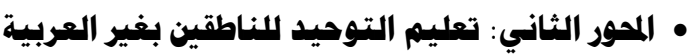

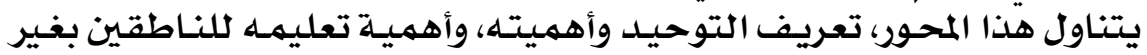

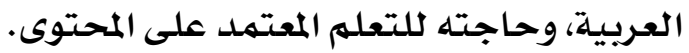

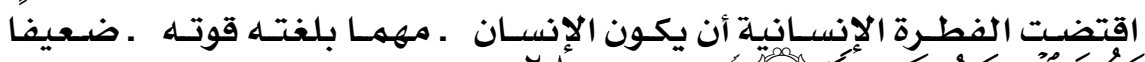

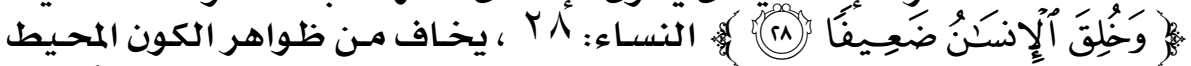

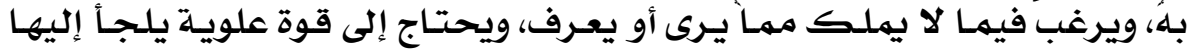

\section{r००}




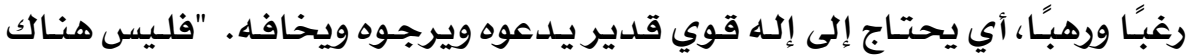

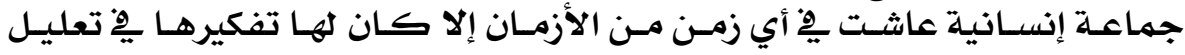

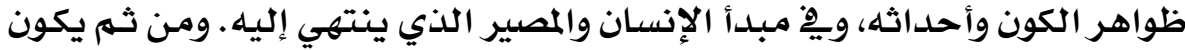

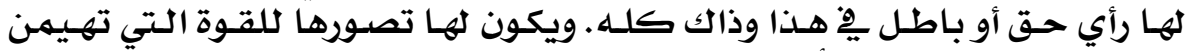

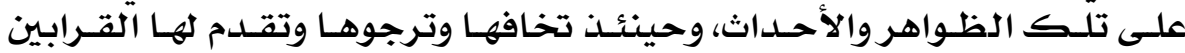

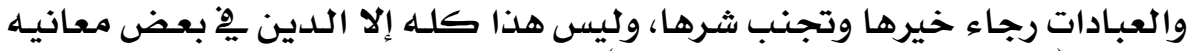

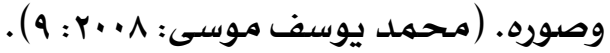

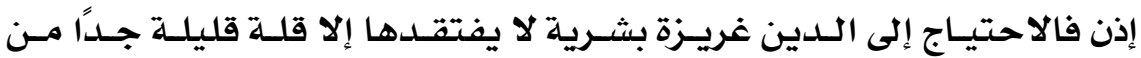

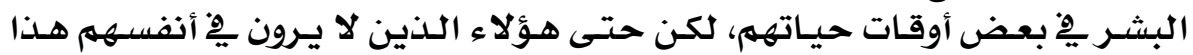

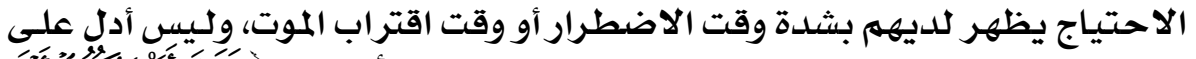

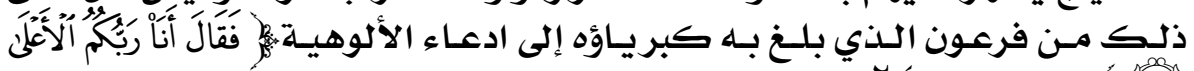

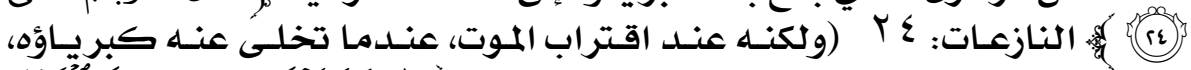

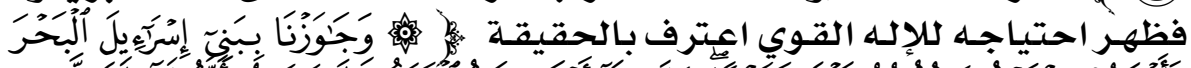

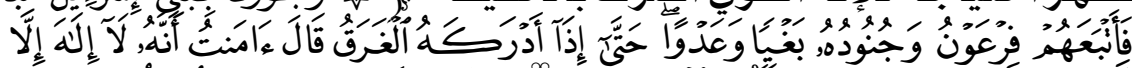

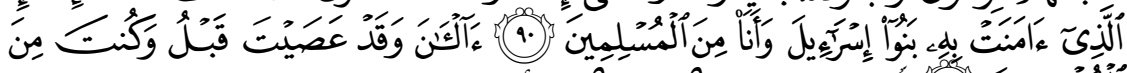

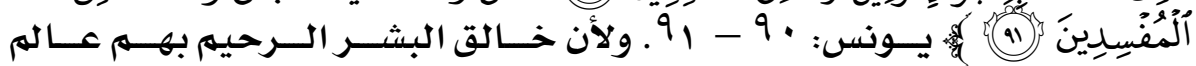

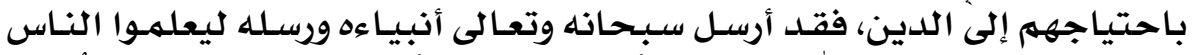

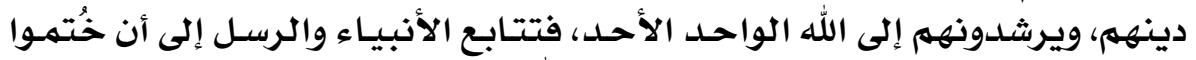

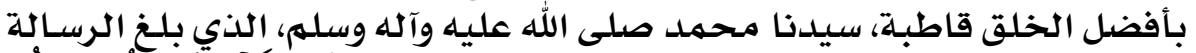

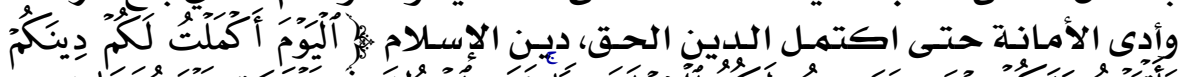

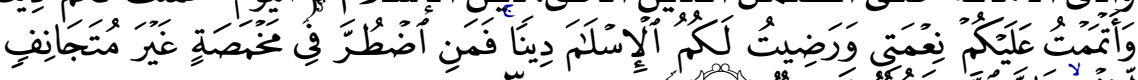

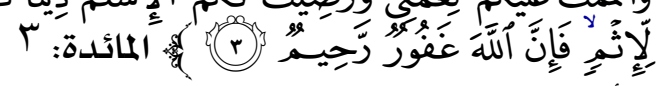

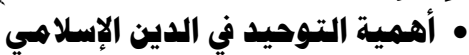

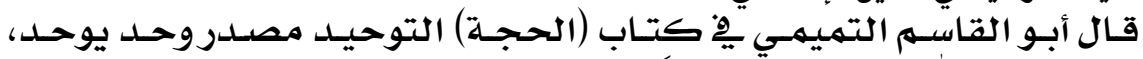

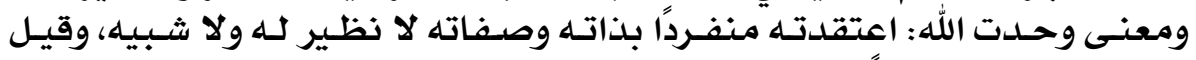

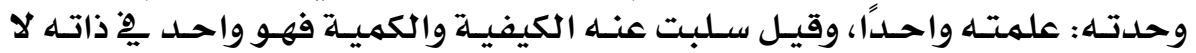

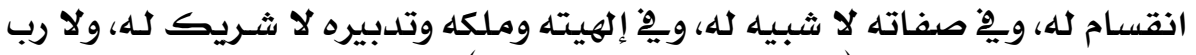

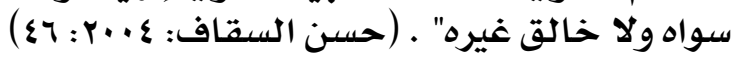

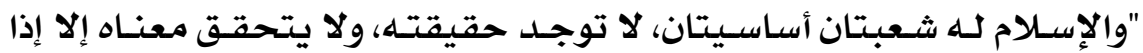

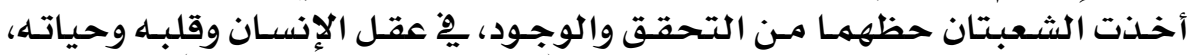

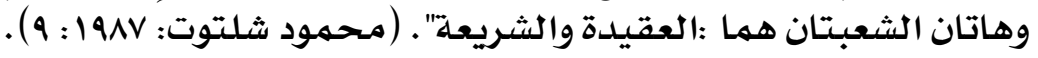

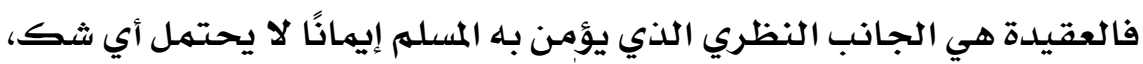

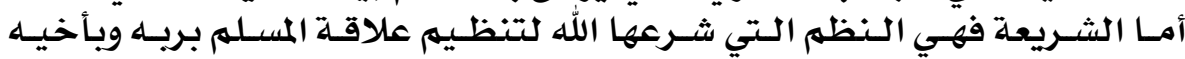

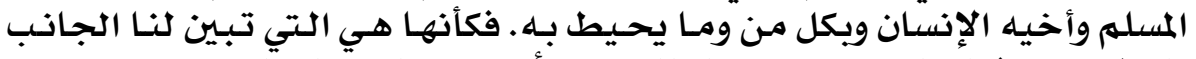

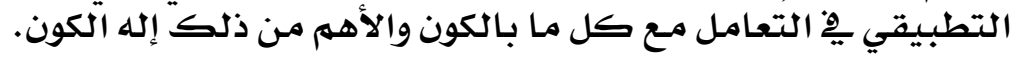

\section{Yo}




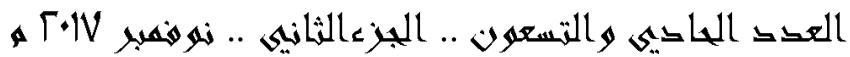

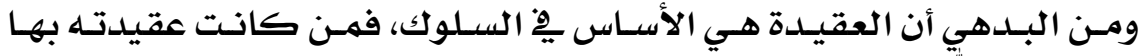

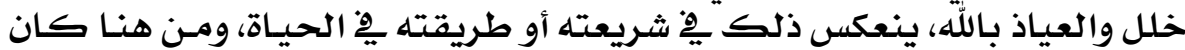
الاهتهمام بتدريس العياذ بالهُ بنديدة.

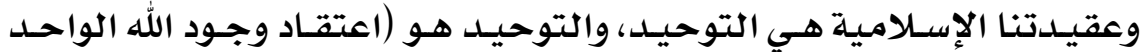

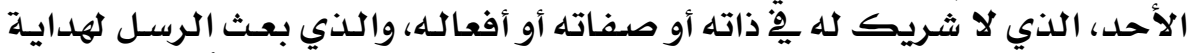

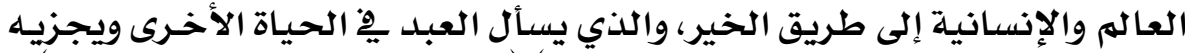

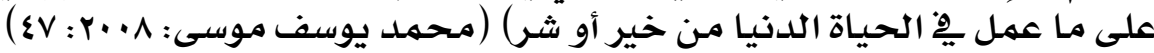

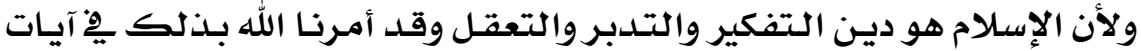

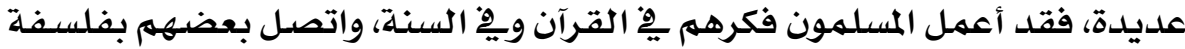

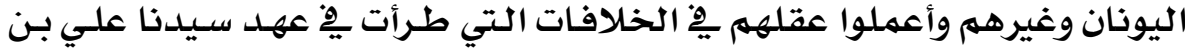

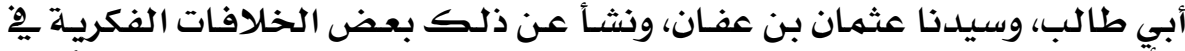

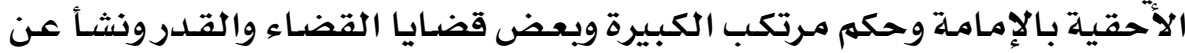

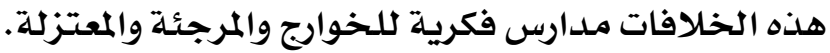

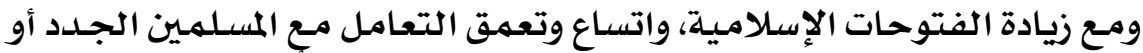

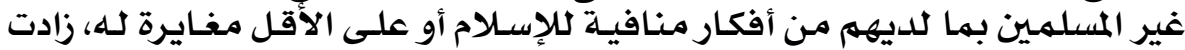

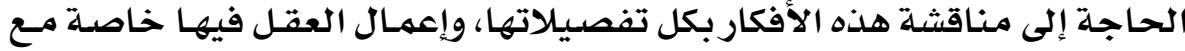

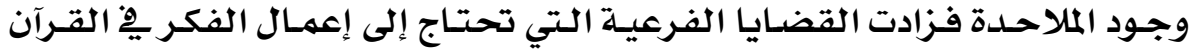

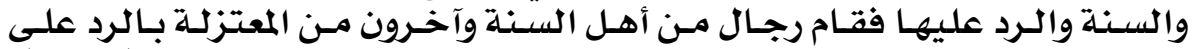

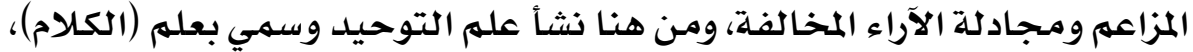

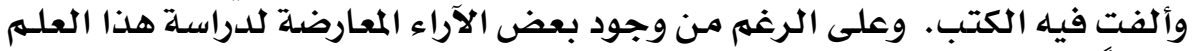

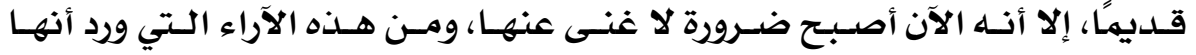

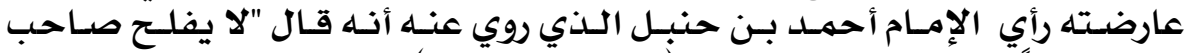

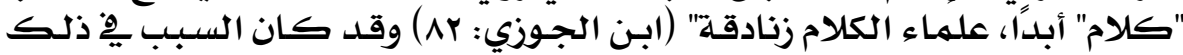

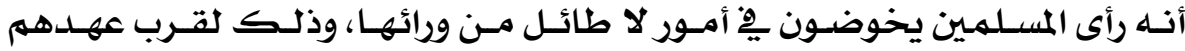

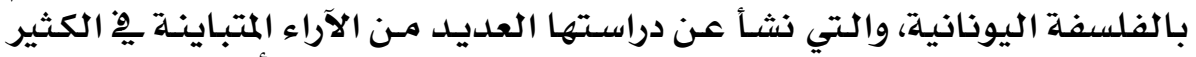

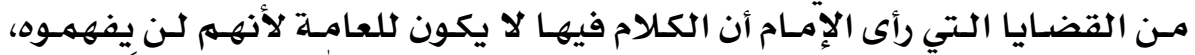

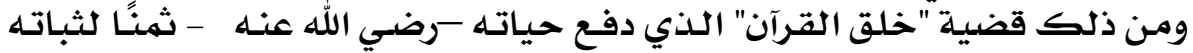

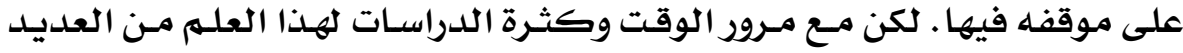

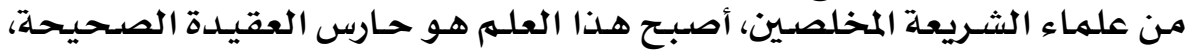

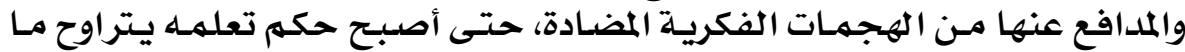

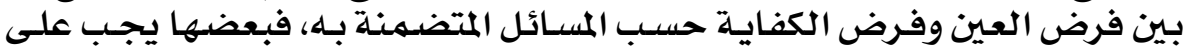

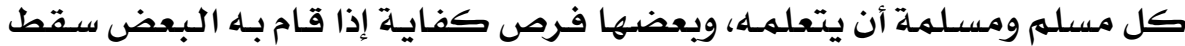

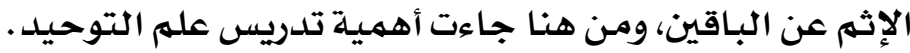

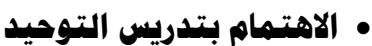

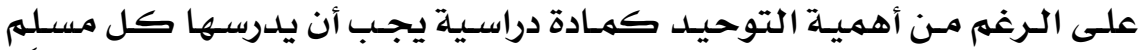

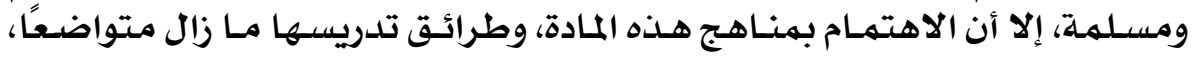

\section{$\mu \circ V$}




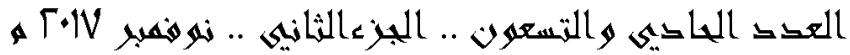

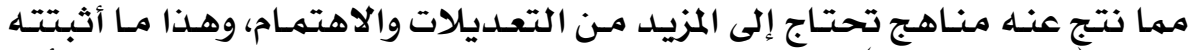

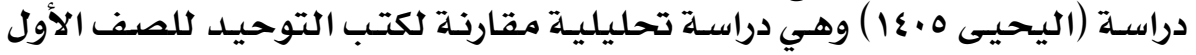

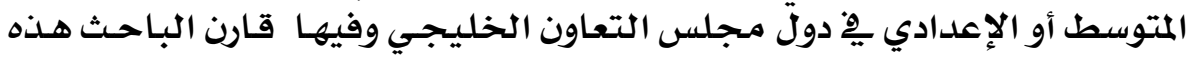

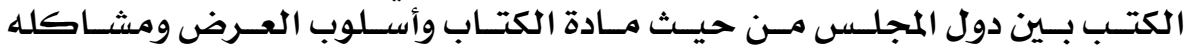

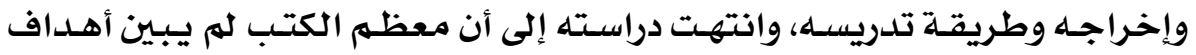

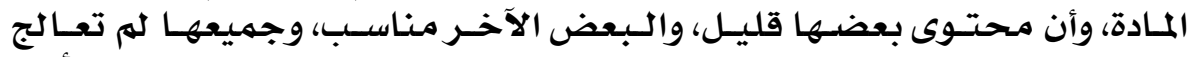

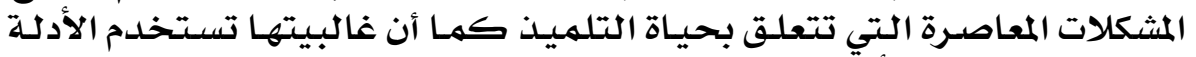

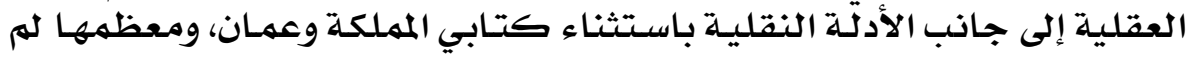

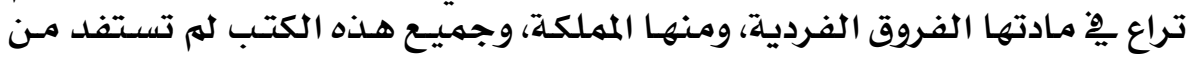

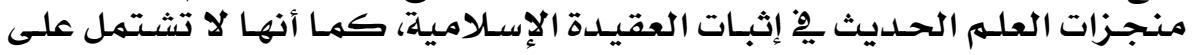

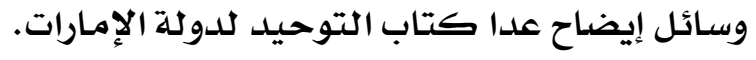

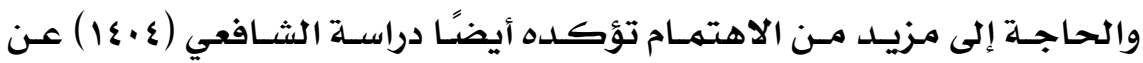

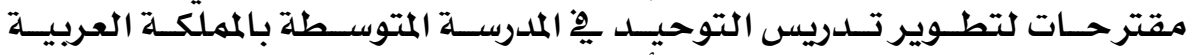

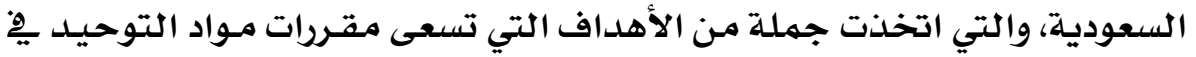

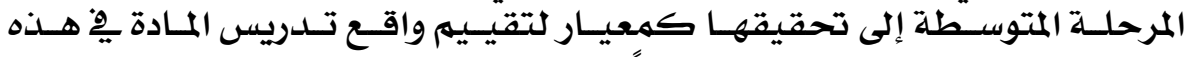

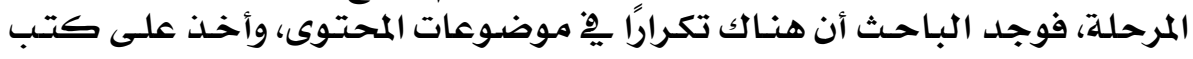

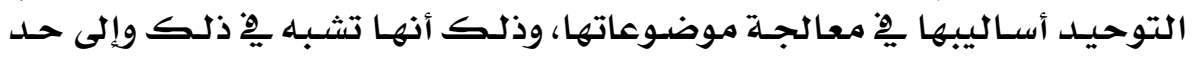

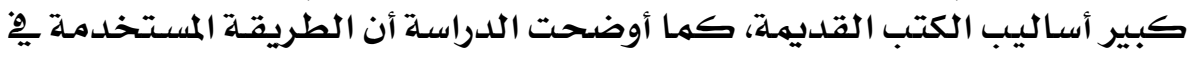

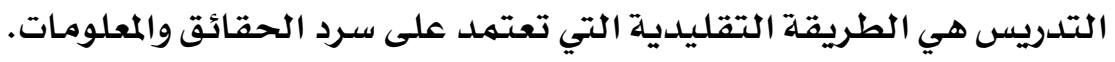

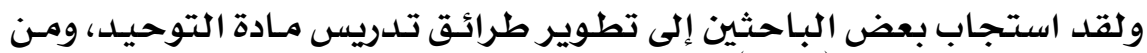

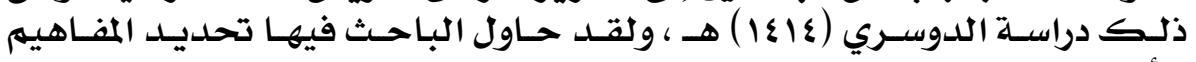

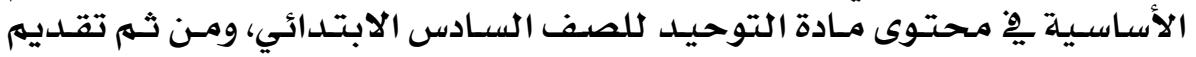

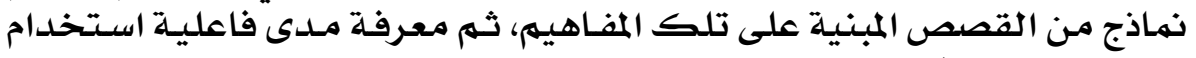

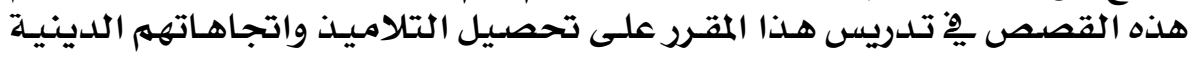

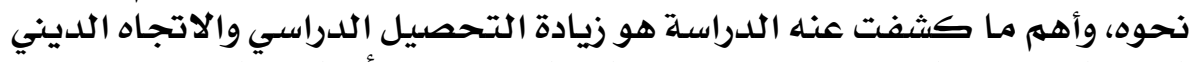

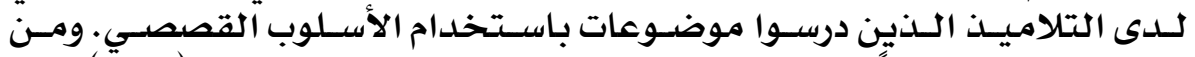

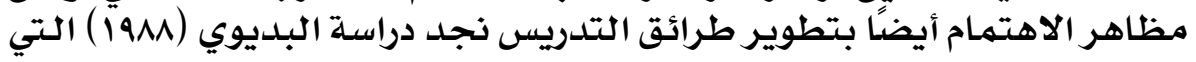

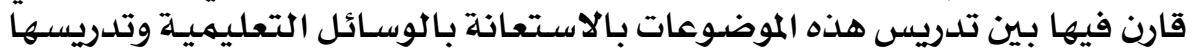

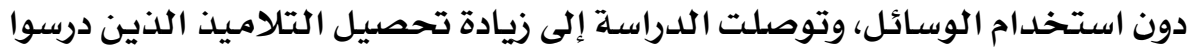
باستخدام الوسائل التعليمية أكثر من من غيرهمر.

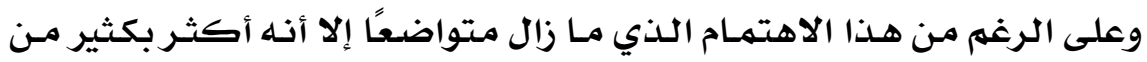

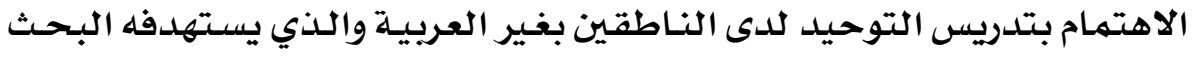
الحالي.

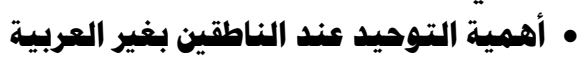

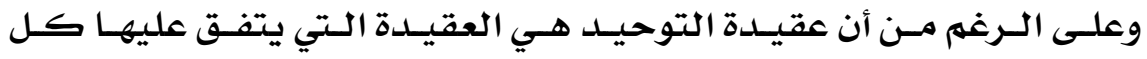

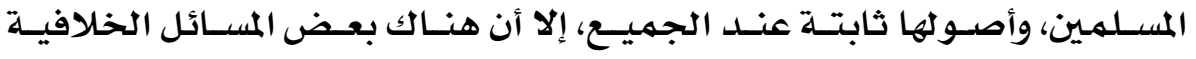

\section{$\mu \circ \Lambda$}




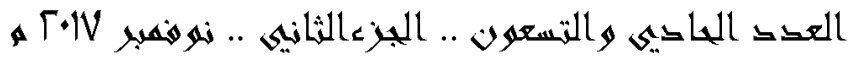

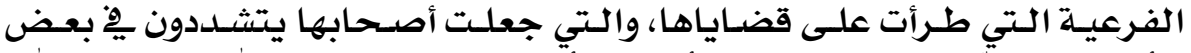

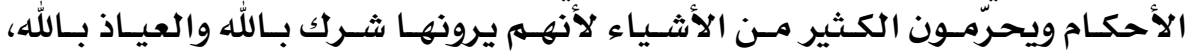

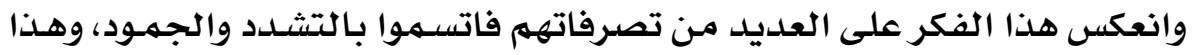

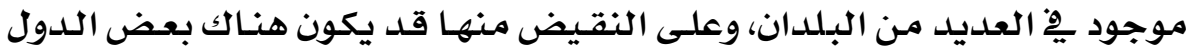

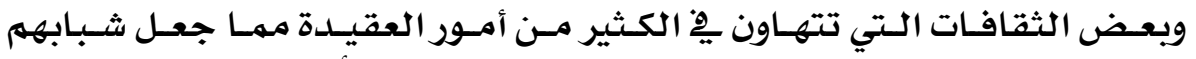

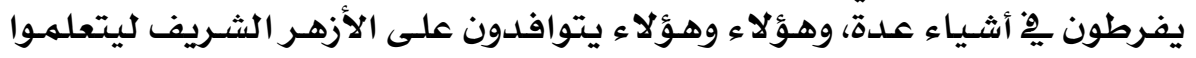

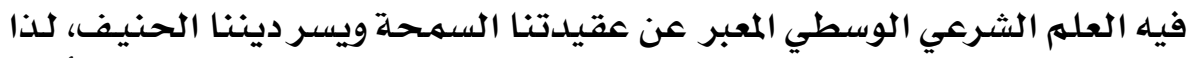

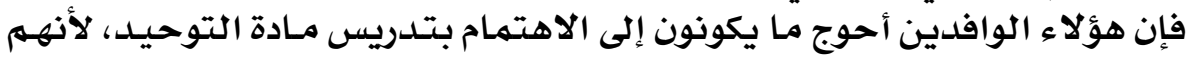

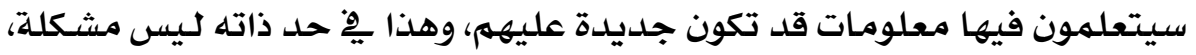

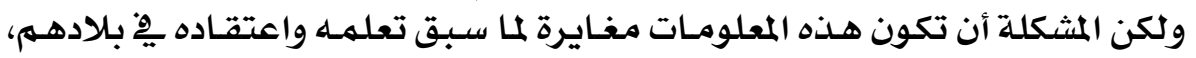

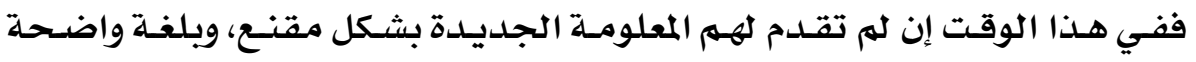

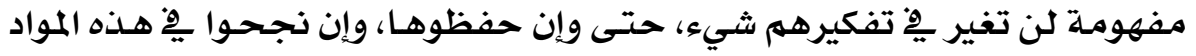

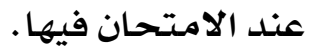

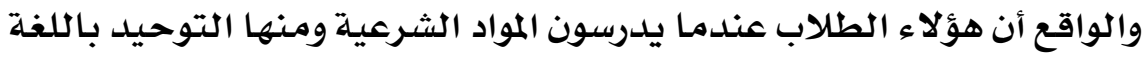

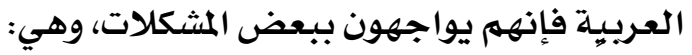

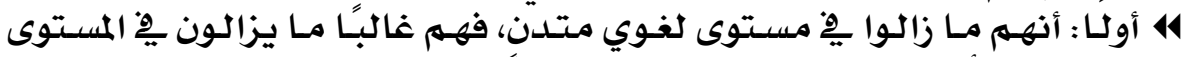

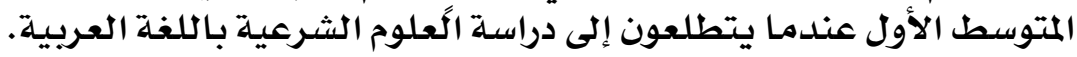

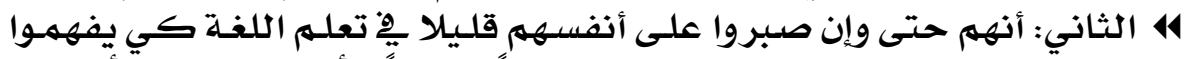

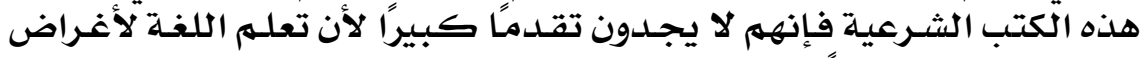

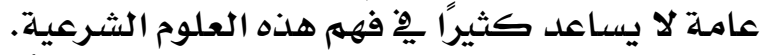

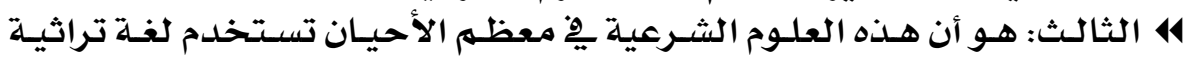

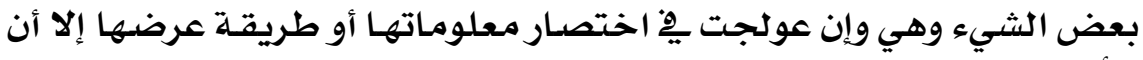

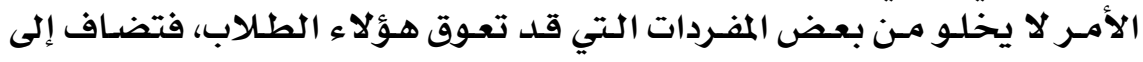

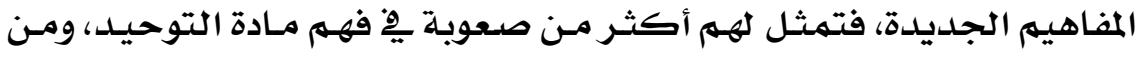

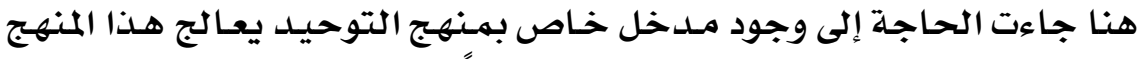

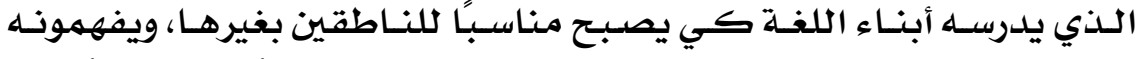

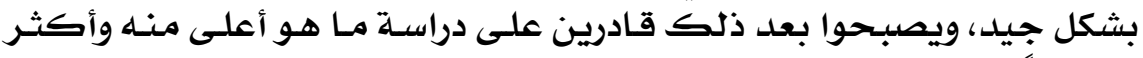

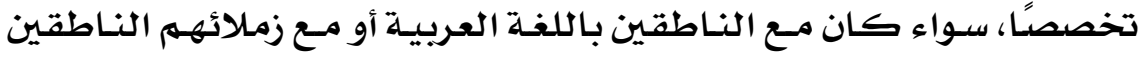

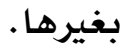

• الحور الثالث: الكفاءة الذاتية الأكاديمية

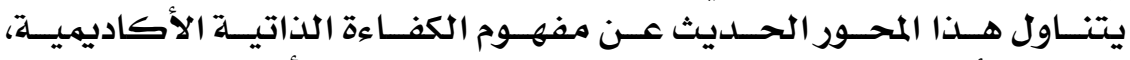

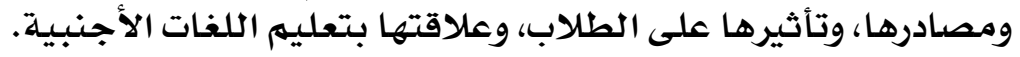

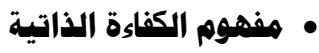

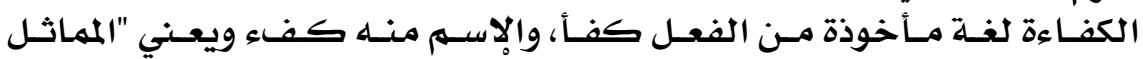

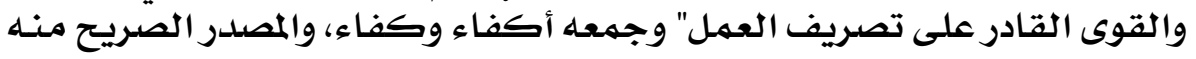

\section{poq}




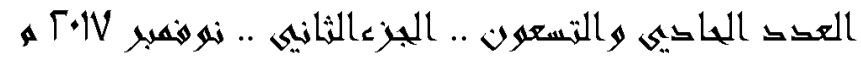

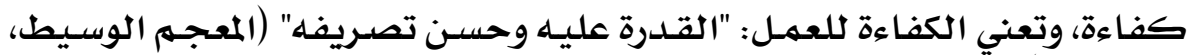

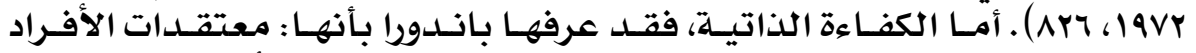

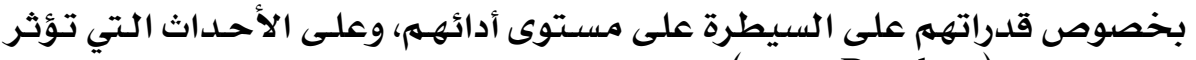
على حياتهـ (199v :Bandora) والكفاءة الذاتية لها أبعاد مختلفة؛ فهي لها بعـد عـام، وآخـر اجتمـاعي، وثالث أكاديهي:

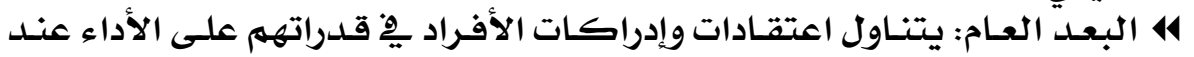

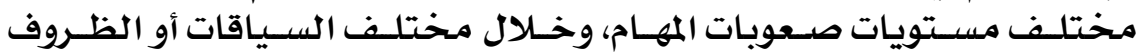
14 البعـد الاجتهمـاعي: يتتــاول اعتقـادات وإدراكـات الأفراد داخل أطر أو سـياقات

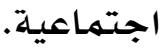

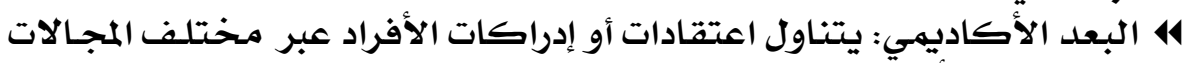

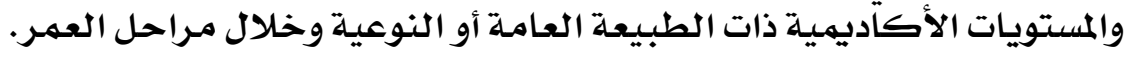

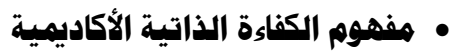

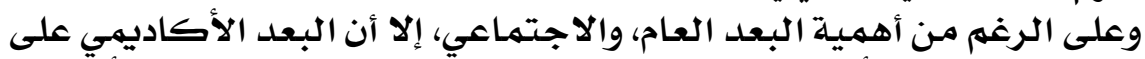

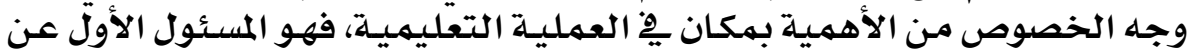

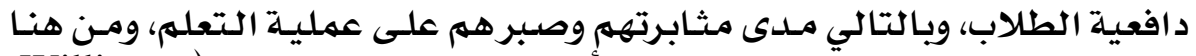

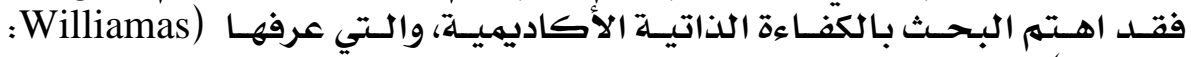

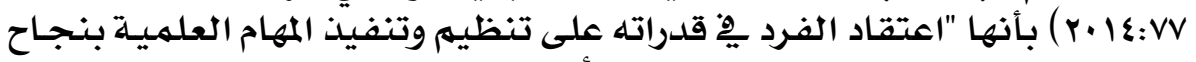

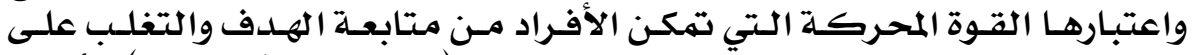

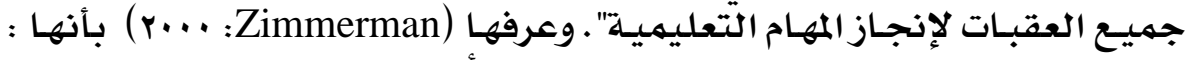

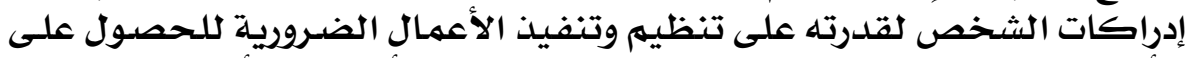

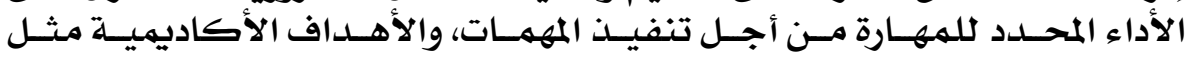

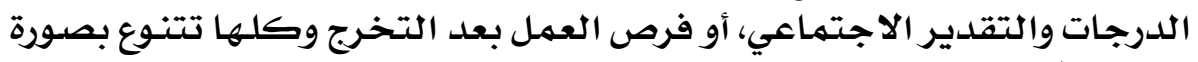

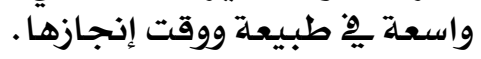

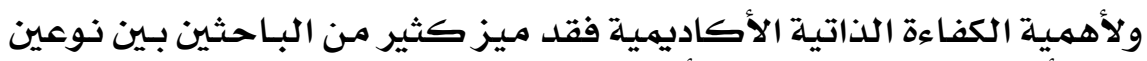

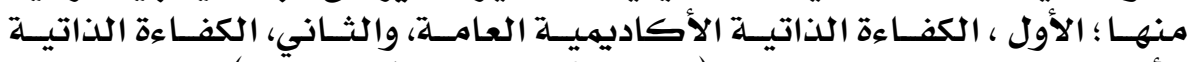

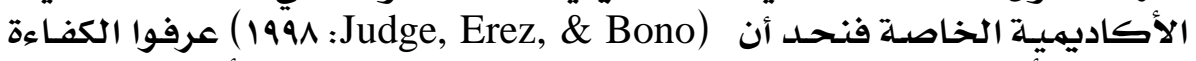

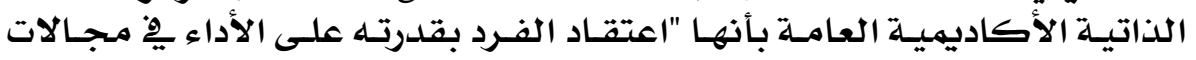

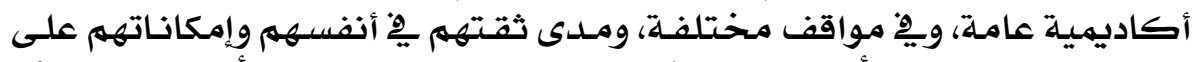

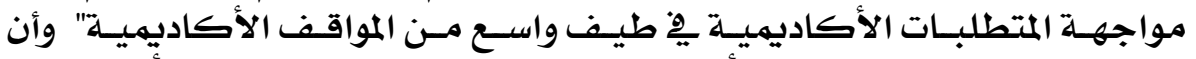

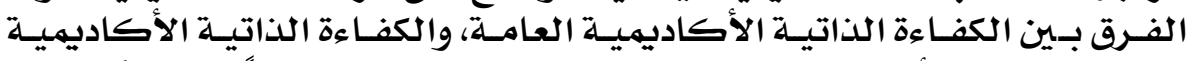

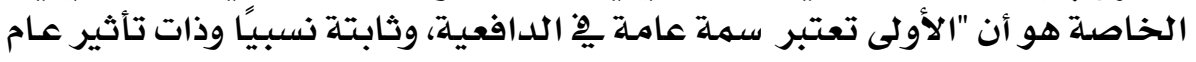

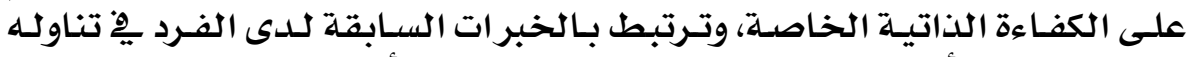

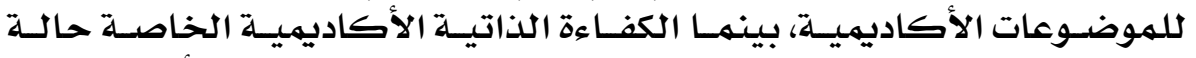

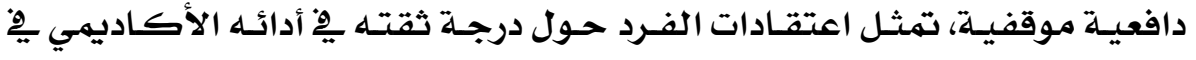

\section{ry.}




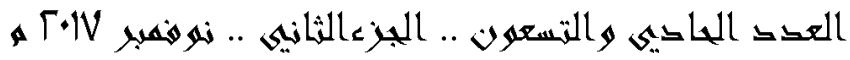

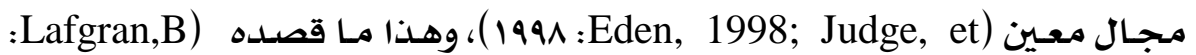

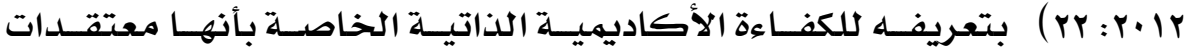

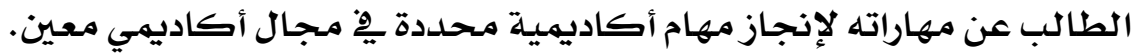

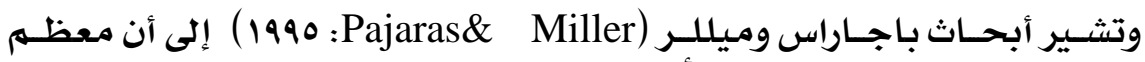

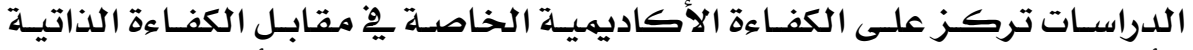

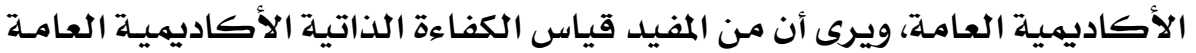

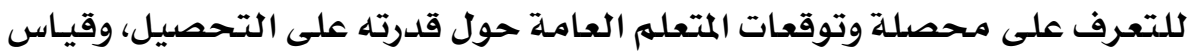

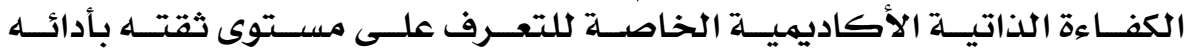

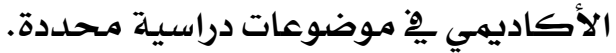

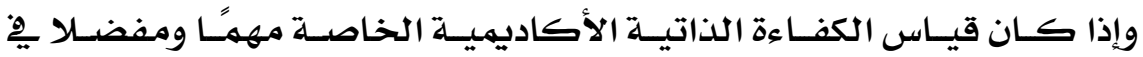

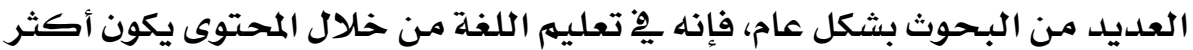

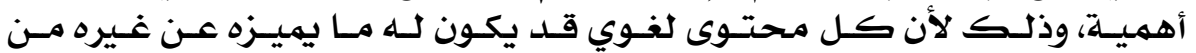

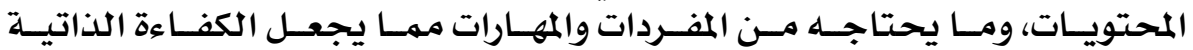

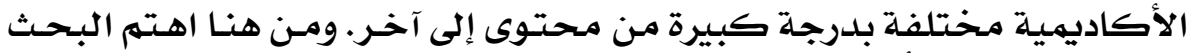

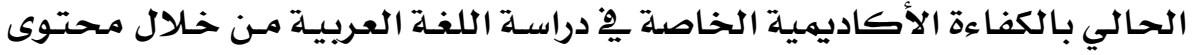
التوحيد.

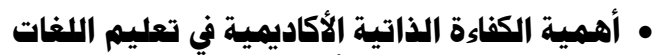

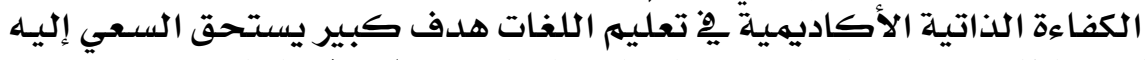

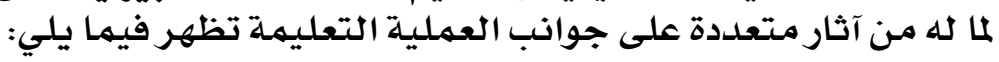

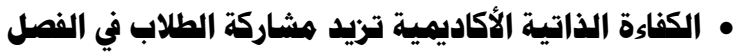

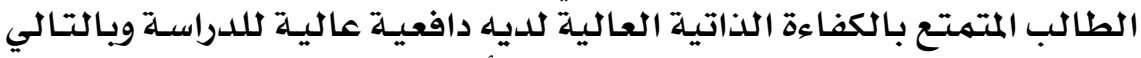

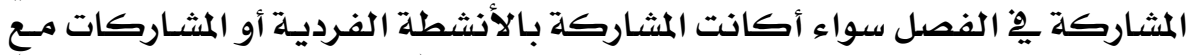

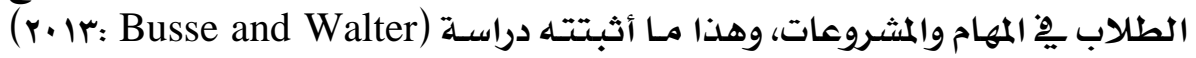

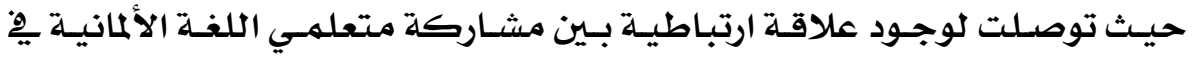

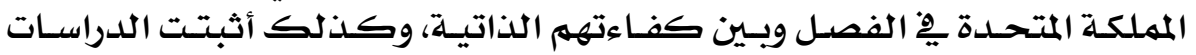

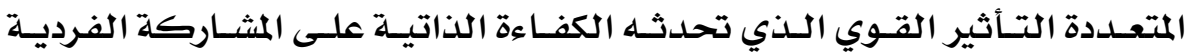

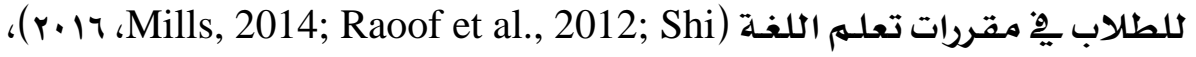

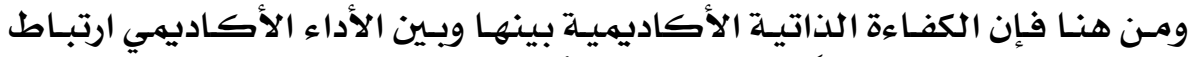

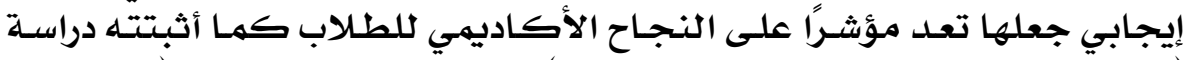

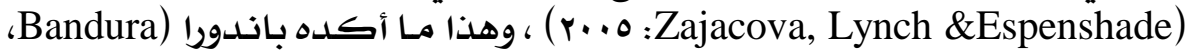

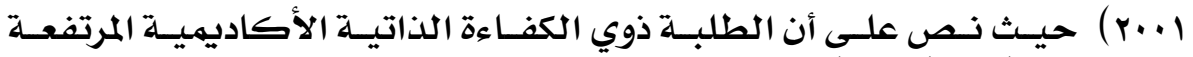

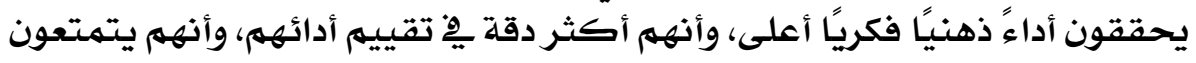

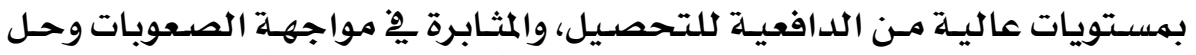

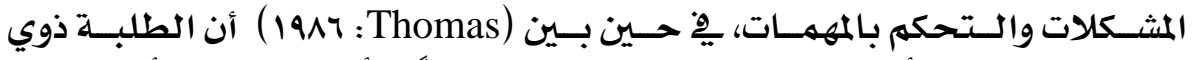

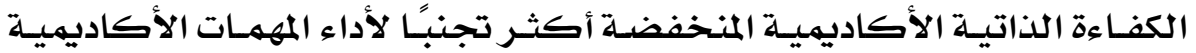

\section{4}




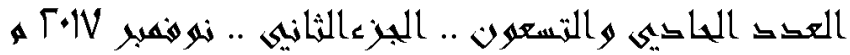

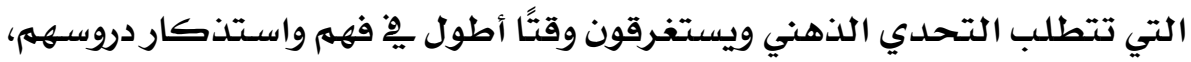

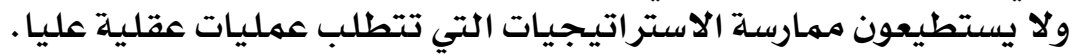

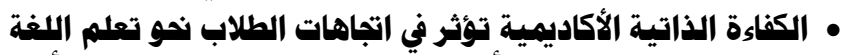

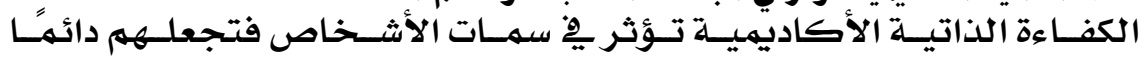

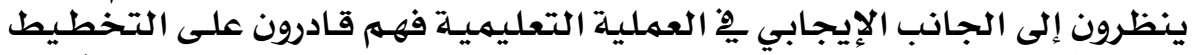

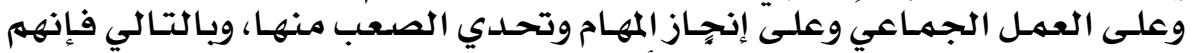

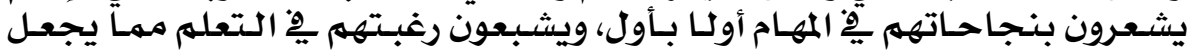

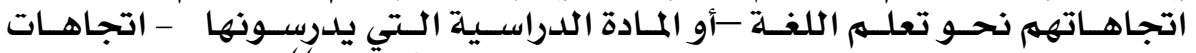

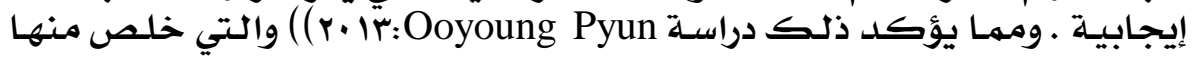

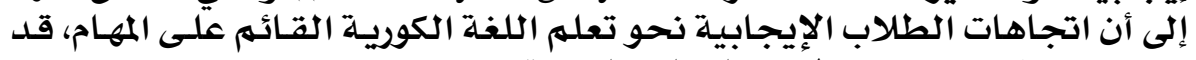

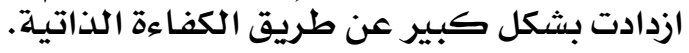

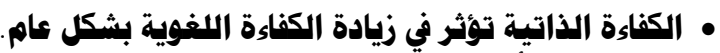

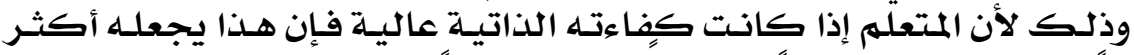

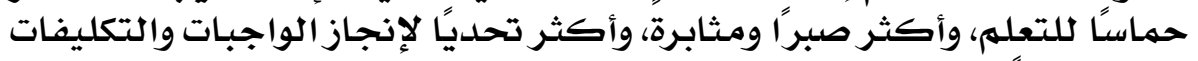

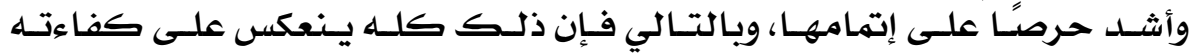

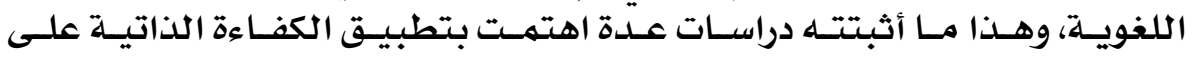

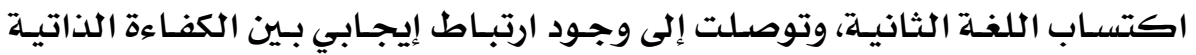

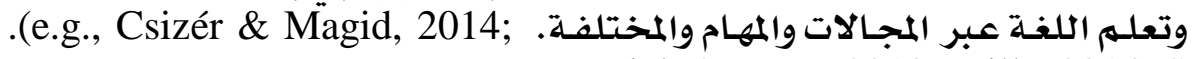
Hsieh \& Kang, 2010; Mills, 2014; S

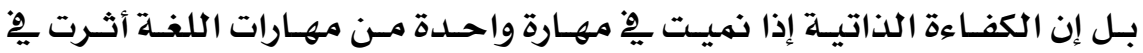

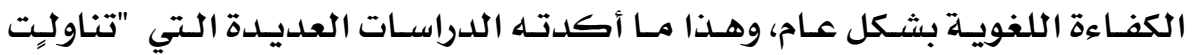

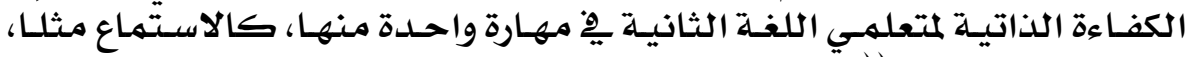

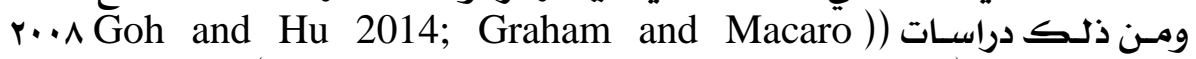

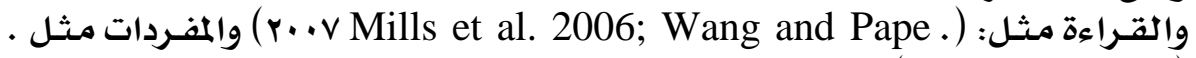
Kormos 2012; Ruan 2014; Woodrow والكتابـة مثل (r (r) . 10.Ping et al) 2011).).

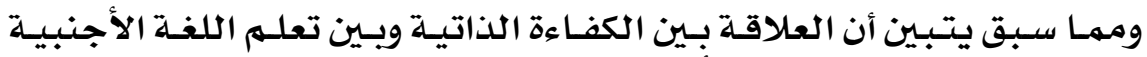

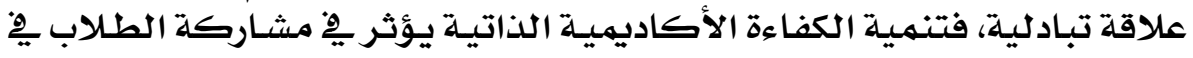

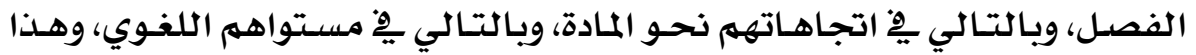

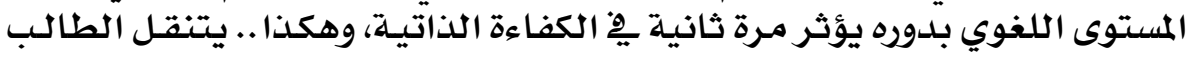

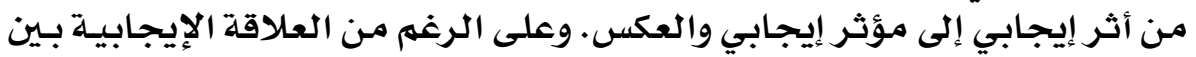

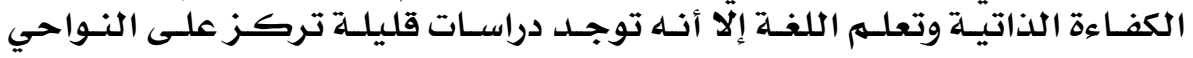

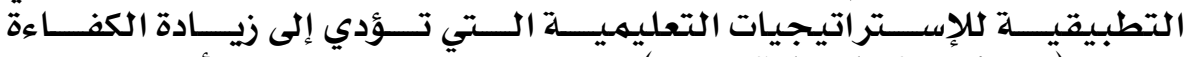

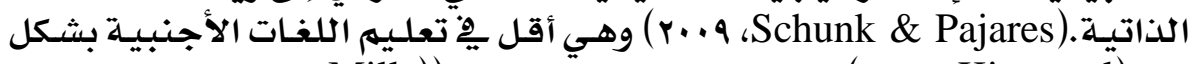

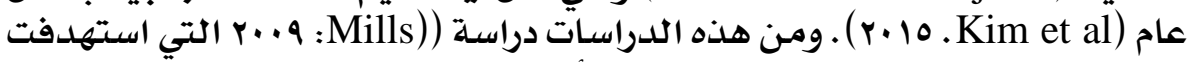

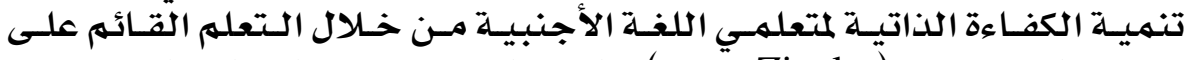

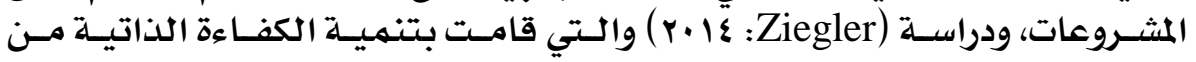

\section{YYY}




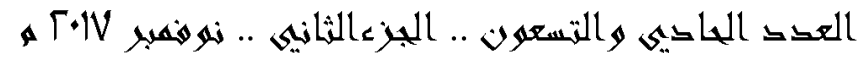

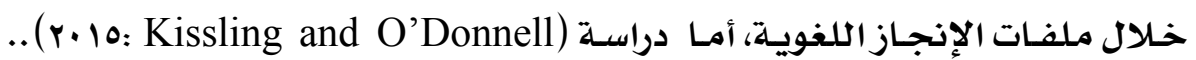

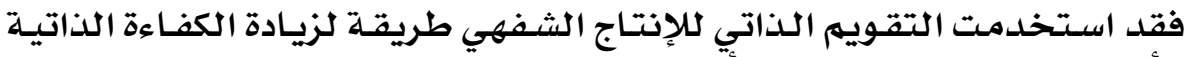

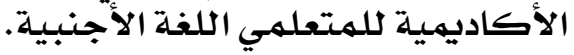

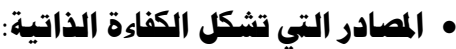

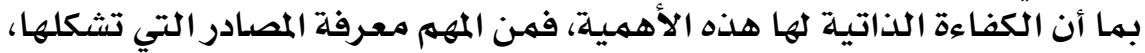

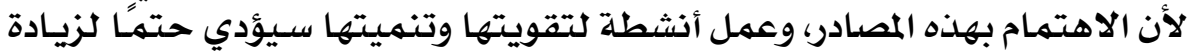

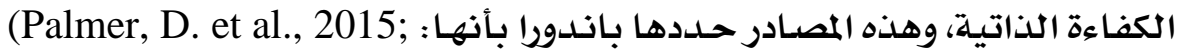
Evans, R., 2014, 2; Brintners, S. \& Pajares, F.,: 2006, Staples:1999)

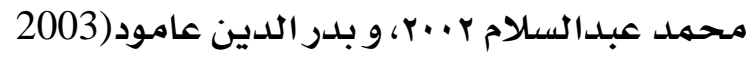

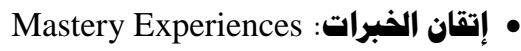

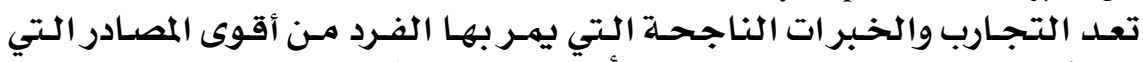

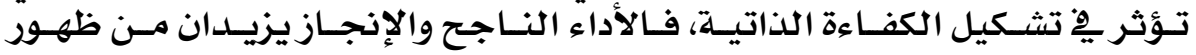

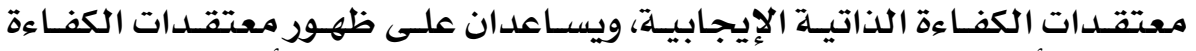

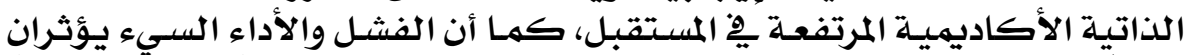

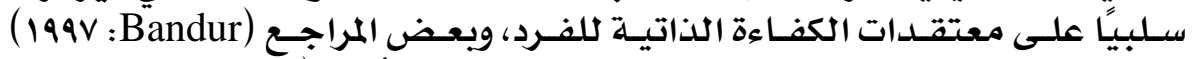

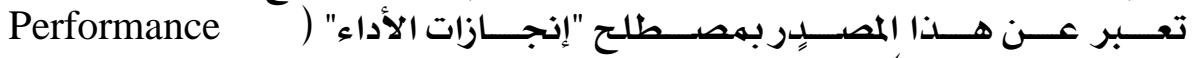

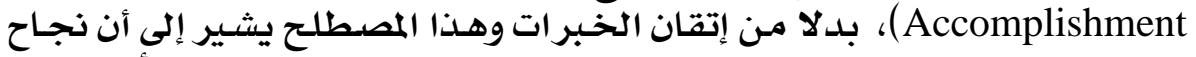

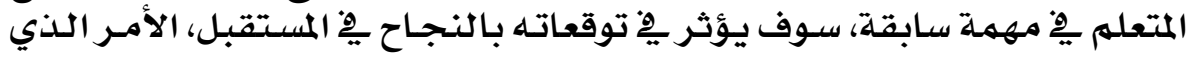

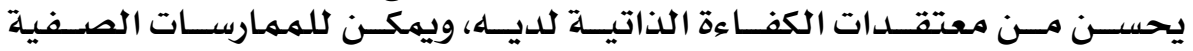

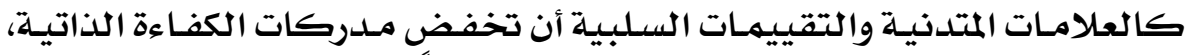

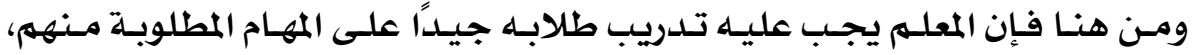

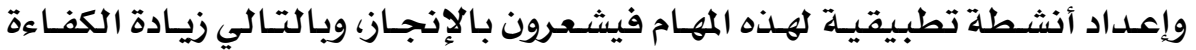

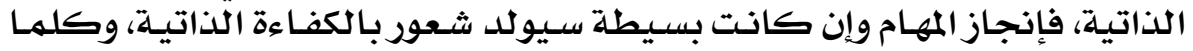

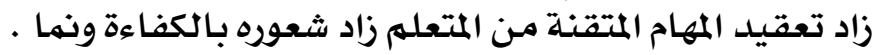

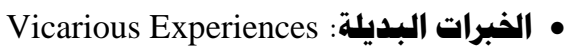

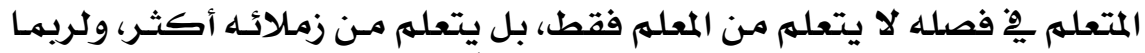

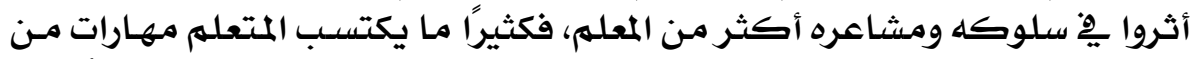

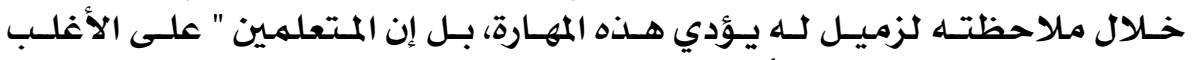

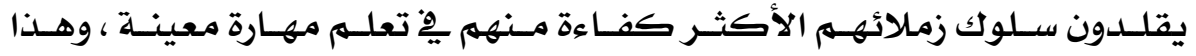

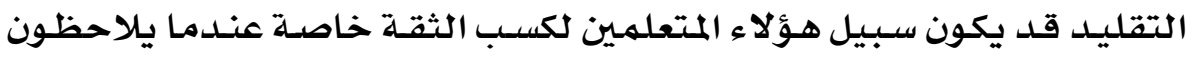

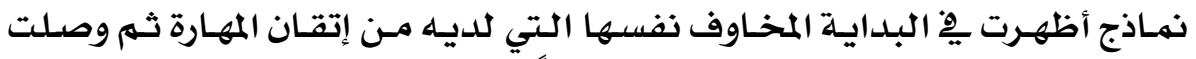

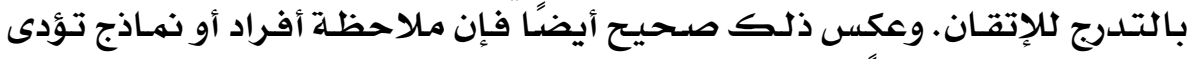

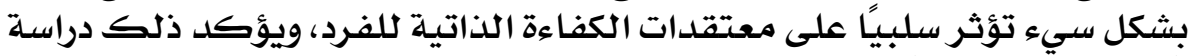

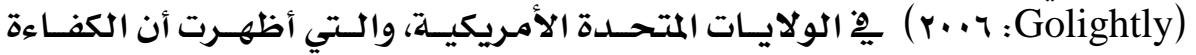

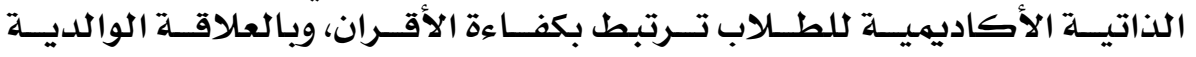
الإيجابية.

\section{ry}




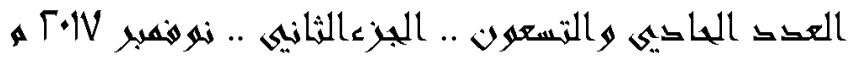

• • ثالثًا: الإقناع اللفظي ( ) ل

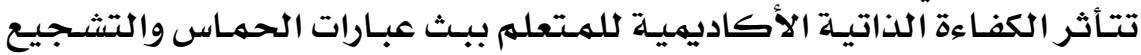

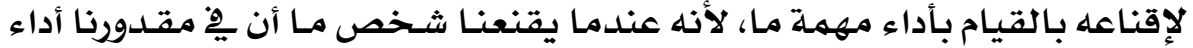

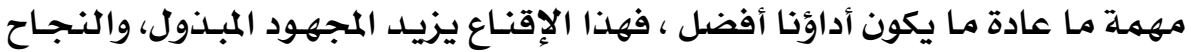

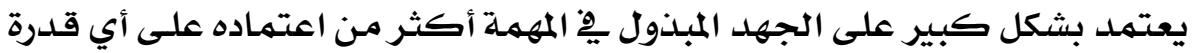

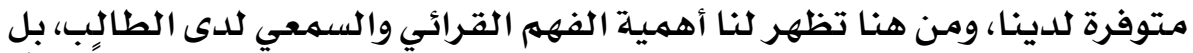

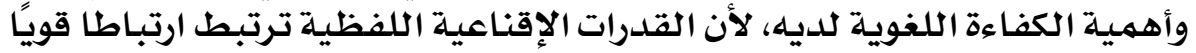

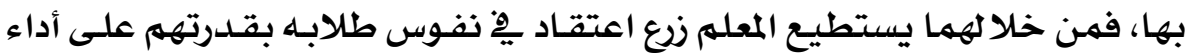

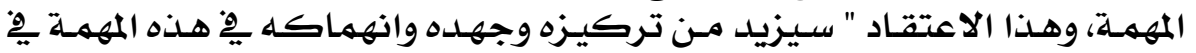

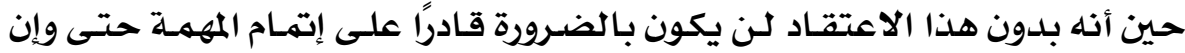

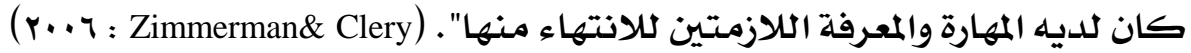

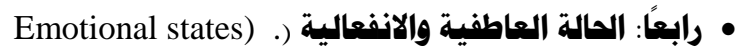

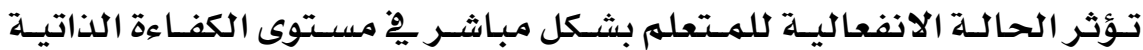

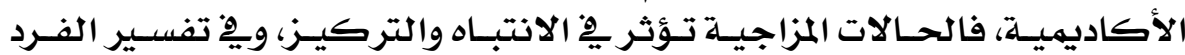

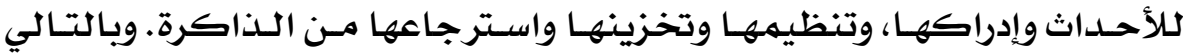

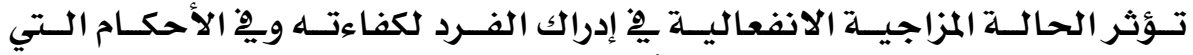

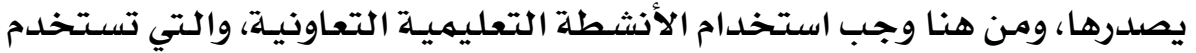

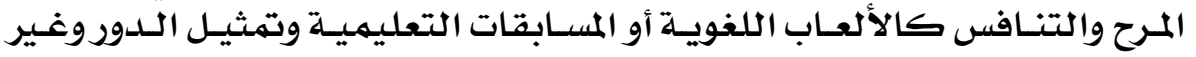

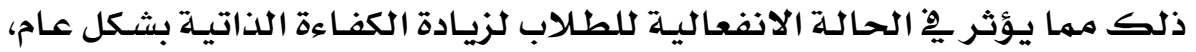

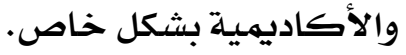

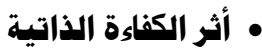

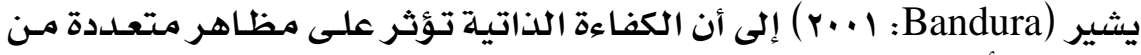

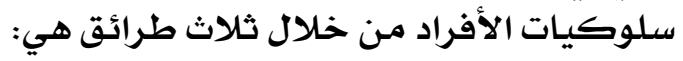

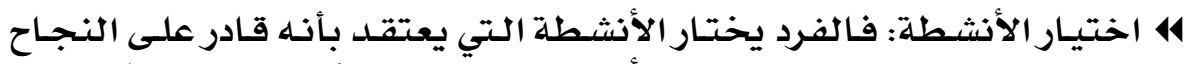

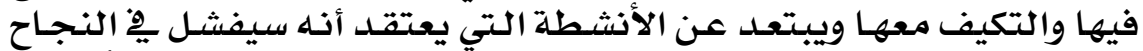

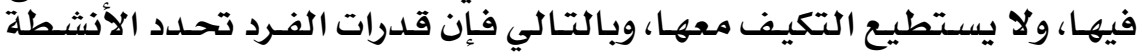
التي سيؤديها. الائ.

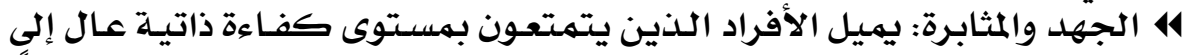

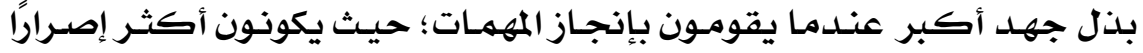

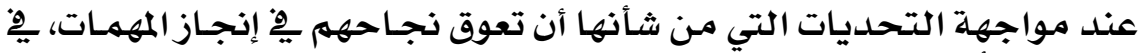

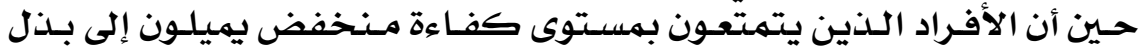

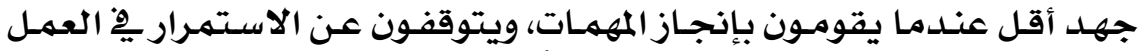

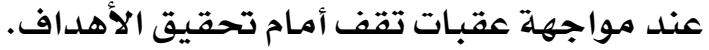

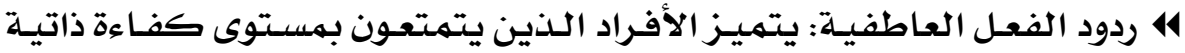

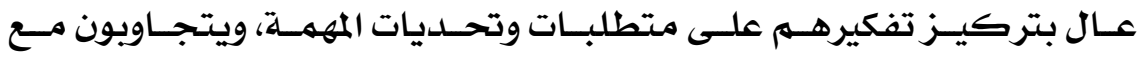

\section{ry}




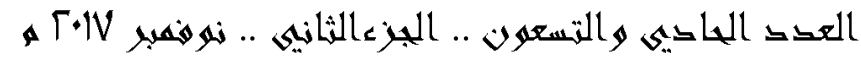

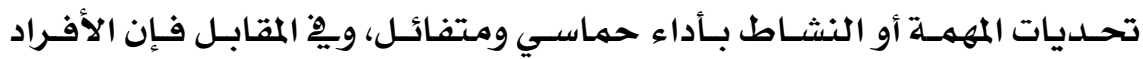

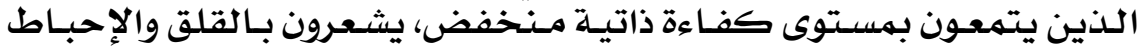

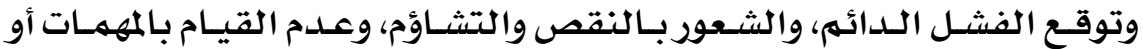

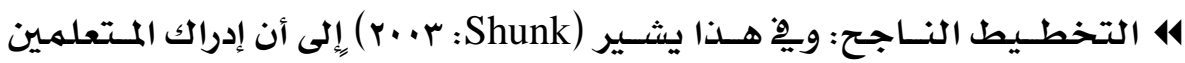

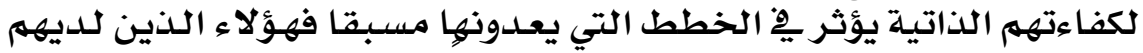

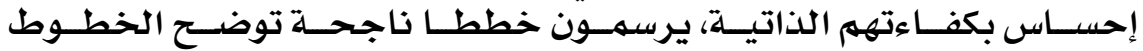

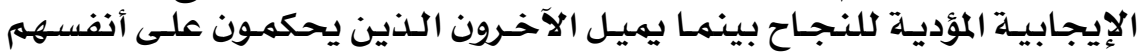

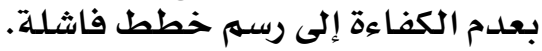

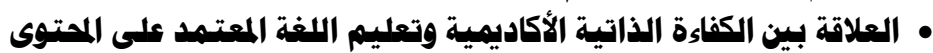

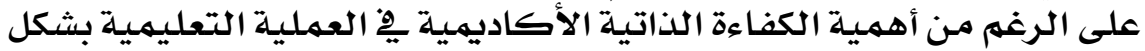

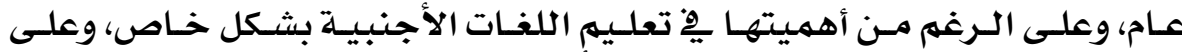

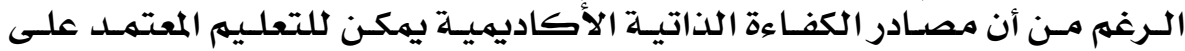

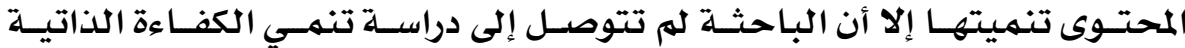

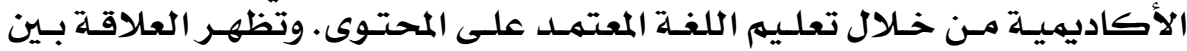

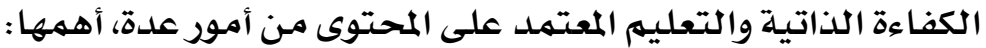

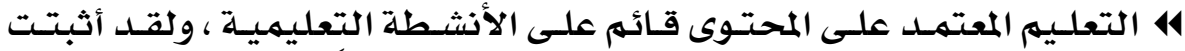

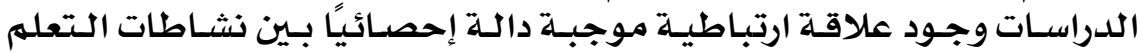

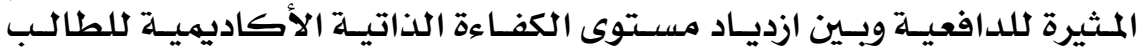

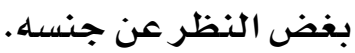

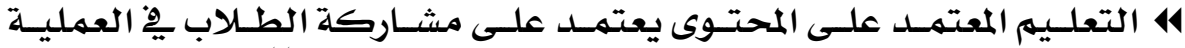

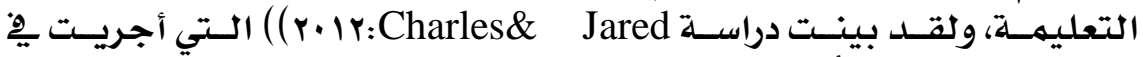

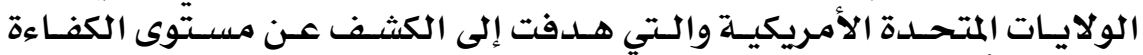

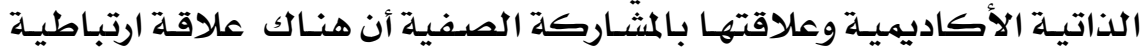

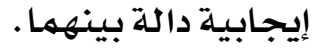

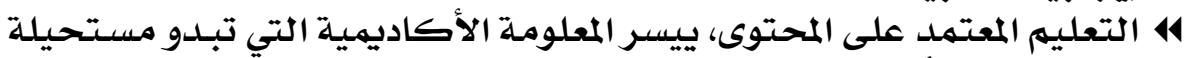

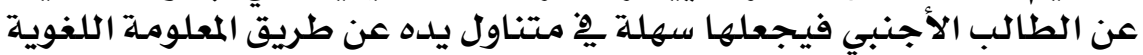

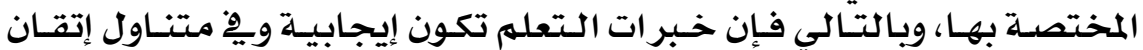

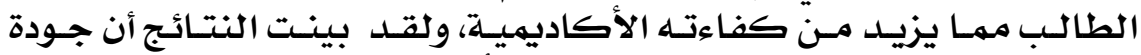

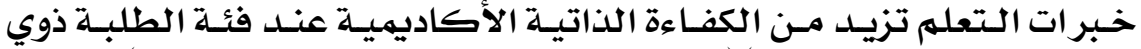

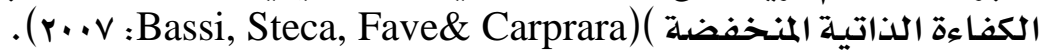

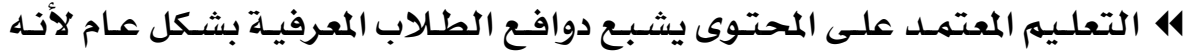

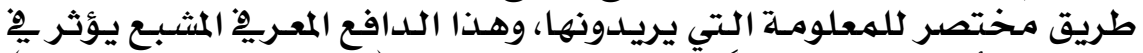

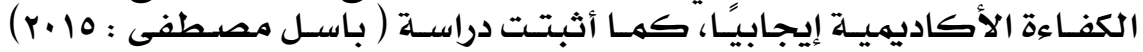

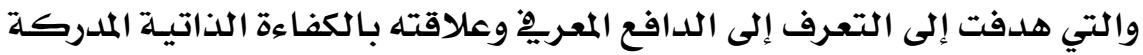

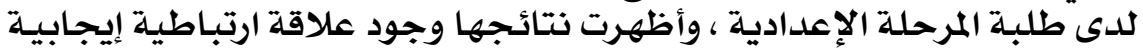

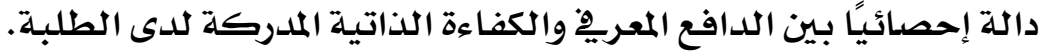

\section{ryo}




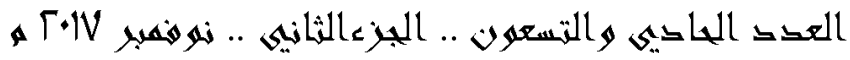

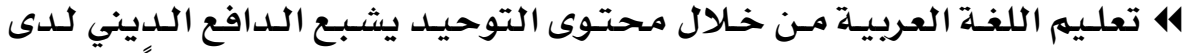

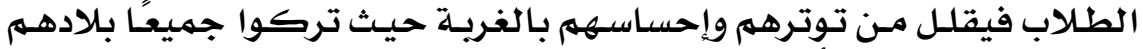

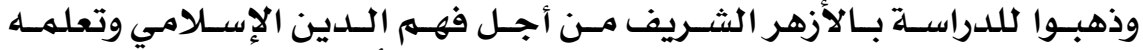

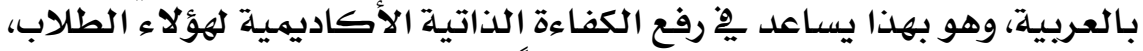

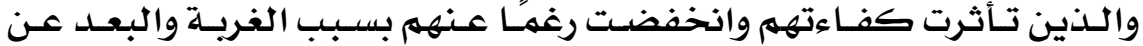

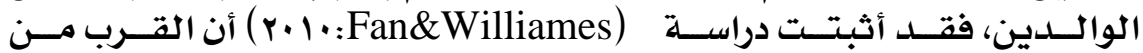

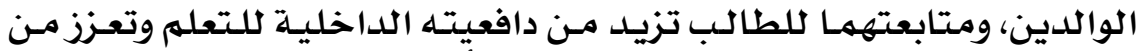

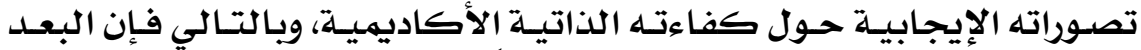

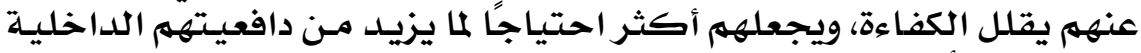

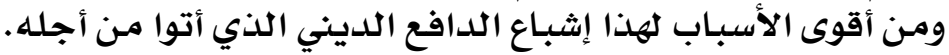

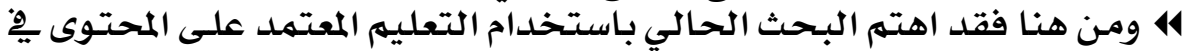

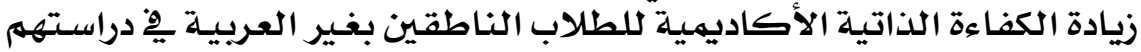
لمادة التوحيد.

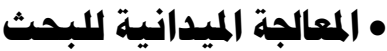

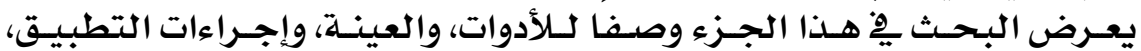
وذلك على النحو البحث التالي: الني: • أولاً: أدوات البحث، وثثانيًا: تطبيق البحث، وثلالثًا: نتائج البحث، وفيسها يلي تفصيل ذلك.

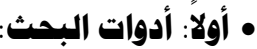

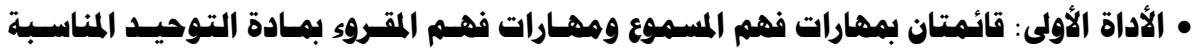

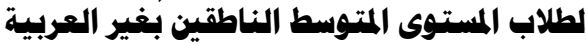

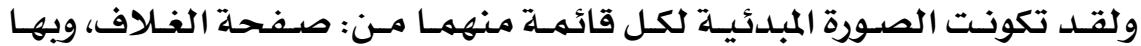

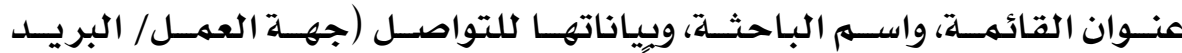

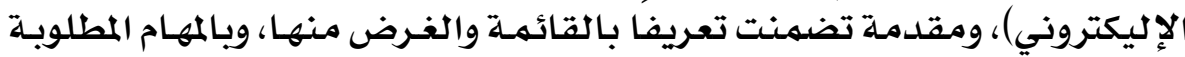

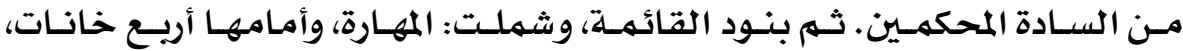

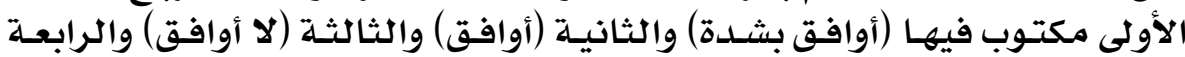

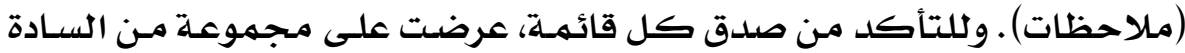

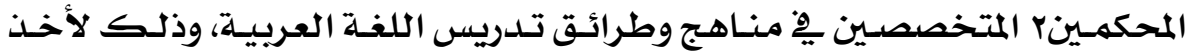
آرائهم -

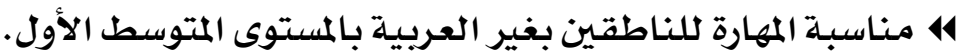

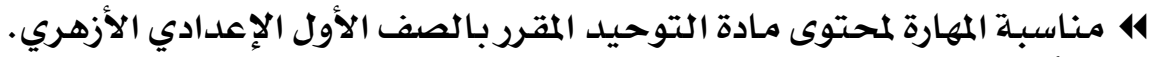

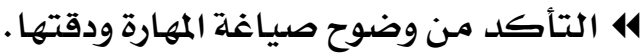

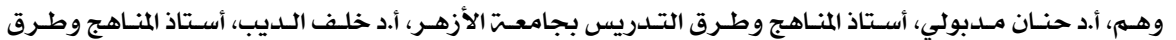

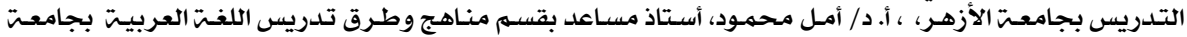

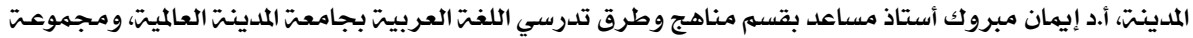

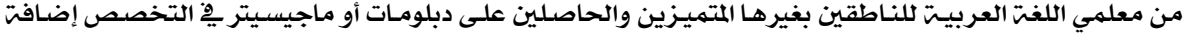
لخبرتهم العمليت.

\section{r7}




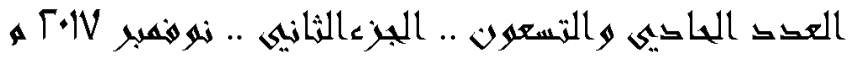

4 إضـافة أو حذف بعض المهارات.

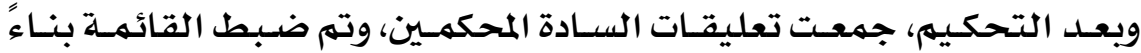

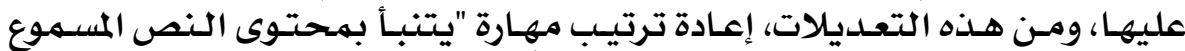

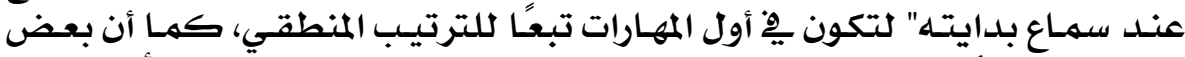

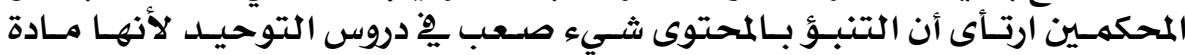

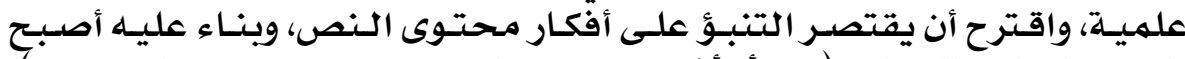

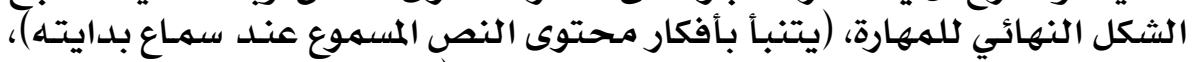

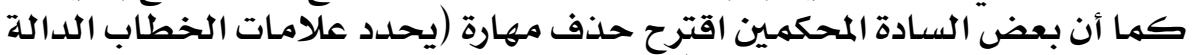

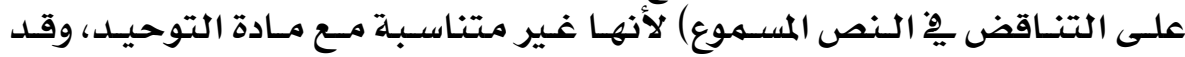

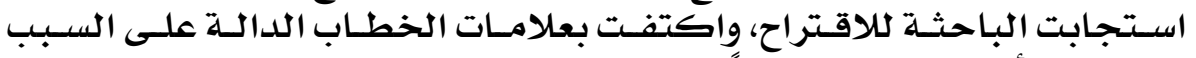

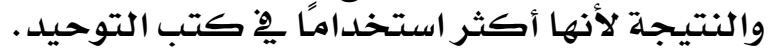

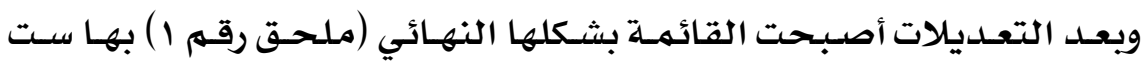

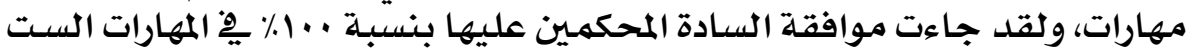

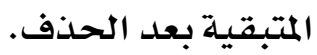

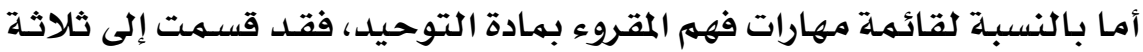

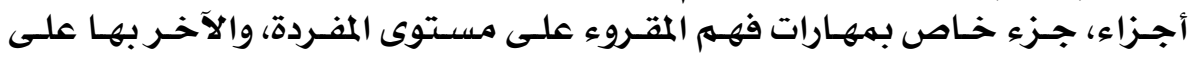

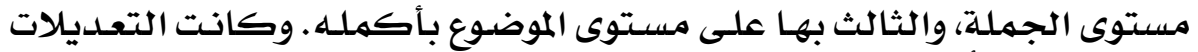

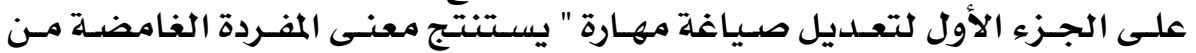

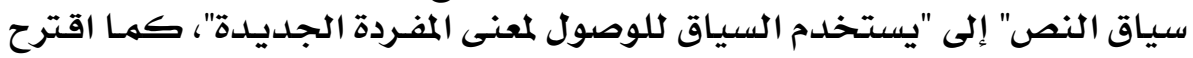

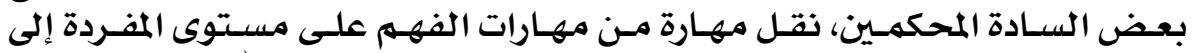

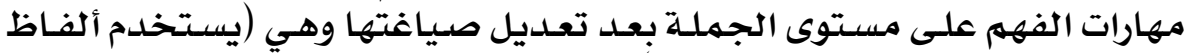

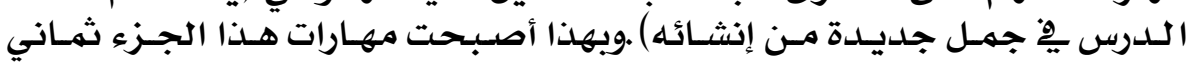

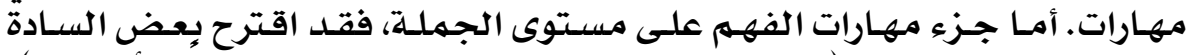

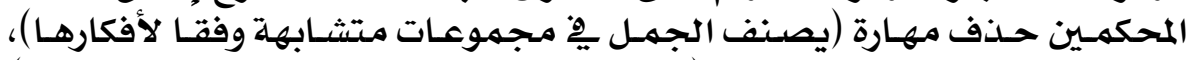

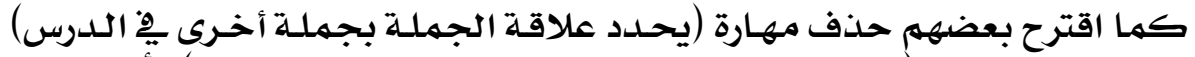

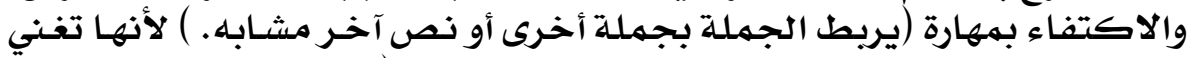

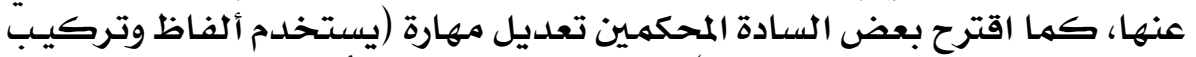

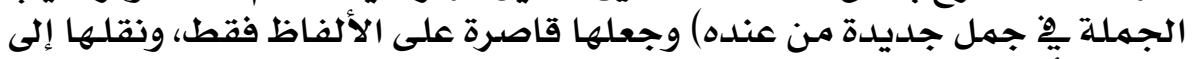

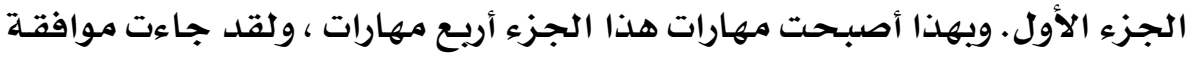

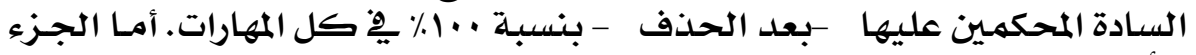

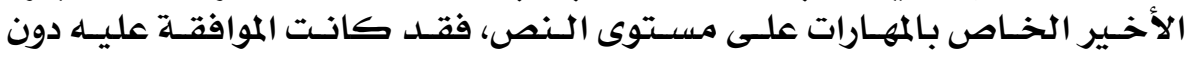

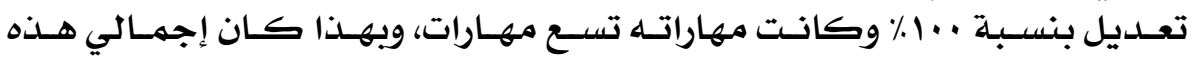
القائمـة إحلدى وعشرون مهارة.

\section{rav}




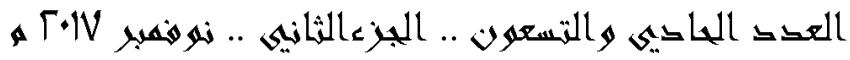

• الأداة الثانية: اختبار لقياس فهم المسمهوع والمتروء في هتوى التوحيد للناطقين بغير العربيسة

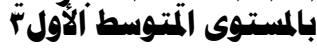

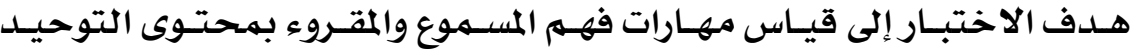

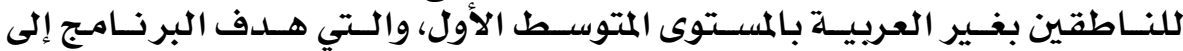

تنهيتها، وهي:

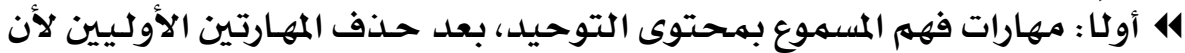

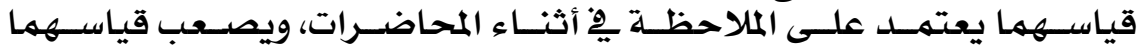

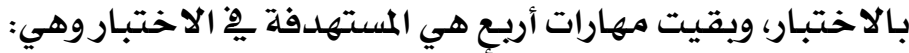

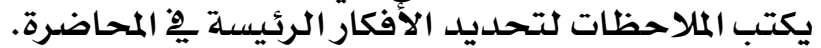

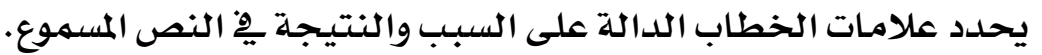

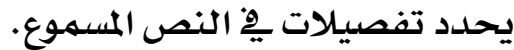

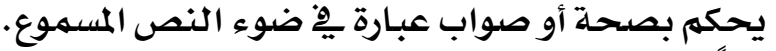

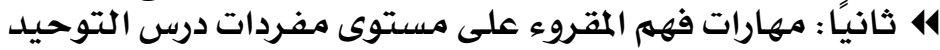

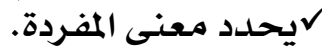

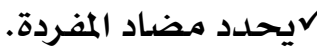

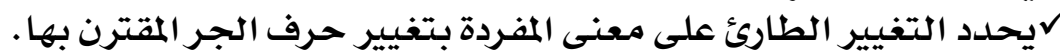

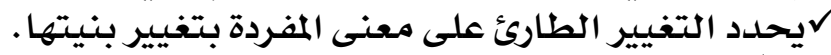

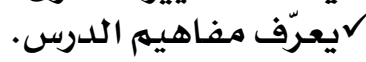

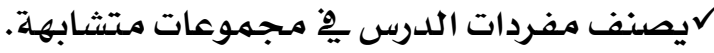

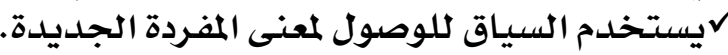

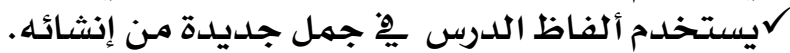

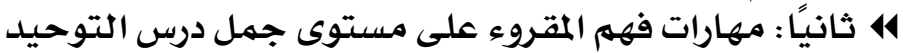

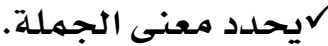

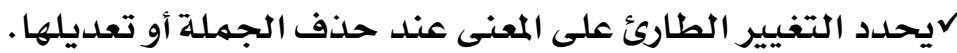

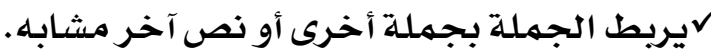

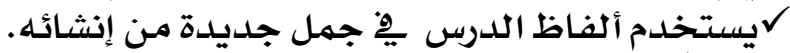

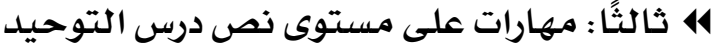
ليحلدد الفكرة الرئيسة.

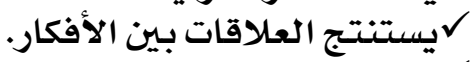

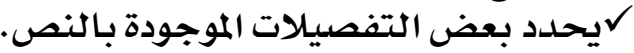

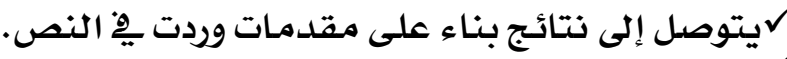

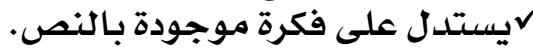

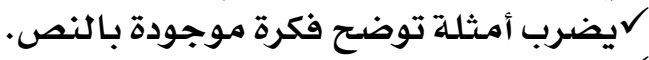

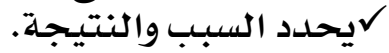

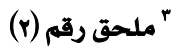

\section{rฯ}




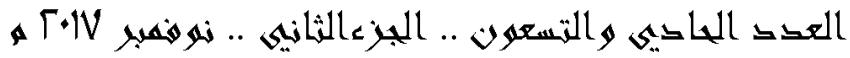

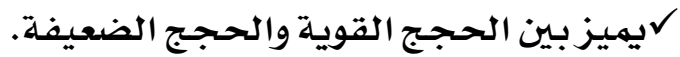

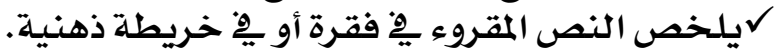

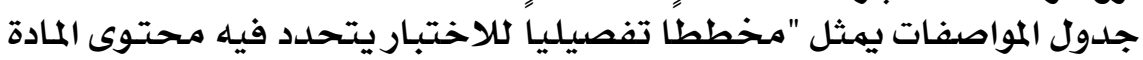

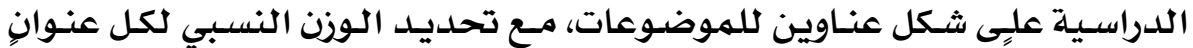

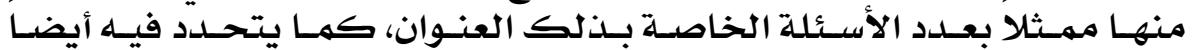

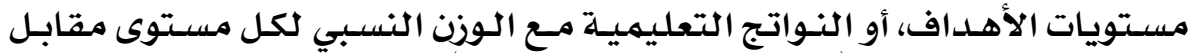

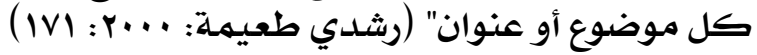

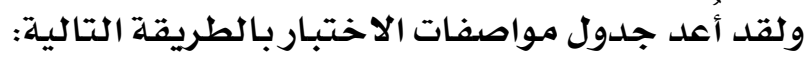

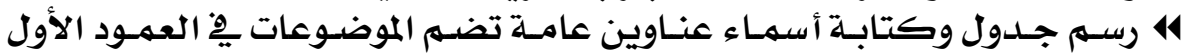

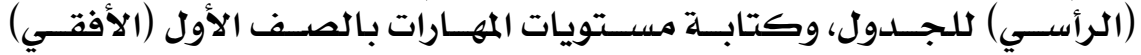

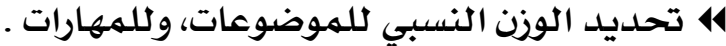

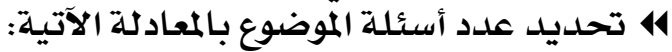
عدد أسئلة الموضوع عادد اسلع

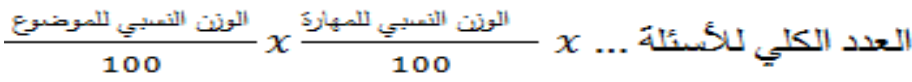

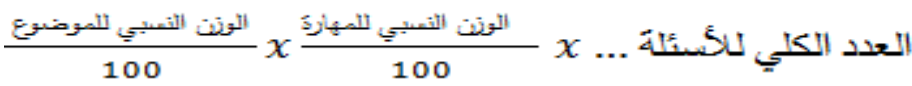

وعلى هذا فإن عدد أسئلة المهارات على مستوى الكلمــة يِّ فقـرة تـدور مفرداتها

$$
\begin{aligned}
& \text { حول محتوى موضوع مبادئ التوحيد } \\
& \text { = } 2.85=\frac{25}{100} X \frac{14.28}{100} \times 80
\end{aligned}
$$

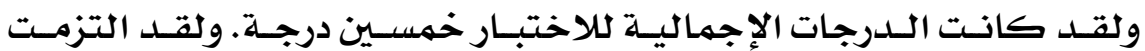

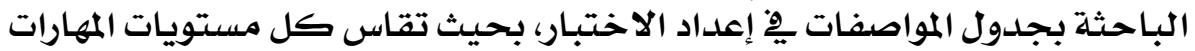

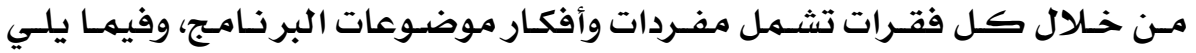

\begin{tabular}{|c|c|c|c|c|c|}
\hline اللنسبي & مستوى & الجملتً & 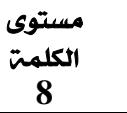 & فهم المسموع & الموضوع المهارة \\
\hline $25 \%$ & 2.25 & 1 & 2 & 1 & مبادئ التوحيد \\
\hline $25 \%$ & 2.25 & 1 & 2 & 1 & أقسام الحكم العقلى \\
\hline $25 \%$ & 2.25 & 1 & 2 & 1 & الواجب لله إجمائا وتفصيًاً \\
\hline $25 \%$ & 2.25 & 1 & 2 & 1 & وجود الله عز وجل \\
\hline $100 \%$ & $36 \%$ & $16 \%$ & $32 \%$ & $16 \%$ & الوزن النسبى المهارة \\
\hline 25 & 9 & 4 & 8 & 4 & عدد الأسئلة \\
\hline
\end{tabular}
جدول مواصفات الاختبار.

جدول (1) : جدول مواصفات الاختبار

\section{rq 9}




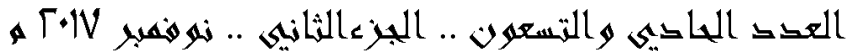

• التبربة الاستطلاعية للاختبار

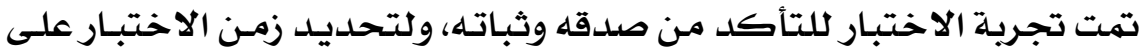
النحو التالي: • التأكد من صدق الاختبار

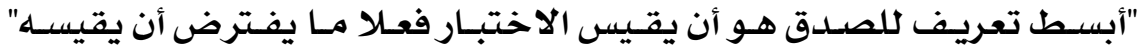

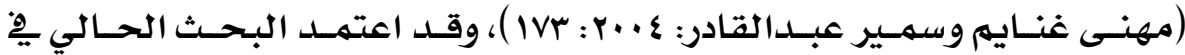

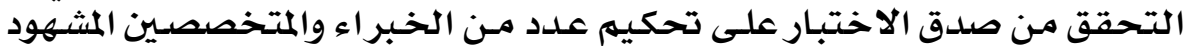

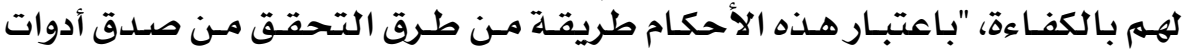

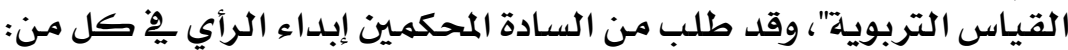

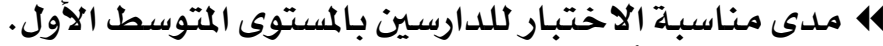

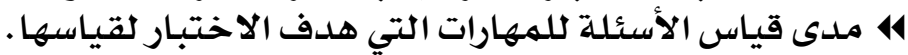
14 مدى وضوى الهياس مفردات الأسئلة.

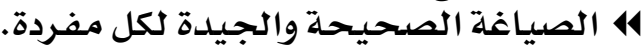

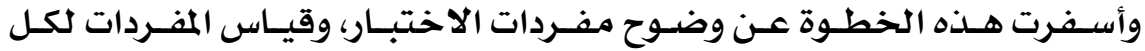

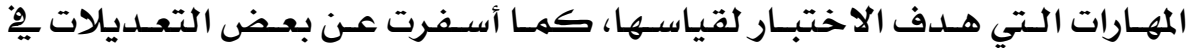
صياغة المفردات. • التأكد هن ثبات الاختبار

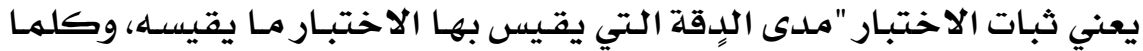

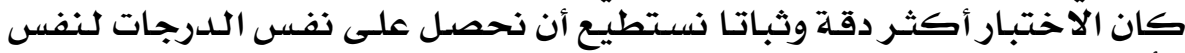

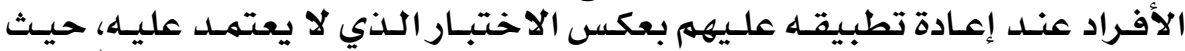

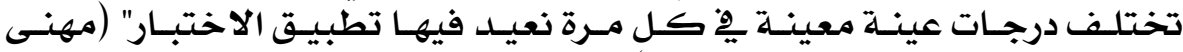

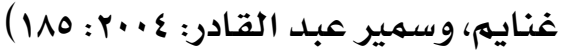

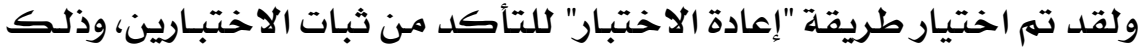

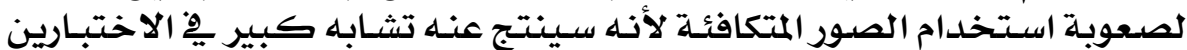

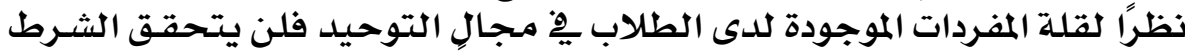

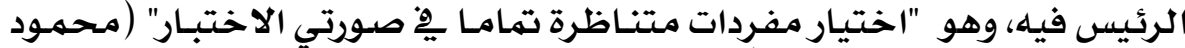

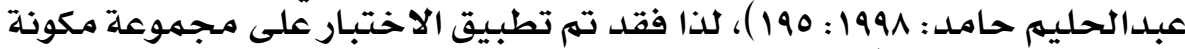

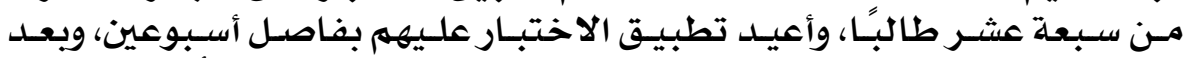

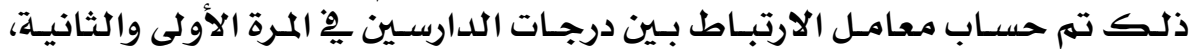

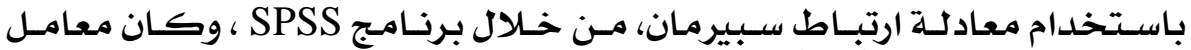

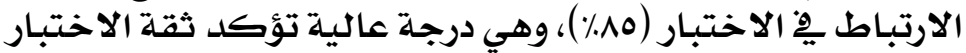

• الأداة الثالثة : هقياس الكفاءة الذاتية الأكاديمية لدى الناطقين بغير العربية الدارسين لمادة التوحيد

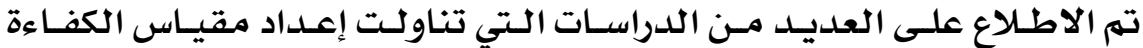

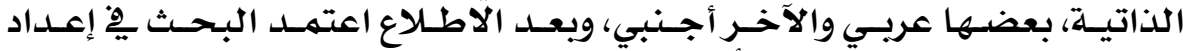

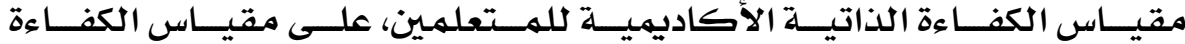

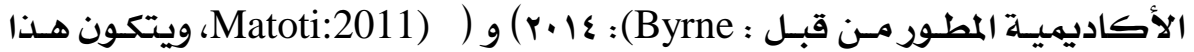

\section{rV.}




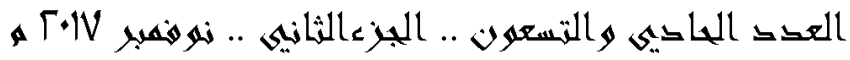

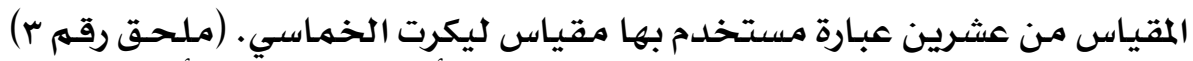

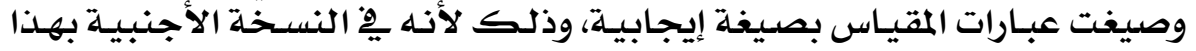

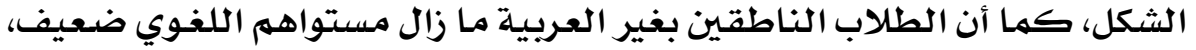

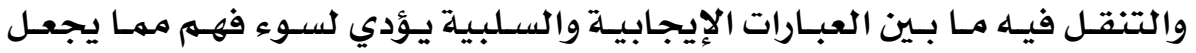

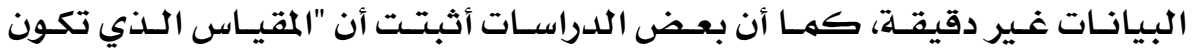

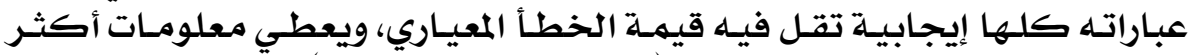

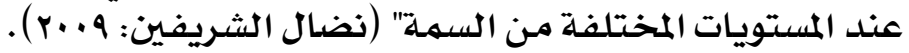

• التجربة الاستطلاعية للمقيساس

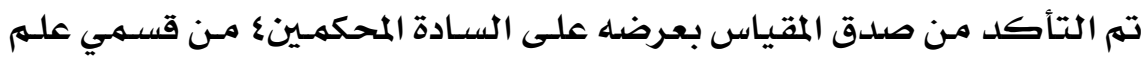

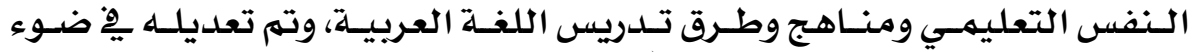

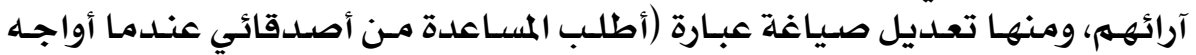

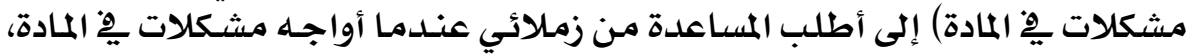

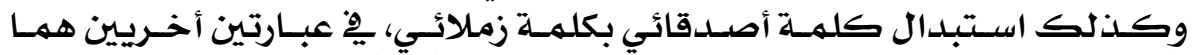

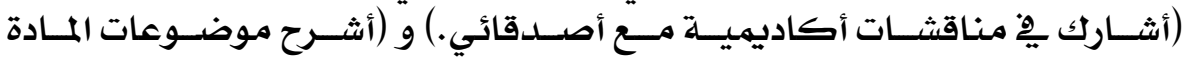

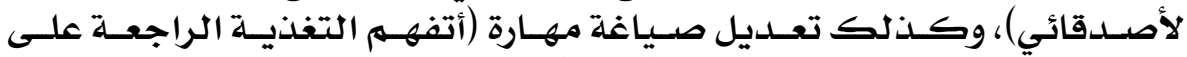

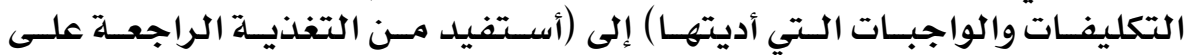

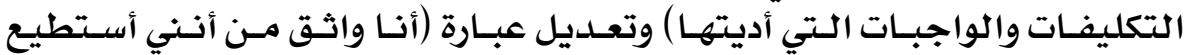

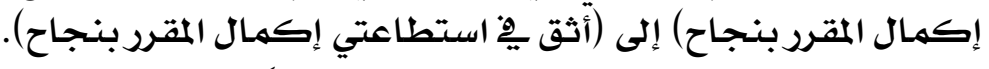

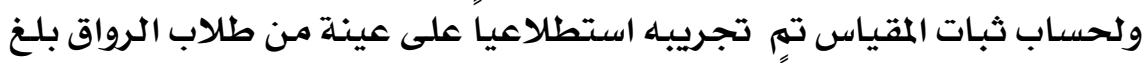

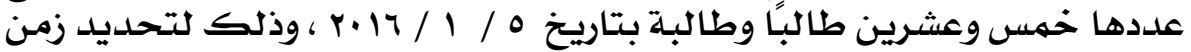

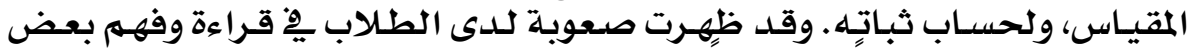

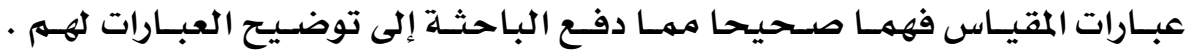

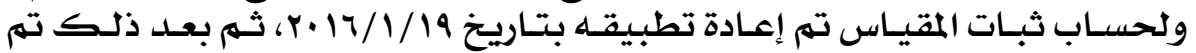

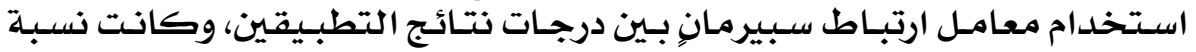

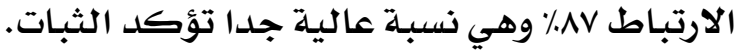

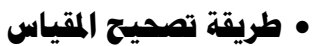

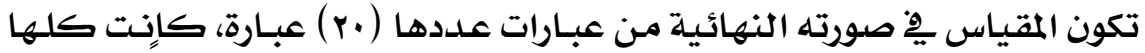

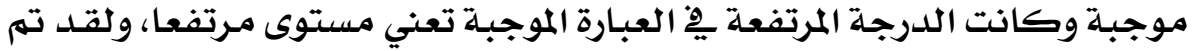

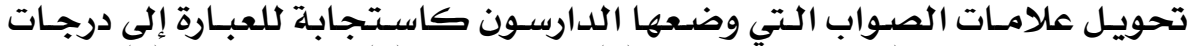

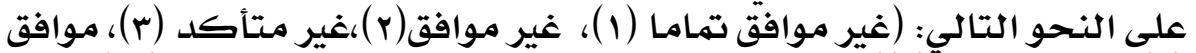

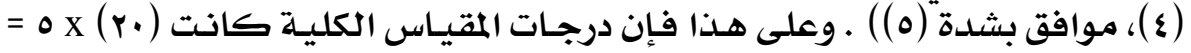

" أ.د سيد عبدالحميد، أستاذ علم النفس التعليمي جامعتة حلوان.

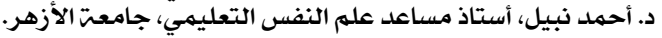

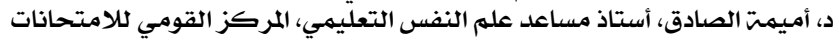

\section{YVI}




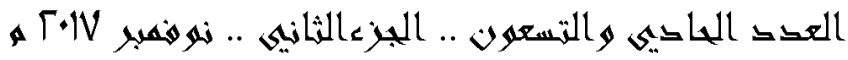

• الأداة الرابع: منهج التوحيد للناطقين بغير العربية

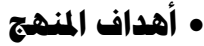

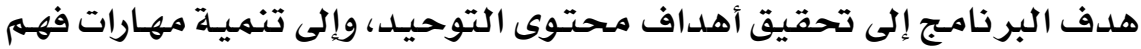

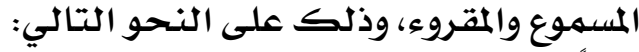

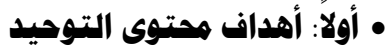

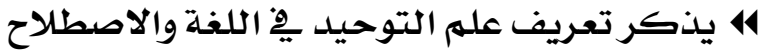

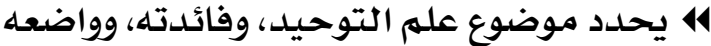

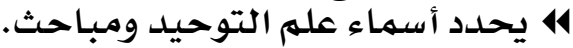

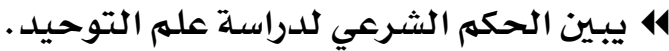

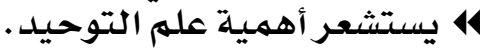

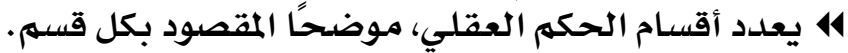

414 يوضح معنى الواجب والجائز والمستحيل.

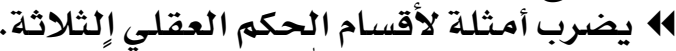

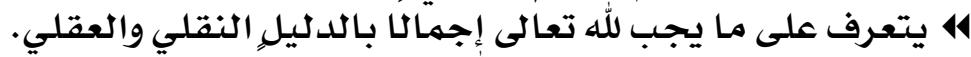

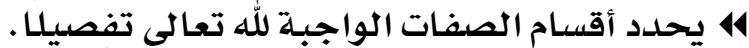

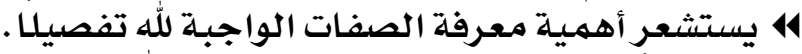

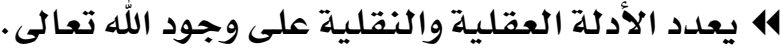

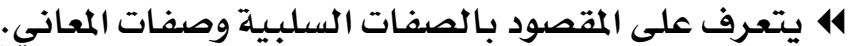

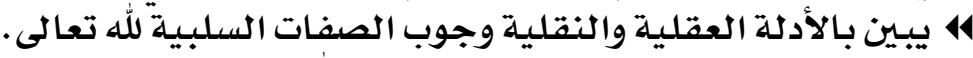

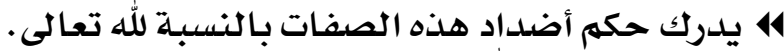

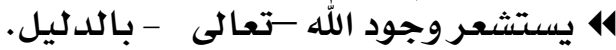

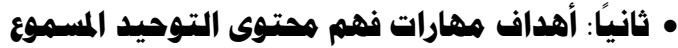

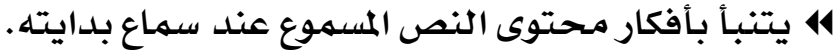

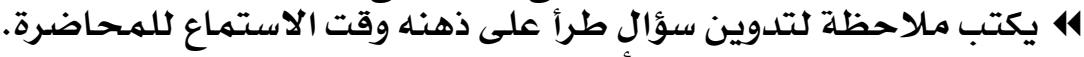

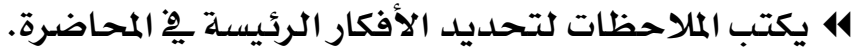

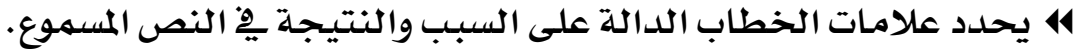

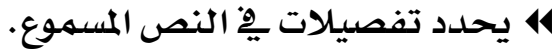

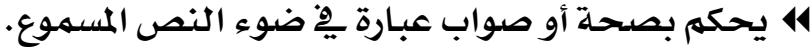

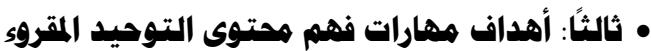

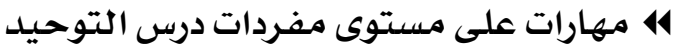

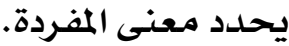

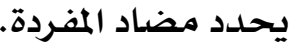

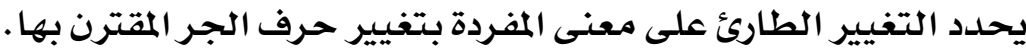

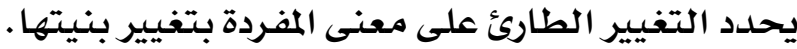

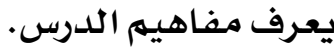

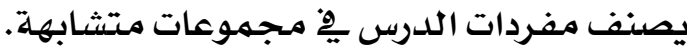

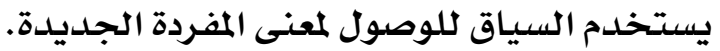

\section{rVY}




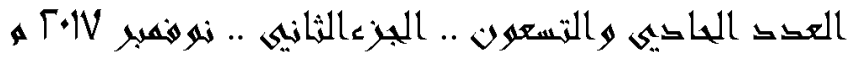

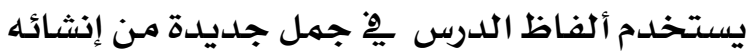

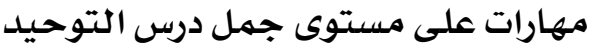
يحلدد معنى الجملية.

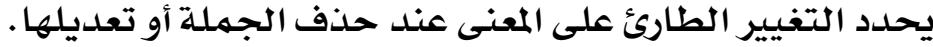

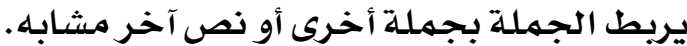

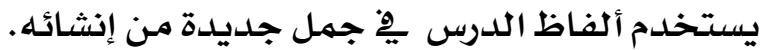

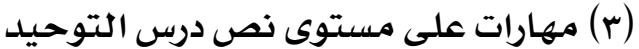
يحلدد الفكرة الرئيسيسة. يستنتج العلاقات بين الأفكار.

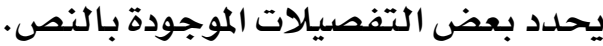

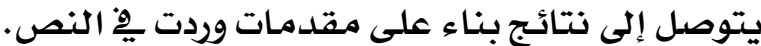

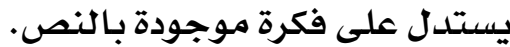

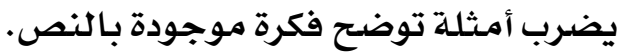

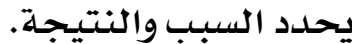

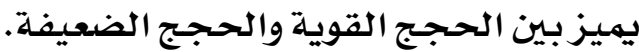

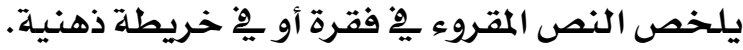

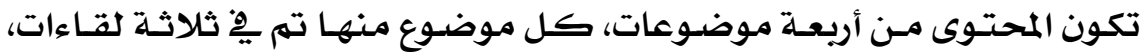

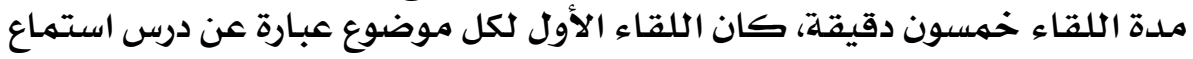

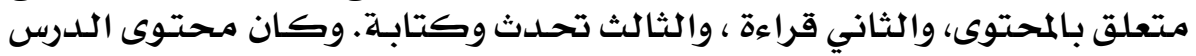

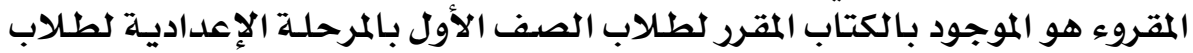

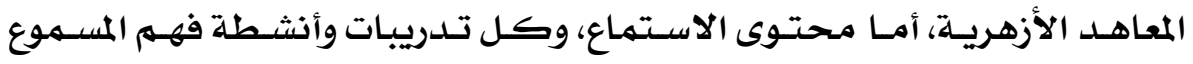

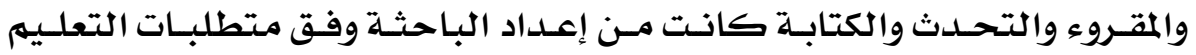

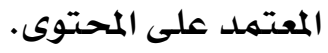

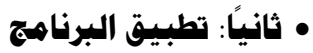

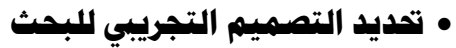

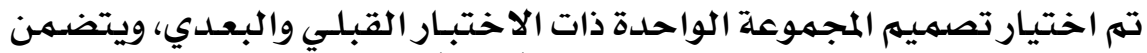

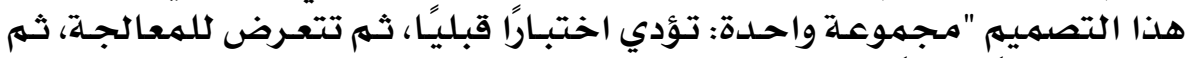

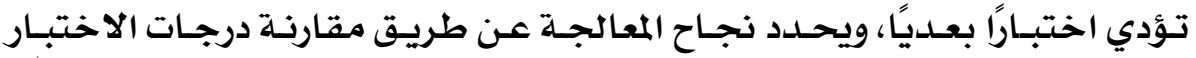

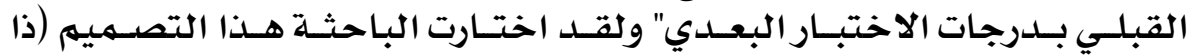

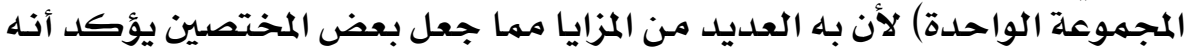

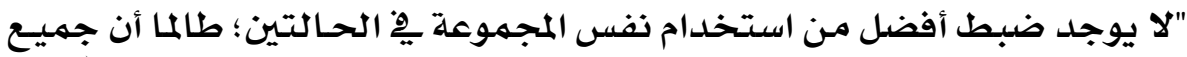

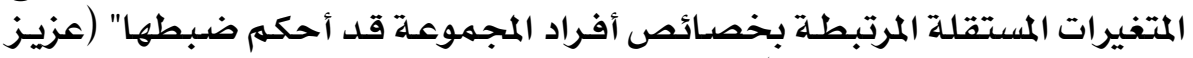

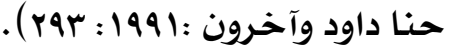

\section{rVr}




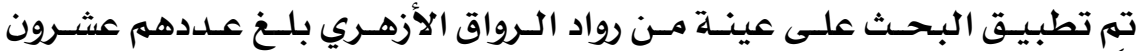

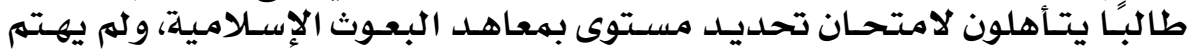

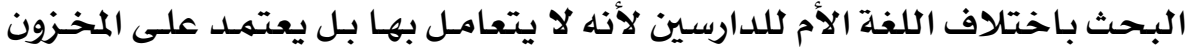

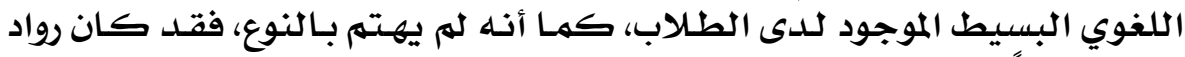
الرواق طلابًا وطالبـات. الموئ.

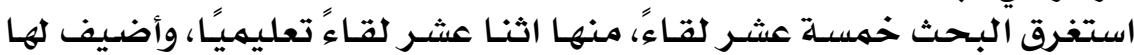

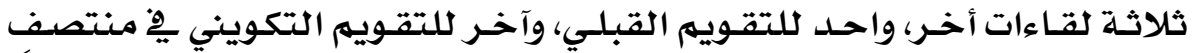

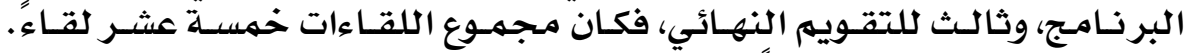

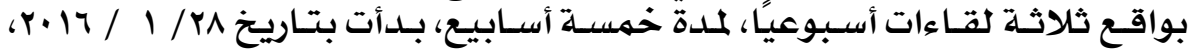

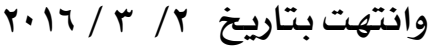

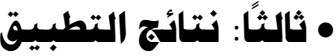

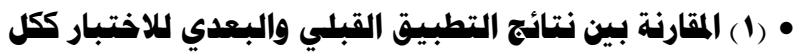

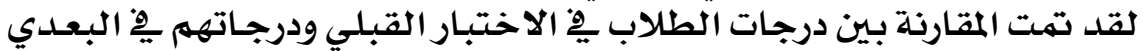

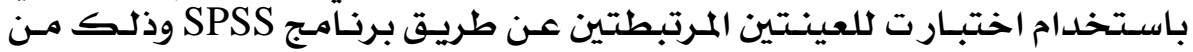

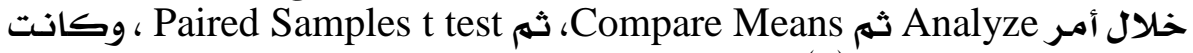

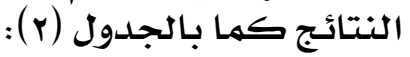

\begin{tabular}{|c|c|c|c|c|c|c|}
\hline الدلالتة & قيمتس (ت) & الحرجتيت & الالمعياريراف & المتوسابي & العينتة & البيانات \\
\hline \multirow[t]{2}{*}{0,01} & \multirow[t]{2}{*}{22,84} & \multirow[t]{2}{*}{19} & 2,064 & 3,45 & 20 & للاختياس القبلي \\
\hline & & & 7,307 & 39,85 & 20 & القلاختبار البعلدي \\
\hline
\end{tabular}

والجدول السـابق يبيـين وجود فروق ذات دلالـة إحصسائية بـين مـتوسـطات درجـات

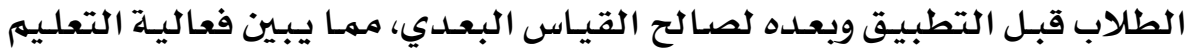

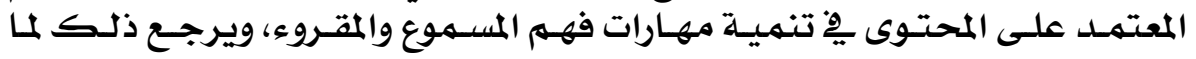

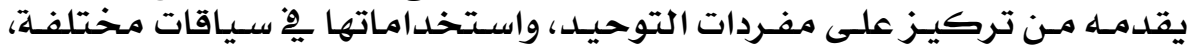

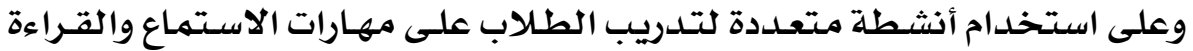

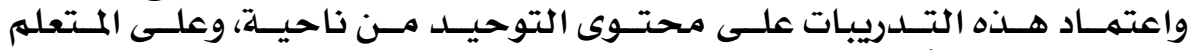

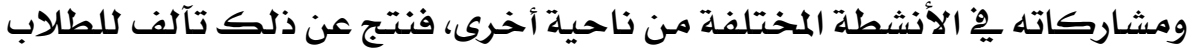

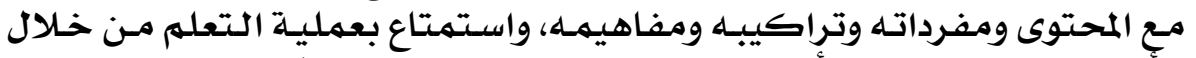

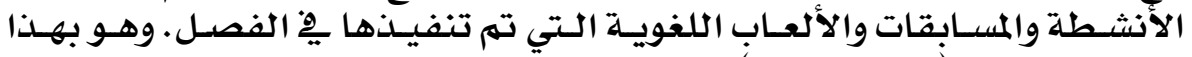

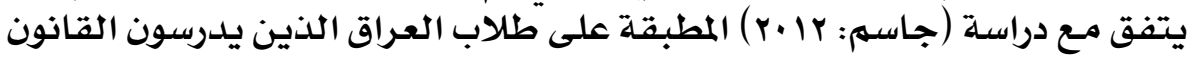

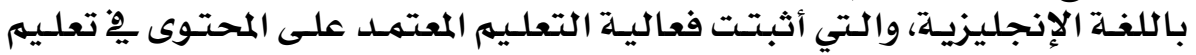

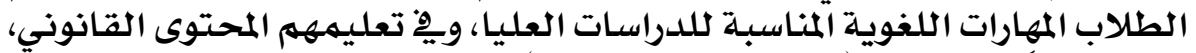

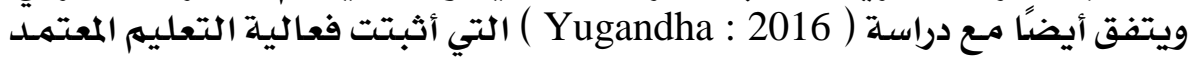

\section{YV $\varepsilon$}




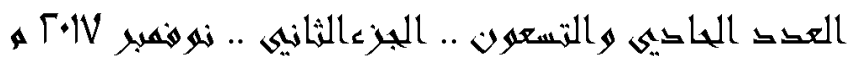

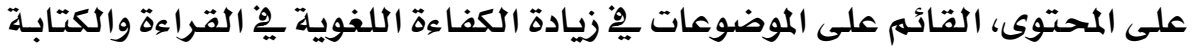
لدى الطلاب متعلهي الإنجليزيـة المعلية كلغة ثانية.

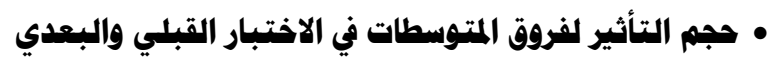

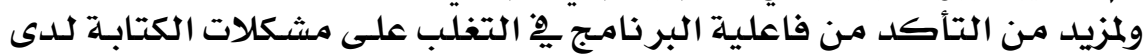

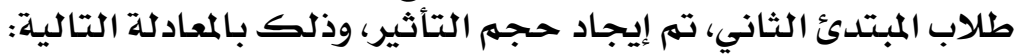

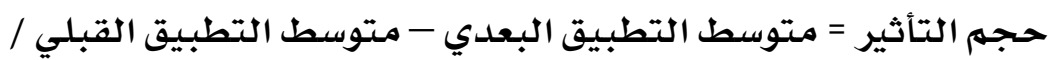

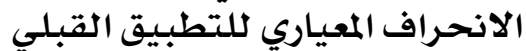

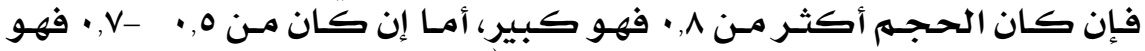

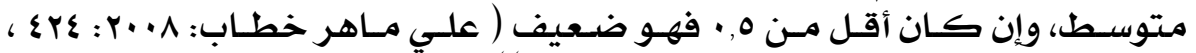

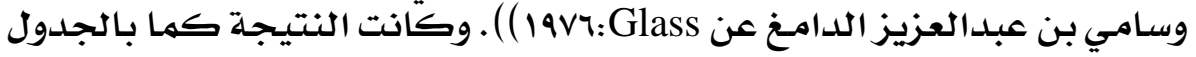

\begin{tabular}{|c|c|c|c|c|c|c|}
\hline مستوى | (مستوى & حجم & الانحراف & المتوسط & أقصى & أدنى درجتة & البيانات \\
\hline الدلالة & التاثير & المعياري - لمي & & درجتَ & & الاختبار \\
\hline \multirow{2}{*}{ كبير } & \multirow{2}{*}{17,6} & 2,06 & 3,45 & 10 & 2 & الاختبار قبل التطبيق \\
\hline & & 7,30 & 39,85 & 49 & 26 & الاختبار بعد التطبيق \\
\hline
\end{tabular}

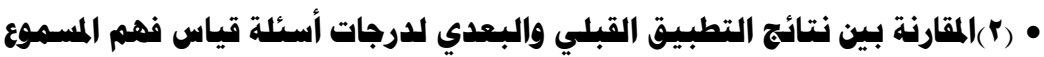

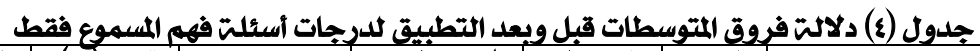

\begin{tabular}{|c|c|c|c|c|c|c|}
\hline الدلاكت & قيمن (ت) & ذالحريت & المعياري & الحسوسطي & العينت & البيانات \\
\hline \multirow[t]{2}{*}{0,01} & \multirow[t]{2}{*}{7,19} & \multirow[t]{2}{*}{19} & 0,7 & 1,00 & 20 & القياس القبلي لفهم المسموع \\
\hline & & & 1,6 & 3,9 & 20 & القياس البعدي لفهم المسموع \\
\hline
\end{tabular}

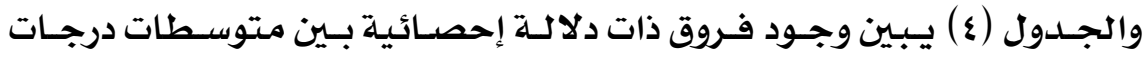

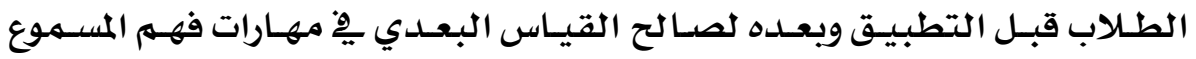

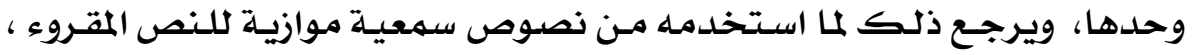

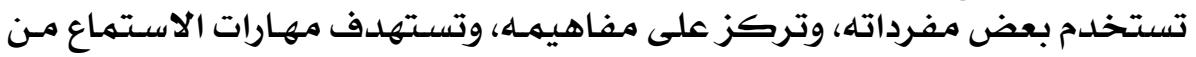

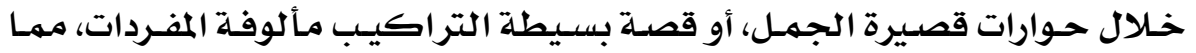

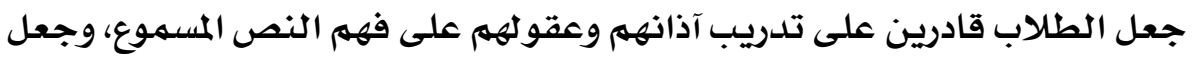

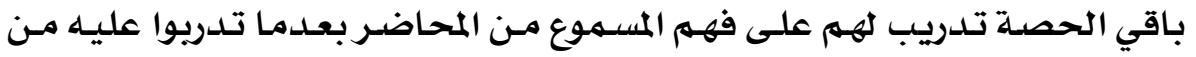

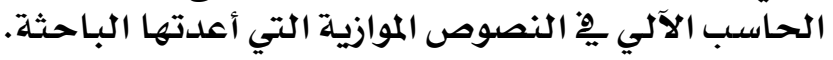

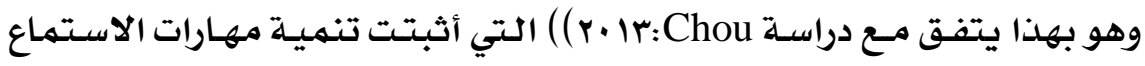

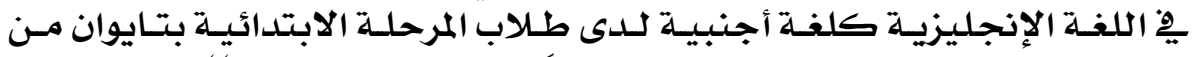

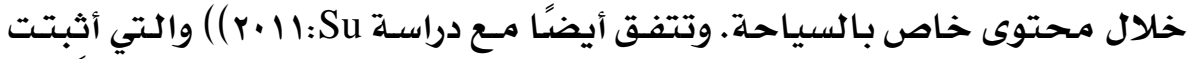

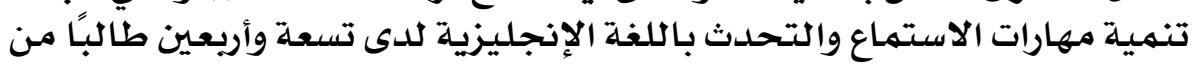

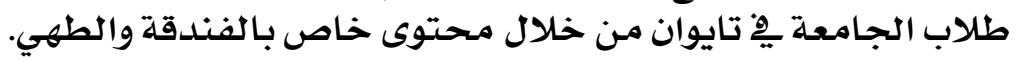

\section{YVO}




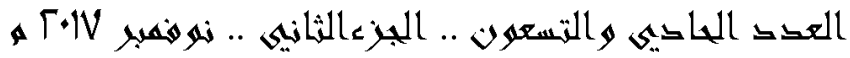

• (r) المقارنة بين نتائج التطبيق القبلي والبعدي لدرجات أسئلة قياس فهم المتروك

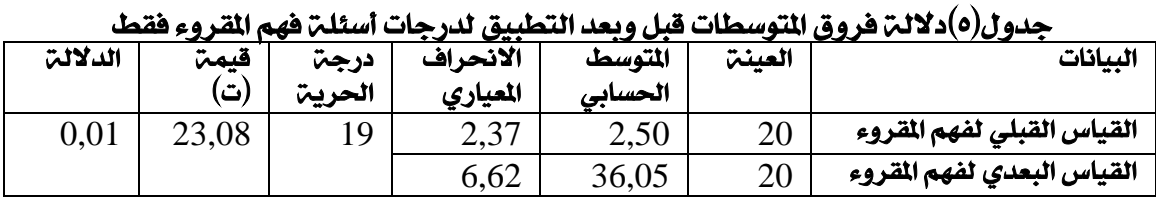

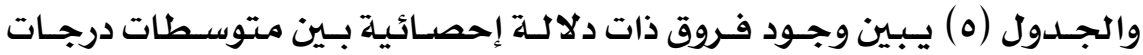

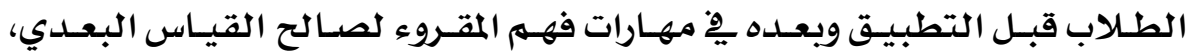

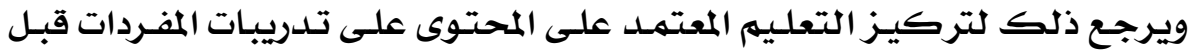

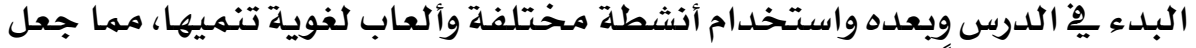

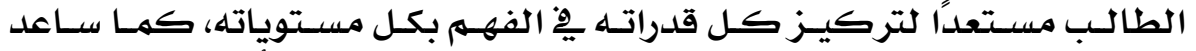

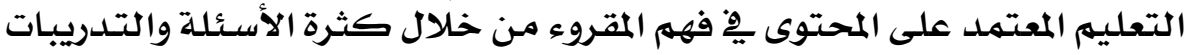

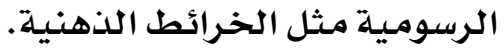

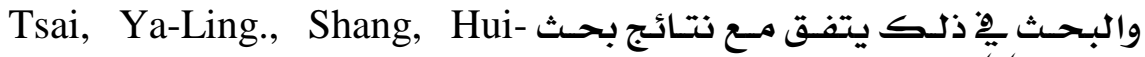

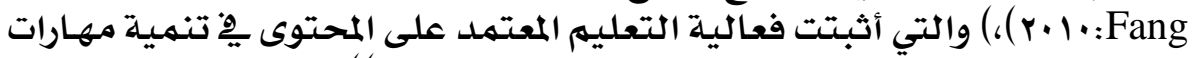

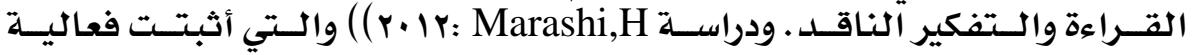

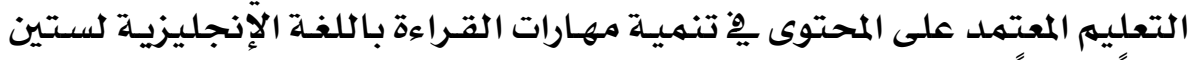

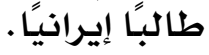

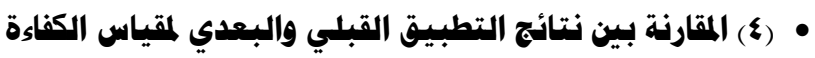

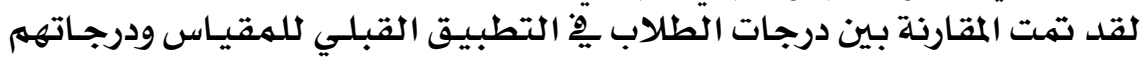

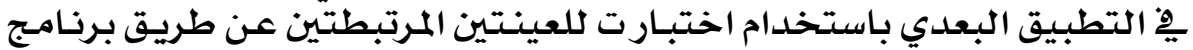

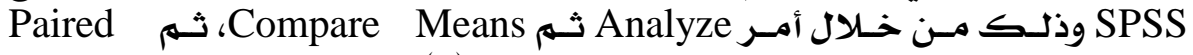

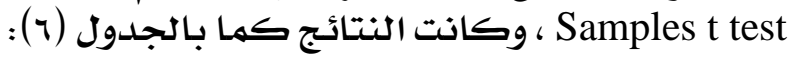

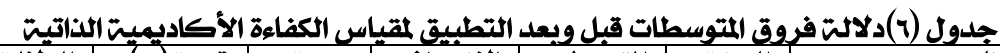

\begin{tabular}{|c|c|c|c|c|c|c|}
\hline الدلاكتة & قيمتة (ت) & الحريتي & الالانحرافي & الحسوابي & العينتة & البيانأت \\
\hline \multirow[t]{2}{*}{0,01} & \multirow[t]{2}{*}{21,84} & \multirow[t]{2}{*}{19} & 4,38 & 21,80 & 20 & القياس القبلي \\
\hline & & & 9,61 & 78,45 & 20 & القياس البعلدي \\
\hline
\end{tabular}

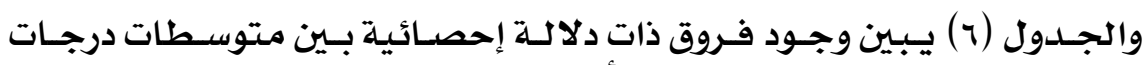

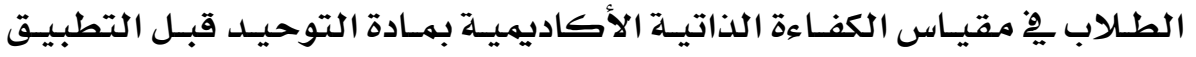

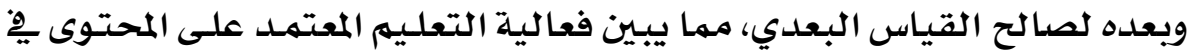

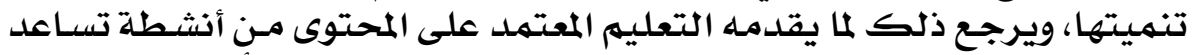

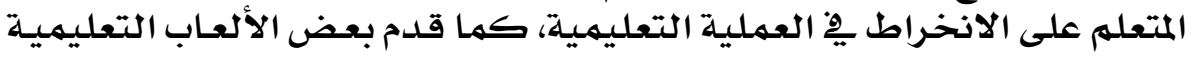

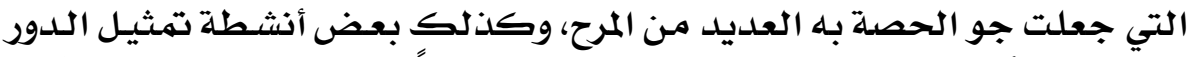

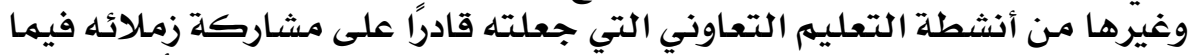

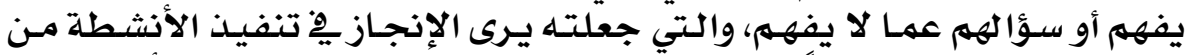

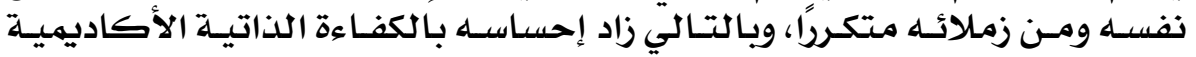

\section{YVY}




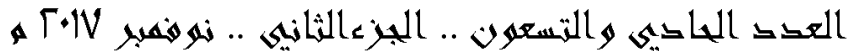

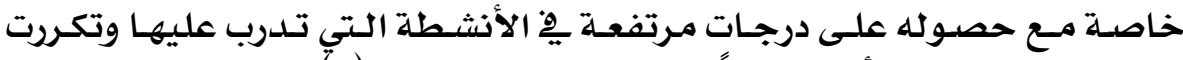

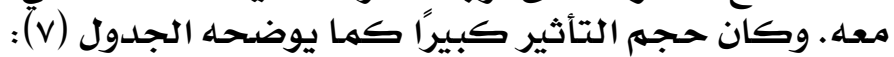

جدول (v) : حجم التأير لدرجات الاختبار القبلي والبعدي لمقياس الكفاوة الذاتيت الأكاديميتي

\begin{tabular}{|c|c|c|c|c|c|c|}
\hline مستوى & حجم & الانحراف & المتوسط & أقصى & أدنى & الاختبار البيانات \\
\hline \multirow[b]{2}{*}{ كبير } & \multirow{2}{*}{12,9} & المعياري & 21,80 & درجيت & 12 & الاختبار \\
\hline & & 9,61 & 78,45 & 92 & 59 & المقياس بعد التطبيق \\
\hline
\end{tabular}

يوصي البـحث بها يلي:

41 تطبيق التعليم المعتمد على المحتوى يِّ تصميهم مناهج كافة العلوم الشـرعية للناطقين بغير العربية.

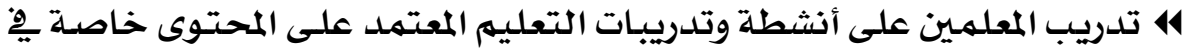

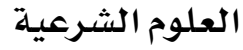

414 المزيد من البحوث العلمية المعية على نهاذج أخرى للتعليه المعتمد على المحتوى.

•

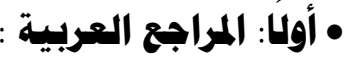

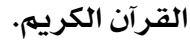

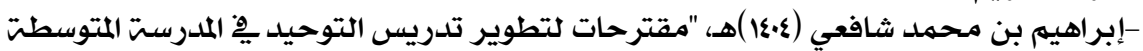

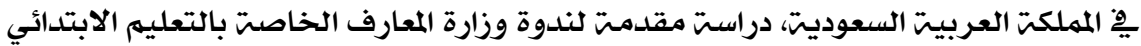

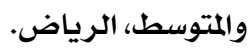

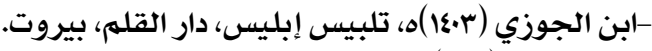

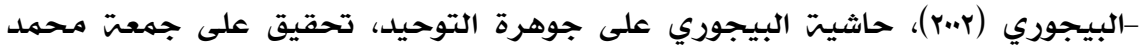

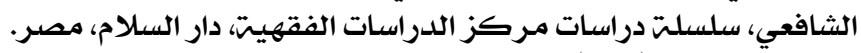

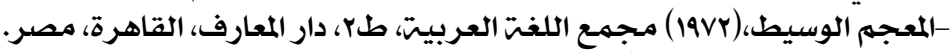

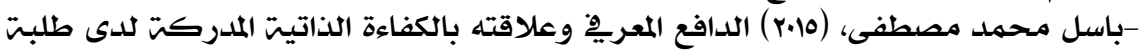

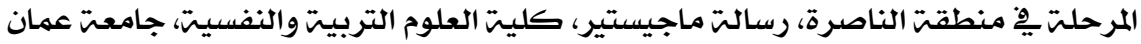

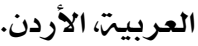

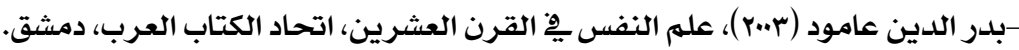

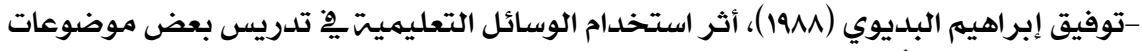

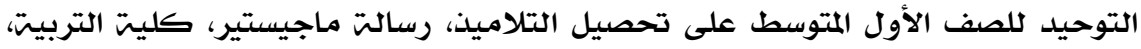

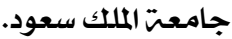

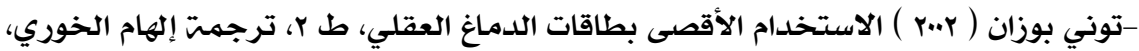

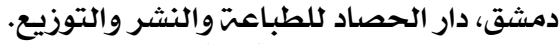

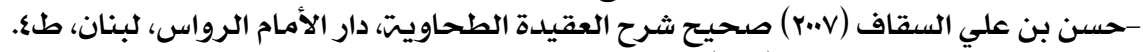

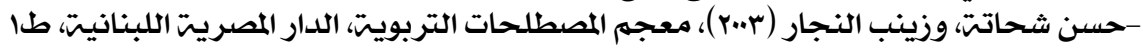

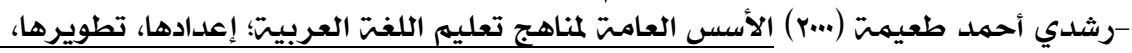
تقويمها، دار الفكر العربي، طن.

\section{rVV}




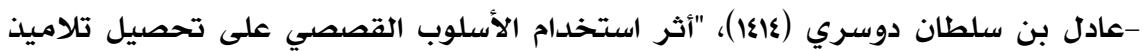

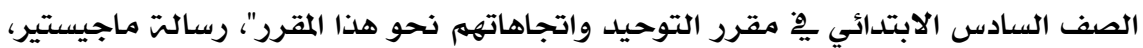

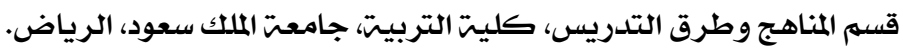

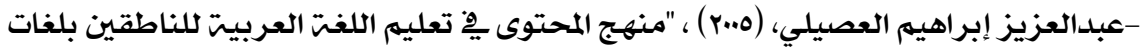

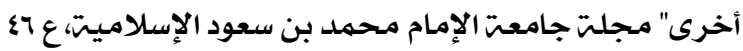

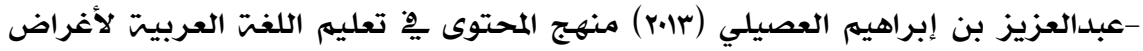

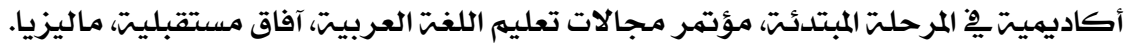

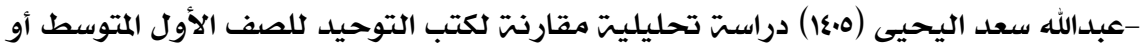

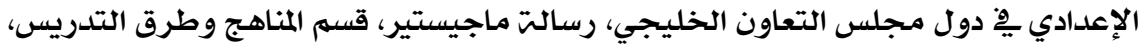

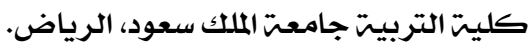

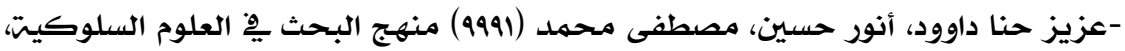

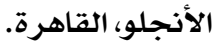

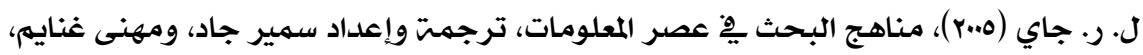

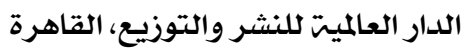

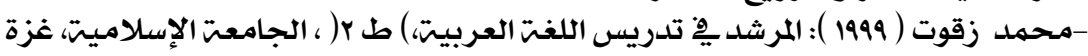

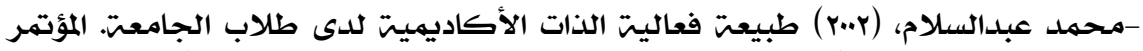

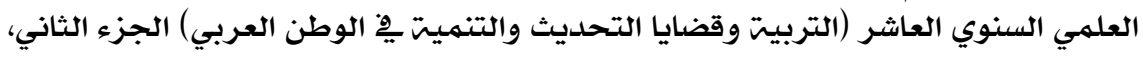

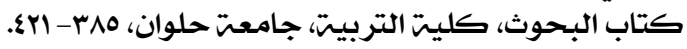

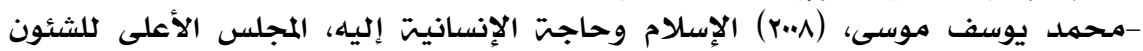

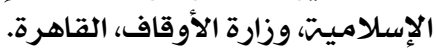

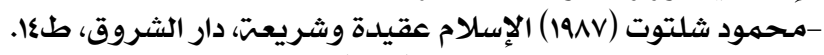

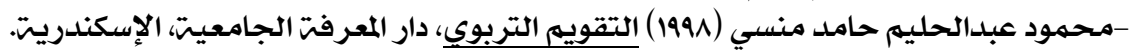

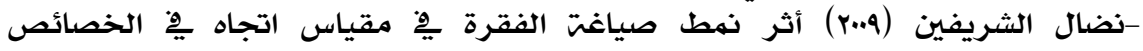

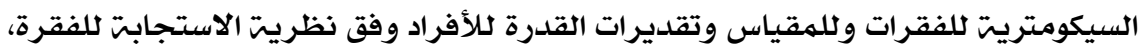

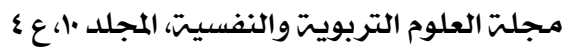

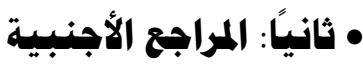

- Allwright, J., \& Allwright, R. (1977). An approach to the teaching of medical English. English for Specific Purposes, 58-62.

- Bandura, A. (2001). Social cognitive theory: An agentic perspective. Annual Review of Psychology, 52(1), 1-26.

- Bassi, M., Steca, P., Delle Fave, A., \& Caprara, G. V. (2007). Academic self-efficacy beliefs and quality of experience in learning. Journal of Youth and Adolescence, 36(3), 301-312.

- Brinton, D. (2000). Out of the mouth of babes: Novice teacher insight Into content-based instruction" in Kasper, L.(ed). ContentBased College ESL Instruction. Mahwah, New Jersey: Lawrence Erlbuam Associates, Publishers.

\section{rVA}


- Brinton, D. M. Snow, MA \& Wesche, M. B. (1989). ContentBased second language instruction. USA: Hein-le\& Heinle.

- Brinton, D., Snow, M. A., \& Wesche, M. B. (2003). Content-based second language instruction. USA: University of Michigan Press.

- Busse, V., \& Walter, C. (2013). Foreign language learning motivation in higher education: A longitudinal study of motivational changes and their causes. The Modern Language Journal, 97(2), 435-456.

- Byrne, M., Flood, B., \& Griffin, J. (2014). Measuring the academic self-efficacy of first-year accounting students. Accounting Education, 23(5), 407-423.

- Canbay, M. O. (2006). Strengthening a content-based instruction curriculum by a needs analysis. (Doctoral dissertation, Bilkent University).

- Chou, M. H. (2013). A content-based approach to teaching and testing listening skills to grade 5 EFL learners. International Journal of Listening, 27(3), 172-185.

- Csizér, K., \& Magid, M. (2014). The impact of self-concept on language learning (Vol. 79). USA: Multilingual Matters.

- Eden, D. (1988). Pygmalion, goal setting, and expectancy: Compatible ways to boost productivity. Academy of Management Review, 13(4), 639-652.

- Eskey, D. E. (1992). Syllabus design in content-based instruction. In M. A. Snow \& D. M. Brinton (Eds.), The content-based classroom: Perspectives on integrating language and content (pp. 132-141). White Plains, NY: Longman.

- Fan, W., \& Williams, C. M. (2010). The effects of parental involvement on students' academic self-efficacy, engagement and intrinsic motivation. Educational psychology, 30(1), 53-74.

- Golightly, T. R. (2006). Defining the components of academic selfefficacy in Navajo American Indian high school students. (Doctoral dissertation, Young University).

- Hardman, M. C. (2009). Developing a teachers' handbook for content-based instruction at Brigham young university's English Language Center. (Master Degree, Brigham Young University).

- Hsieh, P. P. H., \& Kang, H. S. (2010). Attribution and self-efficacy and their interrelationship in the Korean EFL context. Language Learning, 60(3), 606-627.

\section{rVq}


- James, M. A. (2006). Transfer of learning from a university content-based EAP Course. TESOL Quarterly, 40(4), 783-806.

- Johns, A. M. (1997). English for specific purposes and contentbased instruction: What is the relationship? In M. A. Snow \& D. M. Brinton (Eds.), The content-based classroom: Perspectives on integrating language and content (pp. 363-67). White Plains, NY: Addison-Wesley Longman.

- Judge, T. A., Erez, A., \& Bono, J. E. (1998). The power of being positive: The relation between positive self-concept and job performance. Human performance, 11(2-3), 167-187.

- Kim, D. H., Wang, C., Ahn, H. S., \& Bong, M. (2015). English language learners' self-efficacy profiles and relationship with selfregulated learning strategies. Learning and Individual Differences, 38, 136-142.

- Krashen, S. D. (1981). Second language acquisition and second language learning. UK: Oxford University Press.

- Lindquist, T. (1995). Seeing the whole through social studies. UK: Heinemann.

- Loretta, K.(2000). content-based college ESL instruction: an overview. In Kasper, L.(ed.) content-based College ESL instruction.

- Marashi, H., \& Noochirwani, S. (2011). The comparative impact of content-based and task-based teaching in a critical thinking setting on EFL learners' reading comprehension. Journal of English Studies, 1, 27-39.

- Matoti, S. N. (2011). Measuring the academic self-efficacy of students at a South African higher education institution. Journal of Psychology in Africa, 21(1), 151-154.

- Met, M. (1999). Content-based instruction: Defining terms, making decisions. USA: National Foreign Language Center.

- Mills, N. (2014). Self-efficacy in second language acquisition. Multiple perspectives on the self in SLA, 6-22.

- Ooyoung Pyun, D. (2013). Attitudes Toward Task-Based Language Learning: A Study of College Korean Language Learners. Foreign Language Annals, 46(1), 108-121.

- Pajares, F., \& Miller, M. D. (1995). Mathematics self-efficacy and mathematics performances: The need for specificity of assessment. Journal of Counseling Psychology, 42(2), 190.

\section{$\mathrm{r}$.}


- Putra, H., \& Marzulina, L. (2015). Teaching reading comprehension by using content-based instruction (CBI) method to the second years learners at MTs Al-Furqon Prabumulih. Edukasi: Jurnal Pendidikan dan Pengajaran, 2(2), 185-198.

- Raoofi, S., Tan, B. H., \& Chan, S. H. (2012). Self-Efficacy in Second/Foreign Language Learning Contexts. English Language Teaching, 5(11), 60-73.

- Richards, J. C., \& Rodgers, T. S. (2001). Approaches and methods in language teaching. UK: Cambridge university press.

- Schunk, D. H. (2003). Self-efficacy for reading and writing: Influence of modeling, goal setting, and self-evaluation. Reading \&Writing Quarterly, 19(2), 159-172.

- Schunk, D. H., \& Pajares, F. (2009). Self-efficacy theory: Handbook of motivation at school. UK: Taylor \&Francis e-Library.

- Shi, L. (2016). Empirical study on learners' self-efficacy in ESL/EFL context. College Student Journal, 50(3), 454-465.

- Snow, M. A. (1991). Content-based instruction: A method with many faces. In J. E. Alatis (Ed.) Linguistics and language pedagogy: The state of the art (pp. 461-470). Washington, DC: Georgetown University Press.

- Snow, M. A., \& Brinton, D. M. (1997). The content-based classroom. Perspectives on integrating language and content. UK: Longman Printing Press.

- Staples, D. S., Hulland, J. S., \& Higgins, C. A. (1999). A selfefficacy theory explanation for the management of remote workers in virtual organizations. Organization Science, 10(6), 758-776.

- Stoller, F. L., \& Grabe, W. (1997). A six-T's approach to contentbased instruction. The content-based classroom: Perspectives on integrating language and content, 78-94.

- Stryker, S. B., \& Leaver, B. L. (1997). Content-based instruction: From theory to practice. Content-based instruction in foreign language education: Models and methods, 3-28.

- Su, S. W. (2011). A Content-based English Listening and Speaking Class for Hospitality Purposes. Theory \& Practice in Language Studies, 1(8).

- Tsai, Y. L., \& Shang, H. F. (2010). The impact of content-based language instruction on EFL students' reading performance. Asian Social Science, 6(3), 77.

\section{rA}




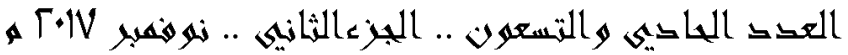

- Yousif, M. T., \& Jasim, B. Y. (2012). A Content-Based Instruction Versus Task-Based Approach to Teaching Legal English: An Experimental Study. University of Sharjah Journal for Humanities and Social Sciences, 111(447), 1-74.

- Yugandhar, K. (2016). Content-theme-based instruction to increase the quality of EFL class. International Journal on Studies in English Language and Literature (IJSELL), 8(4), 86-90.

- Zajacova, A., Lynch, S. M., \& Espenshade, T. J. (2005). Selfefficacy, stress, and academic success in college. Research in Higher Education, 46(6), 677-706.

- Zimmerman, B. J. (2000). Self-efficacy: An essential motive to learn. Contemporary Educational Psychology, 25(1), 82-91.

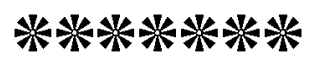

